This document was prepared in conjunction with work accomplished under Contract No. DE-AC09-96SR18500 with the U. S. Department of Energy.

\title{
DISCLAIMER
}

This report was prepared as an account of work sponsored by an agency of the United States Government. Neither the United States Government nor any agency thereof, nor any of their employees, makes any warranty, express or implied, or assumes any legal liability or responsibility for the accuracy, completeness, or usefulness of any information, apparatus, product or process disclosed, or represents that its use would not infringe privately owned rights. Reference herein to any specific commercial product, process or service by trade name, trademark, manufacturer, or otherwise does not necessarily constitute or imply its endorsement, recommendation, or favoring by the United States Government or any agency thereof. The views and opinions of authors expressed herein do not necessarily state or reflect those of the United States Government or any agency thereof.

This report has been reproduced directly from the best available copy.

Available for sale to the public, in paper, from: U.S. Department of Commerce, National Technical Information Service, 5285 Port Royal Road, Springfield, VA 22161, phone: (800) 553-6847, fax: (703) 605-6900

email: orders@ntis.fedworld.gov

online ordering: http://www.ntis.gov/help/index.asp

Available electronically at http://www.osti.gov/bridge

Available for a processing fee to U.S. Department of Energy and its contractors, in paper, from: U.S. Department of Energy, Office of Scientific and Technical Information, P.O. Box 62, Oak Ridge, TN 37831-0062,

phone: (865)576-8401,

fax: (865)576-5728

email: $\underline{\text { reports@ adonis.osti.gov }}$ 
This page was intentionally left blank 
Key Words:

WTP Tanks Antifoaming

Pulse Jet Mixers

Retention:

Permanent

Key WTP R\&T References:

Test Exception

24590-WTP-TEF-RT-04-00012, Rev. 0

Task Plan WSRC-TR-2003-00532

(SRT-RPP-2003-00235)

Scoping Statement S-200

\section{EVALUATION OF FOAMING/ANTIFOAMING IN WTP TANKS EQUIPPED WITH PULSE JET MIXERS AND AIR SPARGERS}

Neguib M. Hassan, 773-A

Timothy M. Jones, 999-W

William E. Daniel, Jr., 999-W

Erich K. Hansen, 999-W

Russell E. Eibling, 999-W

T. Bond Calloway, Jr., 999-W

\section{SEPTEMBER 2004}

Westinghouse Savannah River Company

Savannah River Site

Aiken, SC 29808

Prepared for the U.S. Department of Energy Under Contract Number DE-AC09-96SR18500

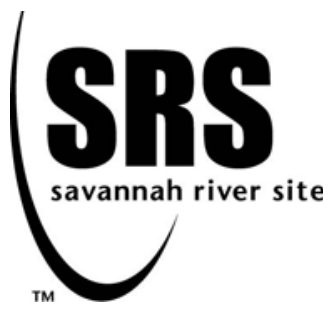


WSRC-TR-2004-00387, REVISION 0 SRNL-RPP-2004-00053, REVISION 0

\section{TABLE OF CONTENTS}

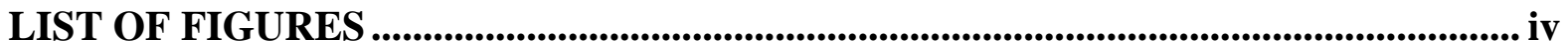

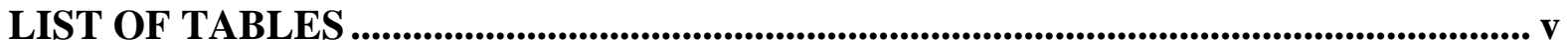

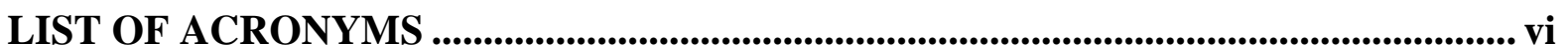

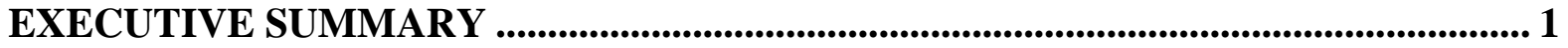

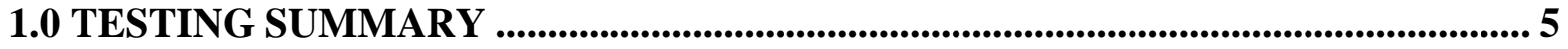

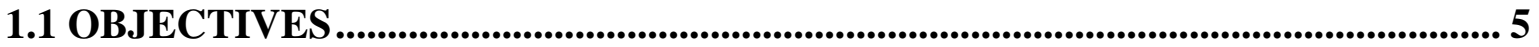

1.2 TEST EXCEPTIONS ......................................................................................6 6

1.3 RESULTS AND PERFORMANCE AGAINST SUCCESS CRITERIA ................ 6

1.4 QUALITY REQUIREMENTS....................................................................... 8

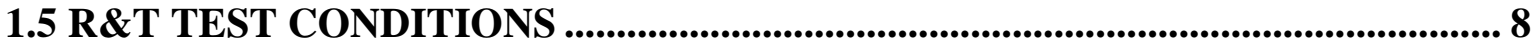

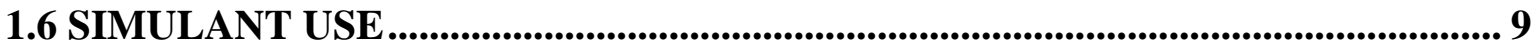

1.7 DISCREPANCIES AND FOLLOW-ON TESTS .................................................9 9

2.0 CD-ROM ENCLOSURES...................................................................................... 11

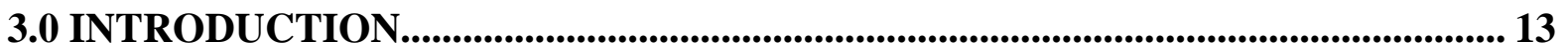

4.0 EXPERIMENTAL APPARATUS AND METHODOLOGY .................................. 15

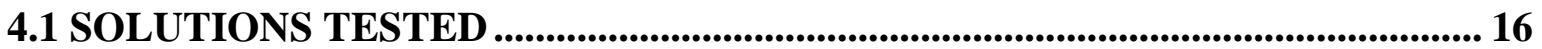

4.2 AIR FLUX DETERMINATION ..................................................................... 19

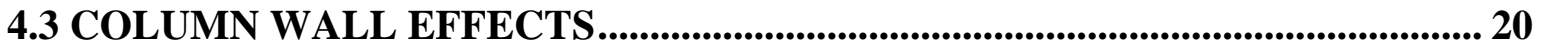

4.4 EFFECT OF NOZZLE SIZE ........................................................................... 21

4.5 20-DAY AIR SPARGING EXPERIMENT ............................................................. 22

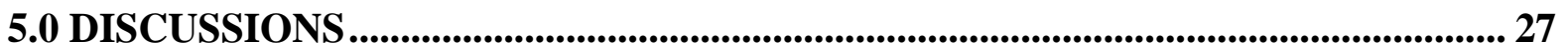

5.1 SMALL-SCALE SIMULANT TEST RESULTS ................................................... 27

5.2 SMALL-SCALE RADIOACTIVE TEST RESULTS ........................................... 33

5.3 Q2 ANTIFOAM TEST RESULTS .................................................................. 37

5.4 RADIATION AND CHEMICAL STABILITY OF Q2-3183A ............................. 44

5.5 PROCESS DESIGN CONSIDERATIONS .......................................................... 45

5.6 TWENTY-DAY AIR SPARGING RESULTS.................................................... 46

5.7 FATE OF ANTIFOAM IN WTP PROCESS ...................................................... 51

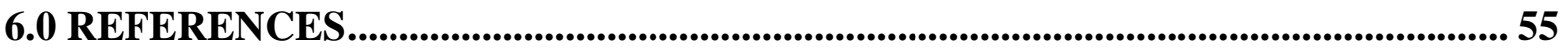

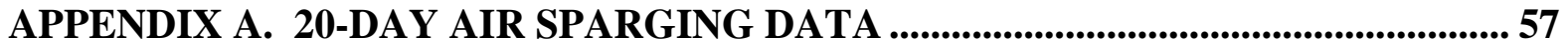


WSRC-TR-2004-00387, REVISION 0

SRNL-RPP-2004-00053, REVISION 0

\section{LIST OF FIGURES}

Figure 1. Photograph of Foam Test Apparatus in Rad hood in SRNL 773-A, C-Wing

Laboratory Module................................................................................................... 15

Figure 2. Plan View of HLW Lag Storage Tank Air Sparge Tubes .................................. 20

Figure 3. The Effect of Column Diameter on Foam Behavior (Wall Effect) ....................... 21

Figure 4. Effect of Air Sparge Tube Sizes on Foaminess of AY-102/C-106 Mixed with AP-

101 from Campaign II (10 wt.\% insoluble solids) ...................................................... 22

Figure 5. Effect of Solid Particles on Foaminess of AY-102/C-106 mixed with AP-101

(campaign II, SIPP feed) Simulant.................................................................... 29

Figure 6. Foaminess of AY-102/C-106 (Campaign I-SIPP Feed) Simulant ...................... 29

Figure 7. Effect of Solid Particles on Foaminess of AP-101 Simulant with AY-102 Sludge

Solids ............................................................................................................... 30

Figure 8. Effect of Solid Particles on Foaminess of AN-104 Simulant with AY-102 Sludge

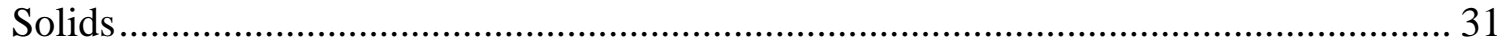

Figure 9. Effect of Solid Particles on Foaminess of Washed AZ-101 Simulant ................ 32

Figure 10. Effect of Solid Particles on Foaminess of Actual Hanford Waste (Pretreated AN-

104/SBS Recycle Solution) with Simulated AY-102 Sludge Solids ............................. 34

Figure 11. Foaming of AN-104/SBS Recycle Hanford Waste Sample with Simulated

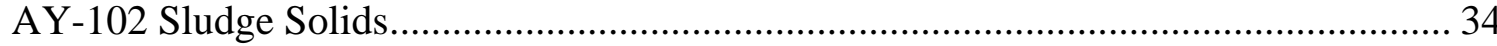

Figure 12. Effect of Solid Particles on Foaminess of Actual Hanford Waste (Pretreated

AN-104/SBS Recycle Solution) with Simulated AY-102 Sludge Solids ...................... 35

Figure 13. Effect of Solid Particles on Foaminess of Actual Hanford Waste (AN-104 Post

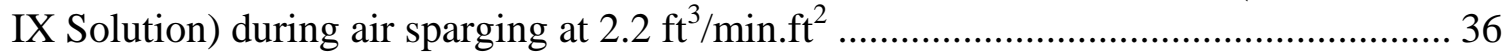

Figure 14. Effect of Q2 Antifoam on AY-102/C-106 Simulant ...................................... 37

Figure 15. Effect of Q2 Antifoam on Actual Hanford Waste (Pretreated AN-104/SBS

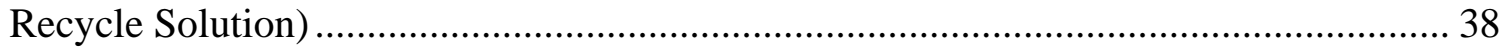

Figure 16. Evolution of the Foam with Time for Q2 Antifoam Addition to Actual Hanford

Waste (Pretreated AN-104 Post Ion Exchange Solution) - Disto data............................ 39

Figure 17. Evolution of the Foam with Time for Q2 Antifoam Addition to Actual Hanford

Waste (Pretreated AN-104 Post Ion Exchange Solution) - Visual data ....................... 40

Figure 18. Effect of Initial $555 \mathrm{mg} / \mathrm{L}$ Q2 Antifoam Addition to Actual Hanford Waste

(Pretreated AN-104 Post Ion Exchange Solution) ...................................................... 41

Figure 19. Effect of Dow Q2-3183A Antifoam Addition to Actual Hanford Waste ........... 42

Figure 20. Q2-3183A Antifoam Viscosity vs. Concentration ....................................... 45

Figure 21. 4-cm Air Sparging Column Analytical Data vs. Time .................................... 46

Figure 22. 5-cm Air Sparging Column Analytical Data vs. Time ..................................... 47

Figure 23. Bingham Plastic Parameters From 4-cm Air Sparing Test .............................. 48

Figure 24. Bingham Plastic Parameters From 5-cm Air Sparing Test .............................. 48

Figure 25. Ultrafiltration Feed Process Vessels Wt\% Total Solids versus Days of Air

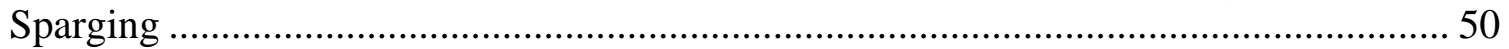

Figure 26. HLW Lag Storage Vessels Wt\% Total Solids versus Days of Air Sparging ...... 51

Figure 27. Vapor pressure of Dimethylmercury (ref. Thompson, W. H and Linnett, J. W.,

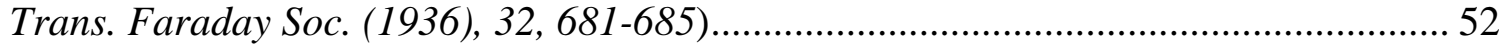


WSRC-TR-2004-00387, REVISION 0

SRNL-RPP-2004-00053, REVISION 0

Figure 28. Degradation Pathway of Organosilicones in the Presence of Bacteria (Feng 2002)

Figure 29. 4-cm Air Sparging Column Bingham Rheology vs. wt\% Insoluble Solids ........ 61

Figure 30. 5-cm Air Sparging Column Bingham Rheology vs. wt\% Insoluble Solids ......... 61

Figure 31. 4-cm Air Sparging Column Bingham Rheology vs. pH.................................... 62

Figure 32. 5-cm Air Sparging Column Bingham Rheology vs. pH...................................... 62

Figure 33. 4-cm Air Sparging Column Bingham Rheology vs. TIC ........................................6 63

Figure 34. 5-cm Air Sparging Column Bingham Rheology vs. TIC ....................................... 63

Figure 35. 4-cm Air Sparging Column Bingham Rheology vs. Density ................................. 64

Figure 36. 5-cm Air Sparging Column Bingham Rheology vs. Density ................................ 64

Figure 37. 4-cm Air Sparging Column Bingham Rheology vs. Density ................................. 65

Figure 38. 5-cm Air Sparging Column Bingham Rheology vs. Density ................................ 65

\section{LIST OF TABLES}

Table 1. Recommended Antifoam Addition Strategy to the UFP Feed, HLW Lag Storage, and HLW Blend Tanks.

Table 2. Composition of Pretreated AN-104 Hanford Waste Sample Blended with SBS

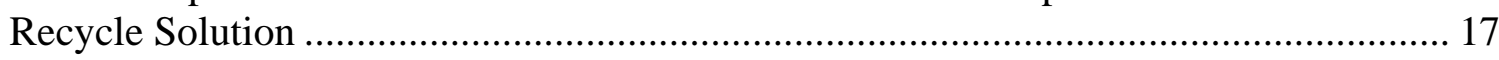

Table 3. Composition of pretreated Hanford AN-104 Waste Sample (Post Ion Exchange

Column) ........................................................................................................... 18

Table 4. Test Simulants Composition and Preparation Reference Documents ..................... 19

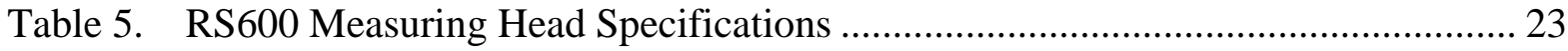

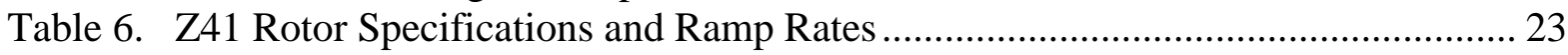

Table 7. Cole-Parmer NIST Traceable Newtonian Oil Standard ...................................... 24

Table 8. 20-Day Air Sparging Analytical Results ………………………………..................5 58

Table 9. 20-Day Air Sparging Analytical Results Continued............................................... 58

Table 10. Rheological Results of 4-cm Column 20-Day Air Sparing of $15 \mathrm{wt} \% \mathrm{HLW}$ Precipitated Hydroxide Simulant AZ 101 at $25^{\circ} \mathrm{C}$...................................................... 59

Table 11. Rheological Results of 5-cm Column 20-Day Air Sparing of $15 \mathrm{wt} \%$ HLW

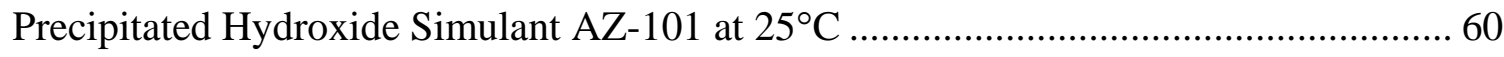




\section{LIST OF ACRONYMS}

$\begin{array}{ll}\text { cP } & \text { centipoise } \\ \text { CRV } & \text { Concentrate Receipt Vessel } \\ \text { GFCs } & \text { Glass Forming Chemicals } \\ \mathrm{H}_{\mathrm{G}+\mathrm{L}} & \text { Height of Air Incorporated Liquid plus Foam } \\ \mathrm{H}_{\mathrm{L}} & \text { Height of Liquid } \\ \text { HLW } & \text { High Level Waste } \\ \text { IX } & \text { Ion Exchange } \\ \text { JPM } & \text { Jet Pulse Mixer } \\ \text { LAW } & \text { Low Activity Waste } \\ \text { M } & \text { Molar } \\ \text { MFPV } & \text { Melter Feed Preparation Vessel } \\ \text { mPas } & \text { milliPascal-seconds } \\ \text { Pa } & \text { Pascals } \\ \text { ppm } & \text { parts per million } \\ \text { RPM } & \text { revolutions per minute } \\ \text { RPP } & \text { River Protection Project } \\ \text { SIPP } & \text { Semi-integrated Pilot Plant } \\ \text { SRNL } & \text { Savannah River National Laboratory } \\ \text { TIC } & \text { Total Inorganic Carbon } \\ \text { TOC } & \text { Total Organic Carbon } \\ \text { UFP } & \text { Ultrafiltration Process } \\ \text { Wt\% } & \text { Weight Percent } \\ \text { WTP } & \text { Waste Treatment Plant }\end{array}$




\section{EXECUTIVE SUMMARY}

The foaminess of Hanford waste samples [i.e., pretreated AN-104 Hanford sample - post ion exchange and AN-104 blended with Submerged Bed Scrubber (SBS) recycle, then evaporated to $5 \mathrm{M} \mathrm{Na}$ ] and waste simulants AP-101, AN-104, and AZ-101 was determined using an air-sparged foam column $(3.1 \mathrm{~cm}$ inside diameter x $60 \mathrm{~cm}$ height). The Hanford waste samples AN-104 post ion exchange solution and AN-104/SBS recycle solution, and the simulants AP-101 and AN-104, were mixed with different weight percents of AY-102/ C-106 sludge to determine the effect of insoluble particles. The AN-104 Hanford samples have shown a tendency to foam when subjected to air sparging. The percent foaminess, defined as $[100 *(($ volume fraction of gas entrained liquid and foam) - (volume fraction of gas entrained liquid)], increased to a well-defined maximum with the increase of the amount of solid particles added to solution. For example, at a sparge rate of $4.4 \mathrm{ft}^{3} / \mathrm{min} / \mathrm{ft}^{2}$, the foaminess of an air-sparged AN-104/SBS recycle sample with no added insoluble solid particles was $80 \%$ vs. $95 \%$ for 12 wt. $\%$ insoluble solids concentration in the sample. A more dramatic foaminess was observed for an AN-104 Hanford sample that was pretreated in ion exchange columns. The foaminess for this sample (no insoluble solids) at a nominal WTP flux of $2.2 \mathrm{ft}^{3} / \mathrm{min} / \mathrm{ft}^{2}$ was $358 \%$ as compared to $1048 \%$ when the sample was mixed with AY-102/C-106 sludge to a 6 wt. \% insoluble solids. For AN-104 simulant with 6 wt.\% insoluble solids sparged at air flux of $2.2 \mathrm{ft}^{3} / \mathrm{min} / \mathrm{ft}^{2}$, the foaminess was less than $2 \%$. The measured surface tension of this simulant was $68.63 \mathrm{dyne} / \mathrm{cm}$ as compared to that of the AN104 Hanford sample (post ion exchange), which was 71.59 dyne/cm.

A 20-day air sparging experiment was performed to examine the effect of $\mathrm{CO}_{2}$ on the $\mathrm{pH}$ or chemical composition of the slurry and to determine how rheology may be impacted by air sparging. The experiment showed that air sparging has no significant effect on $\mathrm{pH}$ or chemical composition of the slurry. The rheology is also not impacted by air sparging. The primary effect of air sparging is the removal of water by the dry air passing through the column and exiting in a saturated condition. This effect can be mitigated by adding water back to the column or vessel during sparging.

The effectiveness of antifoam agent Q2-3183A (Dow Corning) in mitigating the foaming tendency in the WTP tanks was tested. An initial charge of $345 \mathrm{mg} / \mathrm{L}$ antifoam Q2-3183A to an air-sparged Hanford AN-104 sample (a pretreated sample from ion exchange column testing) reduced the foaminess from $358 \%$ to less than $10 \%$ (detection limit of measuring foam). For the Hanford AN-104 sample with 9 wt.\% insoluble solids, the foaminess was reduced by a factor of 40 with an initial charge of $345 \mathrm{mg} / \mathrm{L}$ Q2-3183A antifoam and incremental addition of $70 \mathrm{mg} / \mathrm{L}$ Q2-3183A over 24 hours. Therefore, an initial charge of $350 \mathrm{mg} / \mathrm{L}$ antifoam (Dow Q2-3183A) followed by small batch additions of $70 \mathrm{mg} / \mathrm{L}$ Q2-3183A every 24 hours is recommended for use in WTP tanks equipped with air spargers and pulse jets based upon the testing done in this study. However, this recommendation is based upon a limited set of antifoam degradation data developed for the WTP evaporator R\&T program. Therefore, additional investigation into refining the kinetic behavior of Q2 antifoam under radiation dose is recommended. 
Table 1 provides the antifoam addition strategy to reduce the foaminess of the waste. The Ultrafiltration Feed tanks (UFP-VSL-00002A\&B) undergo several modes of operation:

1) Concentration, 2) Washing, 3) Leaching, 4) Cleaning, and 5) Transfer Pump and Steam Jet Operations. The HLW Lag Storage Tank and Blend Tanks are batch storage vessels that receive treated HLW sludge. In the case of the HLW blend vessel, Cs eluate and washed Sr/TRU precipitate are blended with HLW sludge and then transferred to the HLW vitrification building. The addition strategy is outlined in Table 1 along with relevant comments concerning each specific operation. All antifoam additions (except those noted in Table 1) to the WTP slurry tanks should use the recommended initial charge concentration of $350 \mathrm{mg} / \mathrm{L}$ followed by small batch additions of $70 \mathrm{mg} / \mathrm{L}$ every 24 hours. SRNL recommends adding the antifoam to WTP tanks at the surface. Addition on the surface will allow the antifoam to act as a defoamer as well as an antifoamer, and the antifoam performance (foam reduction) will be faster.

Monitoring the height of the foam in the WTP tanks is recommended. Methods of sensing the foam level, such as using electrodes in which electric circuit or floats designed to rise in a foam layer are recommended. The DWPF installed differential pressure sensors in the DWPF Precipitate Reactor canyon vessel to indicate the presence of foam in the vessel.

Table 1. Recommended Antifoam Addition Strategy to the UFP Feed, HLW Lag Storage, and HLW Blend Tanks

\begin{tabular}{|l|l|l|}
\hline $\begin{array}{l}\text { UFP Operations- } \\
\text { Addition Point }\end{array}$ & $\begin{array}{l}\text { Frequency of } \\
\text { Addition }\end{array}$ & Comments \\
\hline $\begin{array}{l}\text { Feed Tanks } \\
\text { Fentration-UFP }\end{array}$ & $\begin{array}{l}\text { 350 mg/L initial } \\
\text { charge, followed by } \\
\text { batch addition of } \\
70 \mathrm{mg} / \mathrm{L} \text { every } 24 \\
\text { hours }\end{array}$ & None \\
\hline $\begin{array}{l}\text { Washing-UFP Feed } \\
\text { Tanks }\end{array}$ & $\begin{array}{l}\text { 350 mg/L batch } \\
\text { addition to both } \\
\text { addition points } \\
\text { before the start of } \\
\text { to UFP tank }\end{array}$ & $\begin{array}{l}\text { Added to the UFP tank in a single dose at } \\
\text { the start of washing and added to the wash } \\
\text { water makeup/addition tank or wash water } \\
\text { transfer line into the UFP tank. Thus, } \\
\text { antifoam will be added to maintain the } \\
\text { UFP tank at 350 mg/L. }\end{array}$ \\
\hline $\begin{array}{l}\text { Leaching - UFP } \\
\text { Feed Tanks }\end{array}$ & $\begin{array}{l}\text { Continuous addition } \\
\text { to maintain } 350 \\
\text { mg/L in UFP tank }\end{array}$ & $\begin{array}{l}\text { This study did not address the chemical } \\
\text { stability of the antifoam above } 50^{\circ} \mathrm{C} . \\
\text { Conversations with Dow technical } \\
\text { personnel indicate the antifoam may } \\
\text { degrade at temperatures above } 80^{\circ} \mathrm{C} . \\
\text { Continuous antifoam addition to maintain } \\
\text { concentration at } 350 \text { mg/L is recommended } \\
\text { at this time. }\end{array}$ \\
\hline $\begin{array}{l}\text { Cleaning - UFP } \\
\text { Feed Tanks }\end{array}$ & $\begin{array}{l}\text { Foaminess of acidic slurries should be } \\
\text { addressed by future R\&T programs. }\end{array}$ \\
\hline
\end{tabular}


WSRC-TR-2004-00387, REVISION 0

SRNL-RPP-2004-00053, REVISION 0

Table 1. Recommended Antifoam Addition Strategy to the UFP Feed, HLW Lag Storage, and HLW Blend Tanks - continued

\begin{tabular}{|c|c|c|}
\hline $\begin{array}{l}\text { UFP Operations- } \\
\text { Addition Point } \\
\end{array}$ & $\begin{array}{l}\text { Frequency of } \\
\text { Addition }\end{array}$ & Comments \\
\hline $\begin{array}{l}\text { Transfer pump and } \\
\text { steam jet operations } \\
\text { - UFP feed tanks }\end{array}$ & $\begin{array}{l}350 \mathrm{mg} / \mathrm{L} \text { batch } \\
\text { addition before each } \\
\text { transfer }\end{array}$ & $\begin{array}{l}\text { This study did not address the foaminess of } \\
\text { Hanford waste or simulants when } \\
\text { subjected to pumping or steam jet } \\
\text { operations. It is expected that some } \\
\text { sparger air may be entrained in the waste } \\
\text { and become atomized during transfer } \\
\text { operations. The atomized air is likely to } \\
\text { cause foaming in the waste. }{ }^{5} \text { Steam jets } \\
\text { may also cause foaming in the waste. }\end{array}$ \\
\hline $\begin{array}{l}\text { HLW Lag Storage } \\
\text { Tank Operations - } \\
\text { Lag Storage Tank }\end{array}$ & $\begin{array}{l}350 \mathrm{mg} / \mathrm{L} \text { initial } \\
\text { charge, followed by } \\
\text { batch addition of } 70 \\
\mathrm{mg} / \mathrm{L} \text { every } 24 \\
\text { hours and prior to } \\
\text { each transfer of } \\
\text { waste from the tank }\end{array}$ & None \\
\hline $\begin{array}{l}\text { HLW Blend Tank } \\
\text { Operations - Blend } \\
\text { Storage Tank }\end{array}$ & $\begin{array}{l}350 \mathrm{mg} / \mathrm{L} \text { initial } \\
\text { charge, followed by } \\
\text { batch addition of } 70 \\
\mathrm{mg} / \mathrm{L} \text { every } 24 \\
\text { hours and prior to } \\
\text { each transfer of } \\
\text { waste from the tank }\end{array}$ & None \\
\hline Transfer of Sr/TRU & $\begin{array}{l}\text { None, as long as a } \\
\text { batch addition of } 70 \\
\mathrm{mg} / \mathrm{L} \text { is made every } \\
24 \text { hours }\end{array}$ & $\begin{array}{l}\text { The foaminess of HLW sludges with eluate } \\
\text { was not tested by this study. Future R\&T } \\
\text { programs should assess this operating } \\
\text { scenario. }\end{array}$ \\
\hline Transfer of Eluate & $\begin{array}{l}\text { None, as long as a } \\
\text { batch addition of } \\
70 \mathrm{mg} / \mathrm{L} \text { is made } \\
\text { every } 24 \text { hours }\end{array}$ & $\begin{array}{l}\text { The foaminess of HLW sludges with eluate } \\
\text { was not tested by this study. Future R\&T } \\
\text { programs should assess this operating } \\
\text { scenario. }\end{array}$ \\
\hline
\end{tabular}


WSRC-TR-2004-00387, REVISION 0

SRNL-RPP-2004-00053, REVISION 0

This page intentionally left blank. 
WSRC-TR-2004-00387, REVISION 0

SRNL-RPP-2004-00053, REVISION 0

\subsection{TESTING SUMMARY}

This report describes the experimental conditions and results of small-scale foaming and antifoaming tests performed at Savannah River National Laboratory (SRNL) using AN-104 Hanford sample and simulants subjected to air sparging. The Hanford AN-104 sample was previously treated in ion exchange columns with SuperLig® 644 to remove cesium and simulants AP-101, AN-104 and washed AZ-101 (known as HLW Precipitated Hydroxide Simulant) were formulated and prepared according to RPP or SRNL recipes. Simulants of AY-102 and AY-102 mixed with AP-101 (about 4 parts AP-101 to 1 part AY-102/C-106) were obtained from Campaign I and Campaign II of the Semi-integrated Pilot Plant (SIPP). The radioactive test solutions were prepared by mixing the AN-104 Hanford sample and simulants with AY-102/C106 sludge at various concentrations of insoluble solids. The tendency of these solutions to foam when subjected to air sparging was investigated. The parameters studied were the concentration of solid particles, air flux, and time. The effectiveness of the antifoam agent (Dow Corning Q2-3183A) was evaluated under worst case conditions for both Hanford AN-104 sample and simulants. A 20-day air sparging experiment using Hanford simulants was also performed to see how $\mathrm{CO}_{2}$ in the air may impact the $\mathrm{pH}$ or chemical composition and how sparging could affect the rheology of the sludge.

\subsection{OBJECTIVES}

The small-scale foaming and antifoaming tests were initiated at SRNL in April 2004. The overall objectives and their status are listed below.

\begin{tabular}{|c|c|c|}
\hline Test Objective & $\begin{array}{l}\text { Objective } \\
\text { Met (Y/N) }\end{array}$ & Discussion \\
\hline $\begin{array}{l}\text { 1. Determine the foaminess of } \\
\text { Hanford AN-104 sample } \\
\text { mixed with AY-102/C-106 } \\
\text { sludge and subjected to air } \\
\text { sparging. }\end{array}$ & $\mathrm{Y}$ & $\begin{array}{l}\text { The foaminess of AN- } 104 \text { Hanford } \\
\text { samples has been determined at } \\
\text { different air fluxes and as a function } \\
\text { of concentration of solid particles. }\end{array}$ \\
\hline $\begin{array}{l}\text { 2. Determine if the baseline } \\
\text { WTP evaporator antifoam } \\
\text { agent (or alternative antifoam } \\
\text { agents) will effectively } \\
\text { mitigate foaming in non- } \\
\text { Newtonian slurries in WTP } \\
\text { tanks containing non- } \\
\text { Newtonian slurries that are } \\
\text { equipped with pulse jet mixers } \\
\text { and air spargers }\end{array}$ & $\mathrm{Y}$ & $\begin{array}{l}\text { The effectiveness of antifoam agent } \\
\text { Q2-3183A to mitigate the } \\
\text { foaminess of AN-104 Hanford } \\
\text { sample and various Hanford waste } \\
\text { simulants has been tested. An initial } \\
\text { charge of } 350 \mathrm{mg} / \mathrm{L} \text {, followed by } \\
\text { batch additions of } 70 \mathrm{mg} / \mathrm{L} \\
\text { antifoam agent (Q2-3183A) every } \\
24 \text { hours to WTP tanks equipped } \\
\text { with air spargers and pulse jets was } \\
\text { recommended. }\end{array}$ \\
\hline
\end{tabular}


WSRC-TR-2004-00387, REVISION 0

SRNL-RPP-2004-00053, REVISION 0

\begin{tabular}{|c|c|l|}
\hline Test Objective & $\begin{array}{l}\text { Objective } \\
\text { Met (Y/N) }\end{array}$ & Discussion \\
\hline $\begin{array}{c}\text { 3. Determine if incorporation of } \\
\begin{array}{c}\mathrm{CO}_{2} \text { from air sparging changes } \\
\text { the } \mathrm{pH} \text { (chemical composition) } \\
\text { of the simulant as a function of } \\
\text { air sparge time, volume, etc }\end{array}\end{array}$ & $\mathrm{Y}$ & $\begin{array}{l}\text { The 20-day air sparging } \\
\text { experiments at a flux of } 2.5 \\
\mathrm{ft}^{3} / \mathrm{min} / \mathrm{ft}^{2} \text { showed no significant } \\
\text { change in } \mathrm{pH} .\end{array}$ \\
\hline $\begin{array}{l}\text { 4. Determine if the rheology of } \\
\text { simulant changes as a function } \\
\text { of air sparge time, volume, etc. }\end{array}$ & $\mathrm{Y}$ & $\begin{array}{l}\text { Based on analyses of wt\% solids, } \\
\text { pH, TIC/TOC, density and } \\
\text { rheology, yield stress and } \\
\text { consistency does not appear to be } \\
\text { impacted by air sparging other than } \\
\text { by the loss of water due to } \\
\text { evaporation by dry sparge air. }\end{array}$ \\
\hline
\end{tabular}

\subsection{TEST EXCEPTIONS}

The test exception "Foaming and Antifoaming Air Sparging Issues Testing Related to Hybrid Pulse Jet Mixer Systems," 24590-WTP-TEF-RT-04-00012 Rev. 0, was written to provide guidance for this task.

\subsection{RESULTS AND PERFORMANCE AGAINST SUCCESS CRITERIA}

The results obtained in this study met the objectives outlined above in section 1.1. A summary of the results follows.

1. The performance of Dow Q2-3183A as both an antifoam agent and a defoamer has been demonstrated with simulant waste testing of AY-102/C-106 at $10 \mathrm{wt} . \%$ solids concentration. The effectiveness of the Q2-3183A antifoam was also demonstrated with pretreated AN-104 (post IX) Hanford waste samples mixed with AY-102/C-106 at 6 and 9 wt.\% insoluble solids. The addition of $350 \mathrm{mg} / \mathrm{L}$ of Q2-3183A to actual waste sample completely destroyed the foam in the column and suppressed it for more than 8 hours.

2. Actual Hanford waste samples (pretreated AN-104 post ion exchange and AN-104 blended with SBS recycle) and simulants have been demonstrated to foam when subjected to air sparging. The amount of foaminess was quantified by measuring the total height of air entrained liquid and foam minus the gas holdup in the liquid due to air sparging. 
WSRC-TR-2004-00387, REVISION 0

SRNL-RPP-2004-00053, REVISION 0

The amount of foam in the pretreated $\mathrm{AN}-104$ post ion exchange and $\mathrm{AN}-104$ blended with SBS recycle increased with the initial increase in the concentration of solid particles. For the AN-104 post ion exchange, the amount foaminess of the as received pretreated AN-104/SBS recycle sample (which contained no insoluble solids, was $358 \%$ ) as compared to $1048 \%$ foaminess for the sample containing 6 wt.\% insoluble solids at a flux $2.2 \mathrm{ft}^{3} / \mathrm{min} / \mathrm{ft}^{2}$.

3. The amount of foaminess of AN-104 and AP-101 simulants without insoluble solids was negligible.

4. The rate at which air was sparged into the liquid has direct (but not linear) effect on the amount of foaminess.

5. A concentration of about $350 \mathrm{mg} / \mathrm{L} \mathrm{Q2-3183A} \mathrm{has} \mathrm{demonstrated} \mathrm{effectiveness} \mathrm{in}$ reducing the amount of foaminess of AN-104 actual Hanford waste sample (post ion exchange) to negligible levels.

6. The stability of the foam generated in the actual Hanford waste and simulants when subjected to air sparging was negligible, i.e., the foam collapsed as soon as the air sparging was stopped.

7. The $\mathrm{pH}$ of the simulated $15 \mathrm{wt} \% \mathrm{AZ}-101$ sludge did not change significantly during a 20-day air sparging experiment for a $4-\mathrm{cm}$ and a 5-cm column at an air flux of $2.5 \mathrm{ft}^{3} / \mathrm{min} / \mathrm{ft}^{2}$.

8. Based on analyses of weight percent solids, $\mathrm{pH}$, TIC/TOC, density, and rheology of the simulated $15 \mathrm{wt} \%$ AZ-101 sludge, the sludge does not appear to be impacted by air sparging other than by the loss of water due to evaporation by the dry sparge air (approximately 0.11 grams $/ \mathrm{cm}^{2} /$ hour evaporative losses, or $\sim 52 \mathrm{~kg} /$ hour for a $25 \mathrm{ft}$ diameter vessel).

9. The surface tension of AN-104 simulant was $68.63 \mathrm{dyne} / \mathrm{cm}$ as compared to $71.59 \mathrm{dyne} / \mathrm{cm}$ for the AN-104 Hanford sample (post ion exchange). 


\subsection{QUALITY REQUIREMENTS}

This work was conducted in accordance with the RPP-WTP QA requirements specified for work conducted by SRTC as identified in DOE IWO MOSRLE60. SRTC has provided matrices to WTP demonstrating compliance of the SRTC QA program with the requirements specified by WTP. Specific information regarding the compliance of the SRTC QA program with RW-0333P, Revision 10, NQA-1 1989, Part 1, Basic and Supplementary Requirements and NQA-2a 1990, Subpart 2.7 is contained in these matrices.

\subsection{R\&T TEST CONDITIONS}

Foaming experiments were carried out in a foam column $(3.1 \mathrm{~cm}$ inside diameter $\mathrm{x} 60 \mathrm{~cm}$ height). Air was introduced into the foam column through a fritted disk (75-100 $\mu \mathrm{m}$ holes) at a rate of $0.25-4 \mathrm{~L} / \mathrm{min}$ (i.e., air fluxes of 1.1-17.6 $\mathrm{ft}^{3} \mathrm{air} / \mathrm{min} / \mathrm{ft}^{2}$ ). The solutions tested were Hanford waste simulants AP-101 and AN-104 mixed with AY-102/C-106 sludge simulant, and AZ-101 HLW precipitated hydroxide simulant. ${ }^{2,9}$ The AZ-101 HLW Precipitated Hydroxide simulant was diluted with inhibited water $\left(0.01 \mathrm{M} \mathrm{NaOH}+0.01 \mathrm{M} \mathrm{NaNO}_{2}\right)$ to obtain the desired weight percent insoluble solids. The radioactive samples tested were pretreated AN-104 (post ion exchange) ${ }^{1}$, and pretreated AN-104 blended with Submerged Bed Scrubber (SBS) recycle (from simulant tests) and evaporated to $5 \mathrm{M} \mathrm{Na}^{3}$

For each solution, the foaming test was first performed without added sludge. The solution was transferred into the foam column, and the air-flow was started. The foam height was measured as a function of time using a Disto Pro4 ${ }^{\mathrm{TM}}$ laser height detector. The foaminess was defined as $[100 *(($ volume fraction of gas entrained liquid and foam $)-($ volume fraction of gas entrained liquid))]. The percent foaminess was determined as a function of (wt. \% insoluble solids), air flux, and time. A series of foaming tests using both simulants and radioactive waste samples were also performed. An antifoam solution containing 10,000 ppm Dow Corning Q2-3183A in water was made up. Then $10 \mathrm{mg}$ of the antifoam solution was added to the foaming waste contained in the foam column (typical volumes ranged from 29 to $35 \mathrm{~mL}$ ) prior to onset of foaming, and the foaming was carried out as described above. In addition, the antifoam was added to existing foam in a foaming solution subjected to air sparging, and the foam collapse was followed as a function of time.

The surface tension of AN-104 Hanford sample (post ion exchange) was measured and compared to the surface tension of AN-104 simulant formulated at the same density. The surface tension was measure by a capillary tube. The measurements were repeated 10 times for each solution.

For the 20-day air sparging experiments, two glass columns $(4 \mathrm{~cm}$ inside diameter $\mathrm{x} 70 \mathrm{~cm}$ height and $5 \mathrm{~cm}$ inside diameter $\mathrm{x} 40 \mathrm{~cm}$ height) were used for the 20-day air sparging experiments to see if cross-sectional area would impact the effects of sparging. The air flow was set to maintain an air flux of $2.5 \mathrm{ft}^{3} / \mathrm{min} / \mathrm{ft}^{2}$ through each column. The same amount of sludge was initially charged to both columns and column weights and levels were recorded to track mass losses throughout the 20 days. On day 7, 14, and 20 samples were collected from both columns to measure weight percent solids, $\mathrm{pH}$, TIC/TOC, density, iron concentration, anion concentration, and to analyze rheology. 


\subsection{SIMULANT USE}

The simulants tested were AP-101, AN-104, washed AZ-101 (HLW Precipitated Hydroxide Simulant), AY-102 from campaign I and AY-102 mixed with AP-101 from campaign II of the semi-integrated pilot plant (SIPP) feed. The radioactive samples tested were pretreated AN-104 (post ion exchange), and pretreated AN-104 blended with Submerged Bed Scrubber (SBS) recycle (from simulant tests) and evaporated to $5 \mathrm{M} \mathrm{Na}$. To study the effect of insoluble particles, the simulants and radioactive waste samples were mixed with AY-102/ C-106 sludge at different concentrations of insoluble solids. The washed AZ-101 was diluted with inhibited water $\left(0.01 \mathrm{M} \mathrm{NaOH}+0.01 \mathrm{M} \mathrm{NaNO}_{2}\right)$ to the desired weight percent insoluble solids. The physical and chemical properties of the radioactive waste samples are presented in Table 2 and Table 3. The preparation and properties of the test simulants are contained within the documents presented in Table 4.

\subsection{DISCREPANCIES AND FOLLOW-ON TESTS}

Discussion with Dow technical personnel indicate that Q2-3183A will likely breakdown at temperatures above $80^{\circ} \mathrm{C}$. During leaching operations the antifoam may have to be added continuously to the UFP tanks. There is a concern about the forming of dimethylmercury in the UFP system during the leaching process, in which temperature may exceed $80^{\circ} \mathrm{C}$. Since this study did not address leaching, the fate of dimethylmercury and all organic compounds added with the antifoam will require additional study. Therefore, it is recommended that future R\&T studies investigate the foaminess of leached HLW sludge, antifoam performance, and the fate of antifoam degradation products and dimethylmercury during chemical leaching of HLW sludge.

The recommended dose of $350 \mathrm{mg} / \mathrm{L}$ Q2-3183A antifoam to the WTP tanks is based on limited laboratory tests. Thus, evaluation of this antifoam agent during future small scale process demonstration conducted for the WTP is recommended. The DWPF facility conducts these types of process demonstrations prior processing each new sludge batch into the DWPF.

The measurement of foaming used for these tests was not designed to be scaled relative to the WTP. Typically, previous R\&D foaming and antifoaming efforts conducted for the DWPF and WTP have used a combination of small scale simulant and radioactive tests in conjunction with pilot scale testing to demonstrate and validate the performance of the antifoam agents used in these processes. Additionally, the fritted disk used in these tests produced a much smaller bubble than the full scale WTP sparger which is conservative with respect to the WTP design and might result in larger quantities of antifoam than needed by the process. Therefore, pilot scale testing should be conducted before radioactive operations of the WTP. Pilot scale testing and additional antifoam irradiation investigations should also be conducted before optimizing the antifoam addition strategy. 
WSRC-TR-2004-00387, REVISION 0

SRNL-RPP-2004-00053, REVISION 0

This page intentionally left blank. 
WSRC-TR-2004-00387, REVISION 0

SRNL-RPP-2004-00053, REVISION 0

\subsection{CD-ROM ENCLOSURES}

The enclosed CD-ROM, which contains selected video clips of some experiments, is provided as supplemental to the report. The CD contents are not discussed in the report. Included on the CD-ROM are video clips of the following tests:

\section{Simulant Tests}

- AY-102 (10 wt.\% insoluble solids) Air Sparge at $8.8 \mathrm{ft}^{3} / \mathrm{min} / \mathrm{ft}^{2}$ air flux

- AY-102 (10 wt.\% insoluble solids) Air Sparge with 315 mg/L Q2-3183A added

- AY-102 (10 wt.\% insoluble solids) Single Nozzle (0.0625" bore) Air Sparge

- AY-102 (10 wt.\% insoluble solids) Single Nozzle (0.125" bore) Air Sparge

- AY-102 (10 wt.\% insoluble solids) Single Nozzle (0.25" bore) Air Sparge

\section{Rad Solution Tests}

- AN-104/SBS (No Solids Added) Baseline Air Sparge at $4.4 \mathrm{ft}^{3} / \mathrm{min} / \mathrm{ft}^{2}$ air flux

- AN-104/SBS (No Solids Added) w/ 340 mg/L Q2-3183A added Air Sparge at $4.4 \mathrm{ft}^{3} / \mathrm{min} / \mathrm{ft}^{2}$ air flux

- AN-104/SBS (No Solids Added) w/ 1020 mg/L Q2-3183A added Air Sparge at $4.4 \mathrm{ft}^{3} / \mathrm{min} / \mathrm{ft}^{2}$ air flux

- AN-104/SBS (No Solids Added) w/ 2380 mg/L Q2-3183A added Air Sparge at $4.4 \mathrm{ft}^{3} / \mathrm{min} / \mathrm{ft}^{2}$ air flux

- AN-104/SBS (No Solids Added) w/ 3060 mg/L Q2-3183A added Air Sparge at $4.4 \mathrm{ft}^{3} / \mathrm{min} / \mathrm{ft}^{2}$ air flux

- AN-104/SBS (No Solids Added) w/ 3740 mg/L Q2-3183A added Air Sparge at $4.4 \mathrm{ft}^{3} / \mathrm{min} / \mathrm{ft}^{2}$ air flux

A spreadsheet showing the air flow basis and tanks configuration (height to overflow)

is also included.

The CD-ROM should start automatically within 30 seconds when placed in your CD-ROM drive on an IBM compatible PC. If it does not, then do the following:

1. Double-left-click on MyComputer icon on your desktop

2. Right-click on your CD drive icon

3. Left-click on AutoPlay

The recommended minimum computer system is as follows:

- Pentium II running at $233 \mathrm{MHz}$

- $32 \mathrm{MB}$ ram

- Windows 95 or later. 
WSRC-TR-2004-00387, REVISION 0

SRNL-RPP-2004-00053, REVISION 0

This page intentionally left blank. 
WSRC-TR-2004-00387, REVISION 0

SRNL-RPP-2004-00053, REVISION 0

\subsection{INTRODUCTION}

The River Protection Project-Waste Treatment Plant (RPP-WTP) requested Savannah River National Laboratory (SRNL) to conduct small-scale foaming and antifoam testing using actual Hanford waste and simulants subjected to air sparging. The foaminess of Hanford tank waste solutions was previously demonstrated by SRNL during WTP evaporator foaming studies and commercial antifoam Dow Q2-3183A was recommended to mitigate the foam in the evaporators. Currently, WTP is planning to use air spargers in the HLW Lag Storage Vessels (HLP-VSL-00027A/B) and the Ultrafiltration Vessels (UFP-VSL-00002A\&B) to assist the performance of the Jet Pulse Mixers (JPM).

Sparging of air into WTP tanks will induce a foam layer within the process vessels. The air dispersion in the waste slurries and generated foams could present problems during plant operation. Foam in the tanks could also adversely impact hydrogen removal and mitigation. Antifoam (Dow Q2-3183A) will be used to control foaming in Hanford sparged waste processing tanks. These tanks will be mixed by a combination of pulse-jet mixers and air spargers.

The suitability and period of effectiveness of the Dow Corning Q2-3183A anti-foam agent and/or alternative antifoams will be evaluated. Previous investigations into the stability of Dow Q2-3183A antifoam agent have demonstrated very good chemical stability with little or no degradation observed at $50^{\circ} \mathrm{C}$ in 3 molar caustic for periods as long as a week. ${ }^{4}$ Chemical stability of Q2-3183A at temperatures above $50^{\circ} \mathrm{C}$ has not been investigated.

This work was performed under the test exception \# 24590-WTP-TEF-RT-04-00012, Rev. 0, to the Task Technical and Quality Assurance Plan, WSRC-TR-2003-00532 (SRT-RPP-200300235), entitled "Foaming and Antifoaming Air Sparging Issues Testing Related to Hybrid Pulse Jet Mixer Systems.” SRNL prepared a Task Technical and Quality Assurance Plan: WSRC-TR-2004-00104 (SRT-RPP-2004-00015) entitled "Foaming/Antifoaming in WTP Tanks Equipped with Pulse Jet Mixers and Air Spargers" to guide this work. This task plan has been reviewed by WTP. WTP approval was not required. 
WSRC-TR-2004-00387, REVISION 0

SRNL-RPP-2004-00053, REVISION 0

This page intentionally left blank. 


\subsection{EXPERIMENTAL APPARATUS AND METHODOLOGY}

The apparatus used to perform the foaming and antifoam experiments consisted of a glass foam column $(3.1 \mathrm{~cm}$ diameter x $60 \mathrm{~cm}$ height) with graduations along the column wall, an air flow metering device with a three-way valve, a Disto ${ }^{\mathrm{TM}}$ Pro4 laser measuring device interfaced to a computer data collection system, and a Sony ${ }^{\mathrm{TM}}$ Mini-DV video recording camera. The foam column had a coarse fritted disk with 75-100 micron holes fitted into its base. The small bubbles created by the fritted disk were used to simulate a larger air sparger bubble broken up by introduction into a recirculation pump or sheared by some other means. The effect of sparge inlet diameter is discussed in section 4.3.

To provide the air sparging, air was introduced into the column through a $0.6 \mathrm{~cm}$ (1/4-inch) i.d. tube directly below the fritted disk. The flow of air was controlled by a mass flow meter. A three-way valve below the column air-supply tube was utilized to divert air away from the column during intermittent air flux changes between tests.

The non-radioactive experiments were conducted within a ventilation hood at SRNL facilities. The experiments with radioactive waste (actual Hanford sample) were conducted in a rad-hood at SRNL. A photograph of the apparatus in the rad-hood is shown in Figure 1.

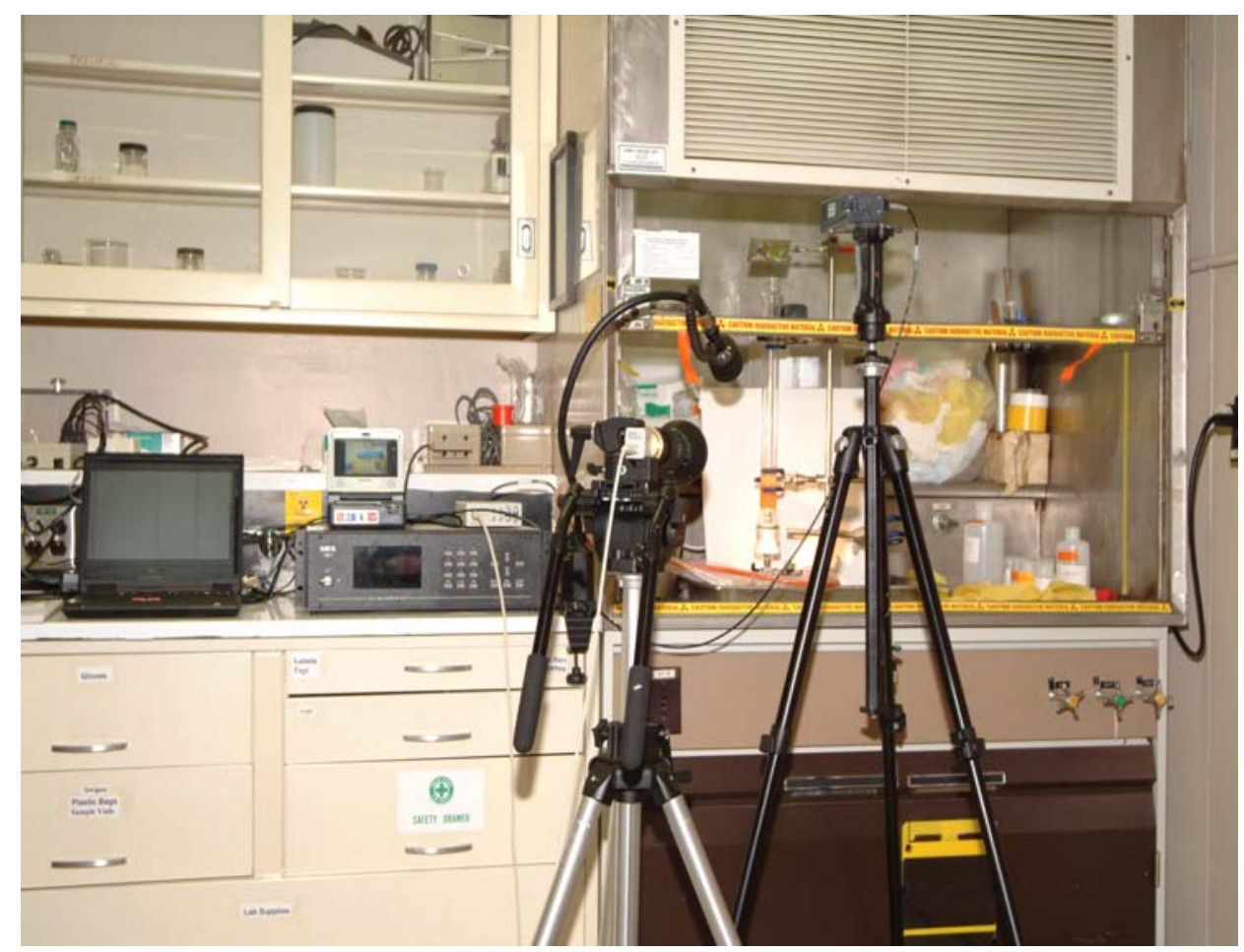

Figure 1. Photograph of Foam Test Apparatus in Rad hood in SRNL 773-A, C-Wing Laboratory Module 
Foaming experiments were carried out in the apparatus described above. Air was introduced via the fritted disk through the sample at air fluxes of 1.1, 2.2, 3.3, 4.4, 6.6, 8.8, 11.0, 13.2, 15.4 , and $17.6 \mathrm{ft}^{3} / \mathrm{min} / \mathrm{ft}^{2}$. These fluxes correspond to air flow rates of $0.25,0.5,0.75,1.0$, $1.5,2.0,2.5,3.0,3.5$, and $4.0 \mathrm{~L} / \mathrm{min}$, controlled by a mass flow meter (MKS Instruments,

Inc.). The experiments were first conducted with simulants (supernatant liquids) free of solid particles. This was followed with simulants containing different initial concentrations of insoluble solids. The solutions with insoluble solids were prepared from the simulants or actual Hanford waste and a simulant of AY-102/C-106 sludge at 20-24 wt.\% insoluble solids. Known amounts of the solutions (typically, 29 to $35 \mathrm{~mL}$ ) were added to the foam column to a level of about $4 \mathrm{~cm}$ above the fritted disk. Airflow was started, and foam height was measured as a function of time using a Disto Pro4 laser measuring device. The foam height at steady state was also recorded by visual observation. The airflow was then switched off, and the foam collapse was followed as function of time. All experiments were performed in an open system at atmospheric pressure and ambient temperature $\left(25 \pm 2{ }^{\circ} \mathrm{C}\right)$.

Antifoam tests were performed by two methods. A solution of Dow Q2-3183A antifoam was prepared using 10 grams of Q2-3183A in 1000 milliliter deionized water. In the first method, $1 \mathrm{~mL}$ increments of the prepared Q2-3183A were added drop wise to existing foam in the foam column under constant air-flow, and the collapse of the foam was followed. In the second method, the Q2 antifoam (approximately $1 \mathrm{~mL}$ ) was added into the test solution (29 to $35 \mathrm{~mL}$ ) at rest, then air was introduced and the foaming test was carried out as previously described.

\subsection{SOLUTIONS TESTED}

The simulants tested were AP-101, AN-104, washed AZ-101 (HLW Precipitated Hydroxide Simulant), AY-102 from campaign I and AY-102 mixed with AP-101 from campaign II of the semi-integrated pilot plant (SIPP) feed. The radioactive samples tested were pretreated AN-104 (post ion exchange), and pretreated AN-104 blended with Submerged Bed Scrubber (SBS) recycle (from simulant tests) and evaporated to $5 \mathrm{M} \mathrm{Na}$. To study the effect of insoluble particles, the simulants and radioactive waste samples were mixed with AY102/C106 sludge at different concentrations of insoluble solids. The washed AZ-101 was diluted with inhibited water $\left(0.01 \mathrm{M} \mathrm{NaOH}+0.01 \mathrm{M} \mathrm{NaNO}_{2}\right)$ to the desired weight percent insoluble solids. The physical and chemical properties of the radioactive waste samples are presented in Table 2 and Table 3. The preparation and properties of the test simulants are contained within the documents presented in Table 4. 
WSRC-TR-2004-00387, REVISION 0

SRNL-RPP-2004-00053, REVISION 0

Table 2. Composition of Pretreated AN-104 Hanford Waste Sample Blended with SBS Recycle Solution*

\begin{tabular}{|c|c|c|c|}
\hline $\begin{array}{c}\text { Hanford } \\
\text { Waste }\end{array}$ & \multicolumn{3}{|c|}{ AN104 / SBS A3 Blend (35:65) } \\
\hline \multirow[t]{2}{*}{ LIMS\#300- } & 196785 & 196785 & Avg. \\
\hline & $\mathrm{mg} / \mathrm{L}$ & mg/L & $\mathrm{mg} / \mathrm{L}$ \\
\hline $\mathrm{Ag}$ & $<0.300$ & $<0.300$ & \\
\hline $\mathrm{Al}$ & 4590 & 4560 & 4575 \\
\hline $\mathrm{B}$ & 194 & 190 & 192 \\
\hline $\mathrm{Ba}$ & $<0.300$ & $<0.300$ & $<0.300$ \\
\hline $\mathrm{Be}$ & $<0.077$ & $<0.077$ & $<0.077$ \\
\hline \multicolumn{4}{|l|}{$\mathrm{Bi}$} \\
\hline $\mathrm{Ca}$ & $<9.06$ & $<9.06$ & $<9.06$ \\
\hline $\mathrm{Cd}$ & $<0.400$ & $<0.400$ & $<0.400$ \\
\hline $\mathrm{Ce}$ & $<4.96$ & $<4.96$ & $<4.96$ \\
\hline \multicolumn{4}{|l|}{ Co } \\
\hline $\mathrm{Cr}$ & 60.7 & 60.1 & 60 \\
\hline $\mathrm{Cu}$ & $<0.620$ & $<0.620$ & $<0.620$ \\
\hline $\mathrm{Fe}$ & $<0.440$ & $<0.440$ & $<0.440$ \\
\hline $\mathrm{Gd}$ & $<0.540$ & $<0.540$ & $<0.540$ \\
\hline $\mathrm{K}$ & 1260 & 1240 & 1250 \\
\hline $\mathrm{La}$ & $<0.400$ & $<0.400$ & $<0.400$ \\
\hline $\mathrm{Li}$ & 13.4 & 13.2 & 13 \\
\hline $\mathrm{Mg}$ & $<1.24$ & $<1.24$ & $<1.24$ \\
\hline $\mathrm{Mn}$ & $<0.440$ & $<0.440$ & $<0.440$ \\
\hline Mo & 14.4 & 16.2 & 15 \\
\hline $\mathrm{Na}$ & 38400 & 38600 & 38500 \\
\hline $\mathrm{Na}(\mathrm{M})$ & 1.67 & 1.68 & 1.67 \\
\hline \multicolumn{4}{|l|}{$\mathrm{Nb}$} \\
\hline $\mathrm{Ni}$ & $<1.50$ & $<1.50$ & $<1.50$ \\
\hline $\mathrm{P}$ & 152 & 154 & 153 \\
\hline $\mathrm{Pb}$ & $<4.92$ & $<4.92$ & $<4.92$ \\
\hline \multicolumn{4}{|l|}{$\operatorname{Re}$} \\
\hline $\mathrm{S}$ & 740 & 738 & 739 \\
\hline $\mathrm{Sb}$ & 14 & 13.4 & 14 \\
\hline $\mathrm{Si}$ & 65.1 & 65.5 & 65 \\
\hline Sn & 8.85 & 8.49 & 9 \\
\hline $\mathrm{Sr}$ & $<2.00$ & $<2.00$ & $<2.00$ \\
\hline $\mathrm{Ti}$ & $<0.120$ & $<0.120$ & $<0.120$ \\
\hline $\mathrm{U}$ & $<15.1$ & $<15.1$ & $<15.1$ \\
\hline $\mathrm{V}$ & 0.978 & 0.987 & 1.0 \\
\hline $\mathrm{Zn}$ & 15.8 & 15.8 & 16 \\
\hline $\mathrm{Zr}$ & $<0.240$ & $<0.240$ & $<0.240$ \\
\hline
\end{tabular}

\begin{tabular}{|c|c|c|c|}
\hline $\begin{array}{c}\text { Hanford } \\
\text { Waste }\end{array}$ & \multicolumn{3}{|c|}{ AN104 / SBS A3 Blend (35:65) } \\
\hline LIMS\#300- & 196785 & 196785 & Avg. \\
\hline \multicolumn{4}{|l|}{ IC Anions } \\
\hline \multirow[b]{2}{*}{ Chloride } & $\mathrm{mg} / \mathrm{L}$ & $\mathrm{mg} / \mathrm{L}$ & $\mathrm{mg} / \mathrm{L}$ \\
\hline & 3290 & 3380 & 3335 \\
\hline Fluoride & 127 & 128 & 128 \\
\hline Formate & 318 & 326 & 322 \\
\hline \multirow{2}{*}{$\begin{array}{l}\text { Nitrate } \\
\text { Nitrite }\end{array}$} & 24100 & 24700 & 24400 \\
\hline & 16500 & 16800 & 16650 \\
\hline Oxalate & 283 & 298 & 291 \\
\hline \multirow{2}{*}{$\begin{array}{l}\text { Phosphate } \\
\text { Sulfate }\end{array}$} & 322 & 318 & 320 \\
\hline & 1580 & 1640 & 1610 \\
\hline \multirow[t]{2}{*}{ Carbon } & Carbon & & Avg. \\
\hline & $\mathrm{mg} / \mathrm{L}$ & $\mathrm{mg} / \mathrm{L}$ & $\mathrm{mg} / \mathrm{L}$ \\
\hline \multirow{3}{*}{$\begin{array}{l}\text { Total Carbon } \\
\text { Inorganic C } \\
\text { Organic C } \\
\end{array}$} & 2300 & 2300 & 2300 \\
\hline & 1700 & 1700 & 1700 \\
\hline & 600 & 600 & 600 \\
\hline \multirow{3}{*}{$\begin{array}{l}\text { Solids } \\
\text { LIMS\#300- }\end{array}$} & Solids & & \\
\hline & 196786 & 196786 & \\
\hline & wt. $\%$ & wt. $\%$ & Avg. \\
\hline \multirow{2}{*}{$\begin{array}{l}\text { Total Solids } \\
\text { Susp. Solids }\end{array}$} & 11.536 & 11.693 & 11.6 \\
\hline & $<0.01^{*}$ & $<0.01 *$ & $<0.01 *$ \\
\hline
\end{tabular}

*Blanks in table are intentional 
WSRC-TR-2004-00387, REVISION 0

SRNL-RPP-2004-00053, REVISION 0

Table 3. Composition of pretreated Hanford AN-104 Waste Sample (Post Ion Exchange Column)*

\begin{tabular}{|c|c|c|c|c|c|c|c|}
\hline \multicolumn{4}{|c|}{ AN104 Ion Exchange Effluent Composite } & \multicolumn{4}{|c|}{ AN104 Ion Exchange Effluent Composite } \\
\hline \multirow[t]{2}{*}{ LIMS\#300- } & 196784 & \multirow{2}{*}{$\begin{array}{c}196784 \\
\mathrm{mg} / \mathrm{L}\end{array}$} & \multirow{2}{*}{$\begin{array}{l}\text { Avg. } \\
\mathrm{mg} / \mathrm{L}\end{array}$} & \multirow{2}{*}{$\begin{array}{l}\text { LIMS\#300- } \\
\text { IC Anions }\end{array}$} & 196784 & \multirow[t]{2}{*}{196784} & \multirow[t]{2}{*}{ Avg. } \\
\hline & $\begin{array}{c}196784 \\
\mathrm{mg} / \mathrm{L}\end{array}$ & & & & & & \\
\hline $\mathrm{Ag}$ & 0.181 & $<0.160$ & & & $\mathrm{mg} / \mathrm{L}$ & $\mathrm{mg} / \mathrm{L}$ & $\mathrm{mg} / \mathrm{L}$ \\
\hline $\mathrm{Al}$ & 13200 & 13300 & 13250 & Chloride & 2910 & 2790 & 2850 \\
\hline $\mathrm{B}$ & 23.2 & 22.5 & 22.85 & Fluoride & 36 & 34 & 35 \\
\hline $\mathrm{Ba}$ & 0.617 & 0.508 & 0.5625 & Formate & 653 & 622 & 638 \\
\hline $\mathrm{Be}$ & 0.161 & 0.198 & 0.1795 & Nitrate & 65500 & 68600 & 67050 \\
\hline $\mathrm{Bi}$ & & & & Nitrite & 38500 & 36200 & 37350 \\
\hline $\mathrm{Ca}$ & 1.07 & 1.08 & 1.075 & Oxalate & 697 & 745 & 721 \\
\hline $\mathrm{Cd}$ & 0.284 & 0.267 & 0.2755 & Phosphate & 1440 & 1090 & 1265 \\
\hline $\mathrm{Ce}$ & 4.99 & 4.35 & 4.67 & Sulfate & 2510 & 2890 & 2700 \\
\hline Co & & & & Carbon & & & \\
\hline $\mathrm{Cr}$ & 152 & 149 & 150.5 & & $\mathrm{mg} / \mathrm{L}$ & $\mathrm{mg} / \mathrm{L}$ & $\mathrm{mg} / \mathrm{L}$ \\
\hline $\mathrm{Cu}$ & 0.528 & 0.463 & 0.4955 & Total Carbon & 5760 & 5760 & 5760 \\
\hline $\mathrm{Fe}$ & 0.929 & 0.797 & 0.863 & Inorganic C & 4010 & 4010 & 4010 \\
\hline $\mathrm{Gd}$ & 0.674 & 0.567 & 0.6205 & Organic C & 1750 & 1750 & 1750 \\
\hline $\mathrm{K}$ & 2990 & 3070 & 3030 & Solids & & & \\
\hline $\mathrm{La}$ & 0.75 & 0.578 & 0.664 & LIMS\#300- & 196784 & 196784 & \\
\hline $\mathrm{Li}$ & $<0.860$ & $<0.860$ & $<0.860$ & & wt. $\%$ & wt. $\%$ & Avg. \\
\hline $\mathrm{Mg}$ & $<0.106$ & $<0.106$ & $<0.106$ & Total Solids & 25.7848 & 25.7812 & 25.8 \\
\hline $\mathrm{Mn}$ & $<0.016$ & $<0.016$ & $<0.016$ & Susp. Solids & None & isible & \\
\hline
\end{tabular}


WSRC-TR-2004-00387, REVISION 0

SRNL-RPP-2004-00053, REVISION 0

Table 4. Test Simulants Composition and Preparation Reference Documents

\begin{tabular}{|l|l|}
\hline Simulant & Reference Document \\
\hline $\begin{array}{l}\text { AY-102 mixed with AP-101 } \\
\text { from campaign II of the semi- } \\
\text { integrated pilot plant }\end{array}$ & $\begin{array}{l}\text { Zamecnik, Burket, Eibling, and Poirier, "Tank 241-AY-102 } \\
\text { Simulant Development, Ultrafiltration and Washing", } \\
\text { WSRC-TR-2003-00547, Rev.0 }\end{array}$ \\
& $\begin{array}{l}\text { Duignan, Zamecnik, and Williams, "Interim Report: RPP- } \\
\text { WTP Semi-Integrated Pilot Plant - Campaign 1," } \\
\text { WSRC-TR-2004-00201, Rev.0 }\end{array}$ \\
\hline AP-101 & $\begin{array}{l}\text { Russell, Fiskum, Jagoda, and Poloski, "AP-101 Diluted } \\
\text { Feed (Envelope A) Simulant Development Report," } \\
\text { PNNL-PNWD-3248, WTP-RPT-057, Rev.0 }\end{array}$ \\
\hline AN-104 & $\begin{array}{l}\text { Crowder, et al., "Evaporation, Rheology, and Vitrification } \\
\text { of a Radioactive Hanford Tank AN-104 Sample Mixed with } \\
\text { Recycle," WSRC-TR-2004-00232 }\end{array}$ \\
\hline Washed AZ-101 & $\begin{array}{l}\text { Eibling, Schumacher, and Hansen, "Development of } \\
\text { Simulants to Support Mixing Tests for High Level Waste } \\
\text { and Low Activity Waste," WSRC-TR-2003-00220, Rev.0 }\end{array}$ \\
\hline
\end{tabular}

\subsection{AIR FLUX DETERMINATION}

The air sparge rates used in the foam experiments were derived from information provided by WTP personnel. The size of the SRNL small-scale foam column was based on the dimensions of the HLW LAG Storage Vessel (HLP-VSL-00027A/B). This vessel has an inside diameter of 25 feet and contains 36 sparge tubes with a total air sparge requirement of $1249 \mathrm{scfm}$ or an air flux of $2.54 \mathrm{ft}^{3} / \mathrm{min} / \mathrm{ft}^{2}$. This air flux was considered to be the nominal for the small-scale foam test being investigated. Air fluxes above and below this nominal value were selected for the sparging tests with the simulant and actual Hanford waste. Section 4.3 addresses the effect of tube diameter on foaming.

The air fluxes used in the experiments were in the range of 1.1 to $17.6 \mathrm{ft}^{3} / \mathrm{min} / \mathrm{ft}^{2}$. The flow rates were calculated based on the dimensions and the total air flow for the full-scale tank (HLW Lag Storage Vessels -HLP-VSL-00027A/B) with 36 sparge tubes as illustrated in Figure 2. The full-scale tank vs. small foam column scale factor was $1 / 49$. The size of the fritted disk (75-100 micron holes) was selected to provide the same air flux as that from 36 air nozzles in the full-scale tank.

The calculated air fluxes for the HLW Blend vessel and Ultrafiltration Feed vessels are encompassed by this test range. 


\begin{tabular}{|c|c|c|c|c|}
\hline \multirow{9}{*}{ 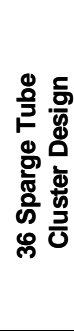 } & $\begin{array}{c}\text { \#OF } \\
\text { TUBES }\end{array}$ & $\begin{array}{l}2 / 3 \mathrm{ZOI} \\
\text { (in.) }\end{array}$ & \begin{tabular}{|c|} 
flow/tube \\
(acfm)
\end{tabular} & $\begin{array}{c}\text { subtotal } \\
\text { (acfm) }\end{array}$ \\
\hline & 14 & 68 & 27.3 & 382 \\
\hline & 7 & 42 & 6.9 & 48 \\
\hline & 7 & 58 & 17.3 & 121 \\
\hline & 7 & 60 & 19.1 & 133 \\
\hline & 1 & 76 & 37.5 & 37 \\
\hline & & \multirow{2}{*}{\multicolumn{2}{|c|}{$\begin{array}{l}\text { Total Sparge Tubes: } \\
\text { Total Air Flow (acfm): }\end{array}$}} & 36 \\
\hline & & & & 722 \\
\hline & & \multicolumn{2}{|c|}{ Total Air Flow (scfm): } & 1264 \\
\hline
\end{tabular}

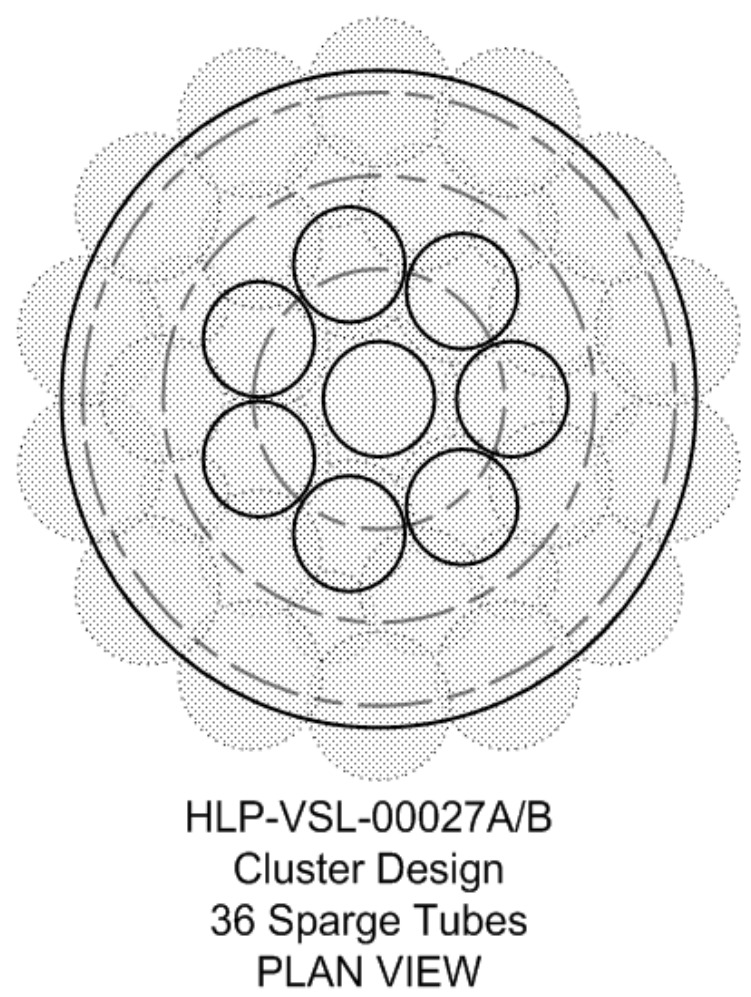

Figure 2. Plan View of HLW Lag Storage Tank Air Sparge Tubes

\subsection{COLUMN WALL EFFECTS}

The effect of column diameter (wall effects) was determined to allow selection of the most appropriate (e.g., sample volume, L/D) size column for the simulant and radioactive tests.

To determine the wall effect of air sparged liquids, three foam columns of different internal diameters were tested. It has already been reported that the wall effect is negligible if the inner diameter of the foam column is larger than $3 \mathrm{~cm} .{ }^{7}$ Therefore, the columns we selected had inside diameters $1.45,3.1$, and $5 \mathrm{~cm}$ and a height of $60 \mathrm{~cm}$. The experiments in the three foam columns were conducted identically at open atmospheric pressure and a temperature of $25 \pm{ }^{\circ} \mathrm{C}$. The air sparge rates used varied from 1.1-6.6 $\mathrm{ft}^{3} / \mathrm{min} / \mathrm{ft}^{2}$. A sample of AY-102/C106 mixed with AP-101 (campaign II, SIPP feed) simulant at 10 wt. \% solids was added into each column to the same height of liquid $(4.0 \mathrm{~cm}$ at rest). Air was introduced into each column through the $75-100$ micron fritted disk located in the base of the column at fluxes between 1.1 and $6.6 \mathrm{ft}^{3} / \mathrm{min} / \mathrm{ft}^{2}$. The steady state foam height (air entrained) was recorded for each flux and is shown in Figure 3. The data suggests close agreement between the behavior of the test simulant in the $3.1-\mathrm{cm}$ and $5.0-\mathrm{cm}$ diameter columns at air fluxes between 1.1 and $4.4 \mathrm{ft}^{3} / \mathrm{min} / \mathrm{ft}^{2}$. With the nominal air sparge tests conducted at $2.2 \mathrm{ft}^{3} / \mathrm{min} / \mathrm{ft}^{2}$, it may be assumed there exists no wall effects influencing the foams being produced in the testing. 
WSRC-TR-2004-00387, REVISION 0

SRNL-RPP-2004-00053, REVISION 0

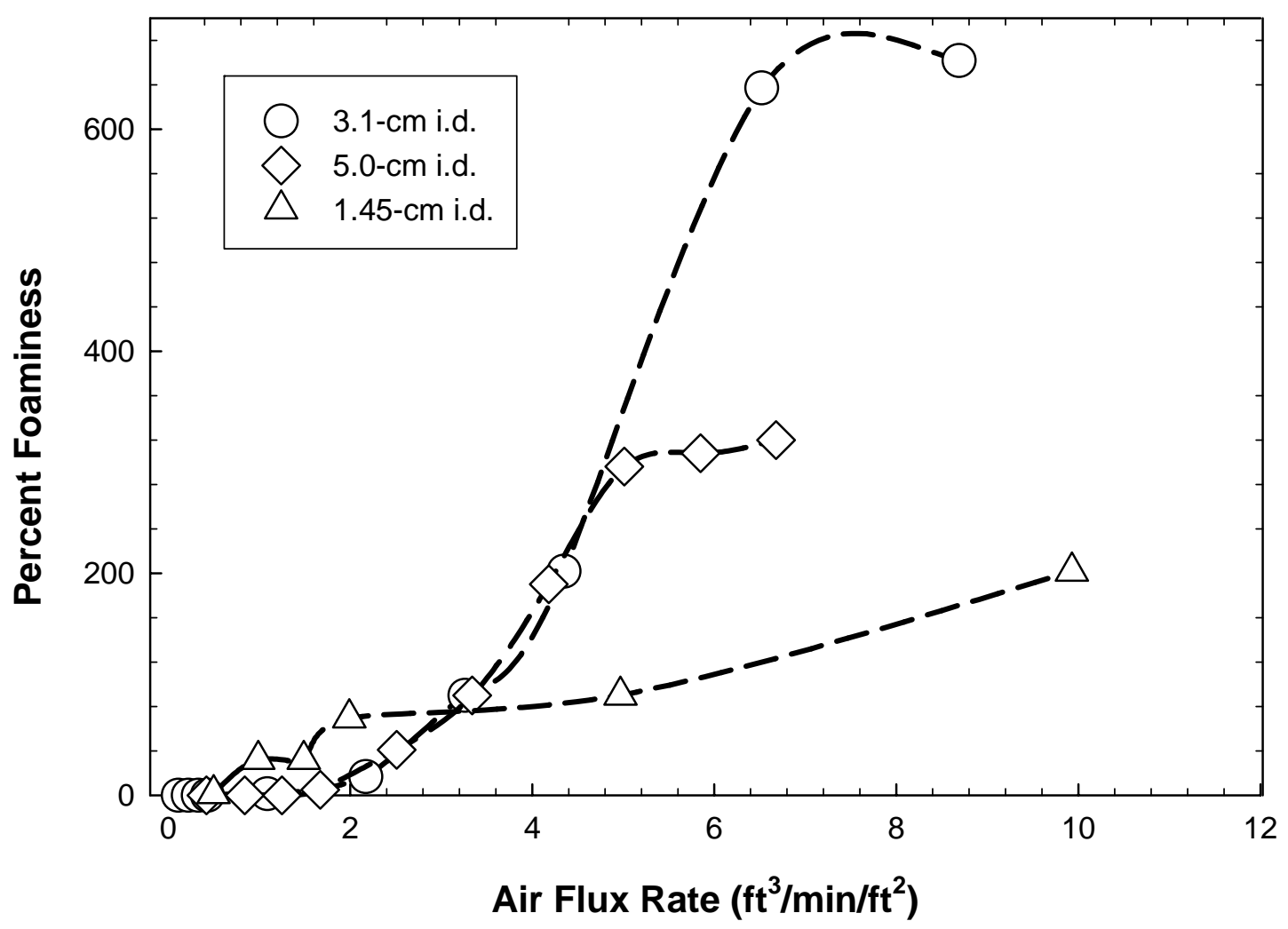

Figure 3. The Effect of Column Diameter on Foam Behavior (Wall Effect)

\subsection{EFFECT OF NOZZLE SIZE}

Three separate column tests were conducted to determine if the method (fritted disk) for introducing the sparge gas into the simulant solution was conservative with respect to the WTP sparge nozzle design. Three different nozzles were fabricated to deliver air into the $3.1-\mathrm{cm}$ i.d. graduated column. The nozzles were constructed with bore sizes of $1 / 16,1 / 8$ and $1 / 4$ inch. Each nozzle was supplied with air that produced incremental sparge rates from 1.1 to $17.6 \mathrm{ft}^{3} / \mathrm{min} / \mathrm{ft}^{2}$ through the $3.1 \mathrm{~cm}$ column. As is indicated by the data chart in Figure 4, all three single nozzles performed similarly to one another. When the $\%$ foaminess produced by the single nozzle air sparge tests are compared to the 75-100 micron coarse fritted disk tests at the same air fluxes, it is evident that the \% foaminess values produced by the fritted disk are more than double those of the single nozzles. The tests performed by SRNL all incorporated the fritted disk, which provides the more extreme foaming condition and therefore provides a conservative test of foaming and antifoam properties. The fritted disk also simulates the condition where a large air sparger bubble is drawn into a recirculation pump (e.g., UFP filter loop pump) and broken up into many smaller bubbles. The WTP also uses steam jets for transfer operations. This scenario was not evaluated by this task. 
WSRC-TR-2004-00387, REVISION 0

SRNL-RPP-2004-00053, REVISION 0

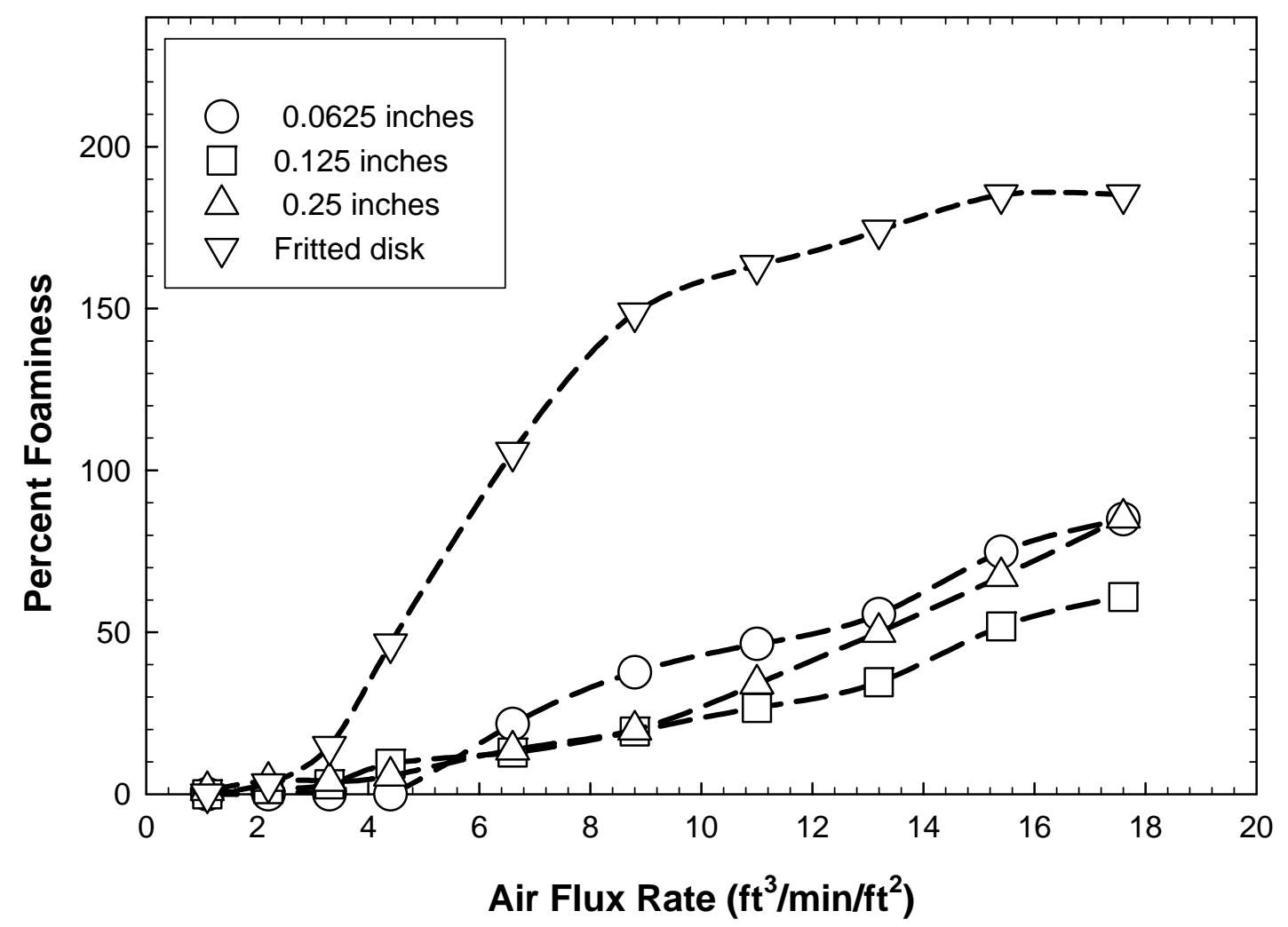

Figure 4. Effect of Air Sparge Tube Sizes on Foaminess of AY-102/C-106 Mixed with AP-101 from Campaign II (10 wt.\% insoluble solids)

\subsection{0-DAY AIR SPARGING EXPERIMENT}

The 20-day air sparging experiments used two glass columns $4-\mathrm{cm}$ by $50-\mathrm{cm}$ and $5-\mathrm{cm}$ by $31-\mathrm{cm}$ with glass fritted plates. The air flow rates for the 4-cm and 5-cm column were 958 and $1496 \mathrm{sccm}$ respectively to maintain a flux of $2.5 \mathrm{ft}^{3} / \mathrm{min} / \mathrm{ft}^{2}$. The same amount of the simulated $15 \mathrm{wt} \%$ AZ-101 sludge (573.4 g) was initially charged to both columns. Two diameter columns were used to see if different cross-sectional areas and thus two different heights of simulant would impact air sparging. Throughout the 20 days, column weights and levels were recorded to track mass losses. On days $0,7,14$, and 20 samples were pulled from both columns for weight percent solids, $\mathrm{pH}$, TIC/TOC, density, iron concentration, anion concentration, and rheology analyses.

The Haake RS 600 rheometer was used for all rheological measurements performed in this task. Published RS600 specifications are shown in Table 5. 
Table 5. RS600 Measuring Head Specifications

\begin{tabular}{|c|c|c|}
\hline Specification & Units & Value \\
\hline Maximum Torque & $\mathrm{N}-\mathrm{m}$ & $0.5 \times 10^{-7}$ \\
\hline Minimum Torque (recommended) & $\mathrm{N}-\mathrm{m}$ & 0.2 \\
\hline Maximum Speed & RPM & 1500 \\
\hline Minimum Speed & RPM & 0.001 \\
\hline
\end{tabular}

Flow curve measurements were obtained using a concentric (Z41) cylindrical rotor. The design is shown in Table 6 . The Z41 rotor is initially installed onto the RS-600 and a zero reference point is determined by the rheometer. The Z41 rotor is then removed. A sample is then placed into the appropriate cup and lowered into a temperature/controlled cup holder, which controlled the temperature at $25^{\circ} \mathrm{C}$ during this task. The RS600 rheometer can control the rate at which the rotor spins and measures both the rotational speed and the torque (the resistance to shear). The shear stress at the wall of the rotating rotor is then calculated (internally by the Haake software) based on the product of the measured torque and geometry (A-factor) of the rotor. The shear rate of the rotating rotor is calculated as the product of the measured speed and geometry (M-factor, assumes fluid is Newtonian) of the rotor. The Afactor, $\mathrm{M}$-factor, shear rate range and the ramp up time, hold time at maximum shear rate, and ramp down time are provided in Table 6.

Table 6. Z41 Rotor Specifications and Ramp Rates

\begin{tabular}{|c|c|c|}
\hline Design of Rotor & \multicolumn{2}{|c|}{ Z41 Rotor } \\
\hline$\frac{\mathrm{Ra}}{\mathrm{Ri}}$ & Rotor radius (mm) & $\mathrm{R}_{\mathrm{i}}=20.7$ \\
\hline & Cup Radius (mm) & $\mathrm{R}_{\mathrm{a}}=21.7$ \\
\hline & Height of rotor $(\mathrm{mm})$ & $\mathrm{L}=55$ \\
\hline & Sample Volume $\left(\mathrm{cm}^{3}\right)$ & $\mathrm{V}=15$ \\
\hline & A factor $(\mathrm{Pa} /(\mathrm{N} \cdot \mathrm{m}))$ & 6750 \\
\hline & $\mathrm{M}$ factor $\left(\mathrm{s}^{-1} /\left(\mathrm{rad} \cdot \mathrm{s}^{-1}\right)\right)$ & 22.40 \\
\hline & Measuring Range $\left(\mathrm{s}^{-1}\right)$ & $0-1000$ \\
\hline & Ramp up time (min) & 5 \\
\hline & Hold time (min) & 1 \\
\hline & Ramp Down time (min) & 5 \\
\hline
\end{tabular}


WSRC-TR-2004-00387, REVISION 0

SRNL-RPP-2004-00053, REVISION 0

Prior to performing any flow curve measurement, the rotor and cup are inspected for visual damage that could potentially impact the flow measurement. National Institute of Standards and Technology (NIST) traceable Newtonian oil standards were used to verify the operability of the RS600 at a measurement temperature of $25^{\circ} \mathrm{C}$. The viscosities of the NIST traceable Newtonian oil standards at $25^{\circ} \mathrm{C}$ are shown in Table 7 . The resulting flow curves were analyzed as a Newtonian fluid and the calculated viscosity was compared to the NIST traceable Newtonian oil standard. The rheometer was considered operable if the calculated viscosity was within $\pm 10 \%$ of the NIST traceable Newtonian oil standard viscosity as stated in Table 7. In all cases, the NIST standard ran between 52.2 to $54.2 \mathrm{cP}$

Table 7. Cole-Parmer NIST Traceable Newtonian Oil Standard

\begin{tabular}{|c|c|c|c|c|c|}
\hline \multirow{2}{*}{$\begin{array}{l}\text { Standard } \\
\text { Type }\end{array}$} & \multicolumn{3}{|c|}{ Viscosity $(\mathrm{cP})$ at $25^{\circ} \mathrm{C}$} & \multirow{2}{*}{ Lot Number } & \multirow{2}{*}{$\begin{array}{c}\text { Expiration } \\
\text { Date }\end{array}$} \\
\hline & $-10 \%$ & Reported & $+10 \%$ & & \\
\hline N35 & 46.34 & 51.49 & 56.64 & 130704 & $2 / 6 / 2006$ \\
\hline
\end{tabular}

The following rheological models (Equation 4-1, Equation 4-2, and Equation 4-3) were used to fit both the up and down curves. The flow curves were fitted from 0 to $1000 \mathrm{sec}^{-1}$ using the Haake ${ }^{\mathrm{TM}}$ software. ${ }^{7}$

\section{Equation 4-1}

Power Law:

$$
\begin{array}{ll}
\tau=m & \dot{\gamma}^{n} \\
\text { Where: } & \begin{aligned}
\tau & =\text { shear stress }(\mathrm{Pa}) \\
& \dot{\gamma}=\text { shear rate }(\mathrm{sec}-1) \\
\mathrm{m} & =\text { the consistency coefficient }\left(\mathrm{Pa}-\mathrm{sec}^{\mathrm{n}}\right) \\
\mathrm{n} & =\text { the power law exponent (unit less) }
\end{aligned}
\end{array}
$$

\section{Equation 4-2}

Bingham Plastic:

$$
\tau=\tau_{B P}+\eta_{B P} \cdot \dot{\gamma}
$$

Where: $\quad \tau \mathrm{BP}=$ Bingham Plastic yield stress $(\mathrm{Pa})$

$$
\eta_{\mathrm{BP}}=\text { Bingham Plastic Viscosity (or consistency) (Pa-sec) }
$$




\section{Equation 4-3}

$$
\begin{aligned}
& \tau=\tau_{H B}+k \cdot \dot{\gamma}^{b} \\
& \text { Where: } \quad \tau \mathrm{HB}=\text { Herschel-Bulkley yield stress }(\mathrm{Pa}) \\
& \mathrm{k}=\text { the consistency coefficient }\left(\mathrm{Pa}-\mathrm{sec}^{\mathrm{b}}\right) \\
& \mathrm{b}=\text { the power law exponent (unit less) }
\end{aligned}
$$

Duplicate flow curves of each AZ-101 sludge samples were measured at $25^{\circ} \mathrm{C}$. The flow curves, both up and Down curves, were individually fitted to the following rheological models using the complete shear rate range of 0 to $1000 \mathrm{sec}^{-1}$, Power Law, Bingham Plastic, and Hershel-Bulkley models. 
WSRC-TR-2004-00387, REVISION 0

SRNL-RPP-2004-00053, REVISION 0

This page intentionally left blank. 


\subsection{DISCUSSIONS}

\subsection{SMALL-SCALE SIMULANT TEST RESULTS}

The foam is generally produced by introduction of gas into the liquid, during which time bubbles form and become encapsulated in a film of liquid. The thin films separating two or more bubbles are referred to as lamellae. Liquid drainage occurs from the lamella region due to gravitational forces, and as a result the lamella becomes thinner and thinner until it can no longer support the pressure of the gas in the bubble. Foam collapse due to film rupture or coalescence then occurs. The presence of surface active agents in a foaming solution can retard the liquid drainage and bubble coalescence and therefore enhances the foam stability. The role of solid particles in the foam stability can be related to the effect of the particles on lamella drainage. The solid particles tend to accumulate in the lamella and plateau borders (i.e., adjoining menisci), and thus result in an increase in the size of these areas and reduces the thinning of the film and liquid drainage. These solid particles, which are poorly wetted, adsorb and concentrate in the interface.

There is some ambiguity involved in the definition of foaminess as being calculated from the air incorporated liquid height vs. the actual height of the foam. Either the height of the foam, the volume of foam, or another appropriate experimental constant combining volume with volumetric flow rate of gas may be used to define foaminess for the purpose of experimental system. These methods can be advantageous where the foam is stable and easy to observe or measure. In non-stable foam systems, the degree of foaminess of liquid may be regarded as being proportional to the actual height of foam created upon air sparging minus the gas holdup in the system. Thus, re-adjusting our method, we calculated percent foaminess as follows:

Degree of air incorporated in the system $=\frac{H_{G+L}-H_{L}}{H_{L}}$

where $\mathrm{H}_{\mathrm{G}+\mathrm{L}}$ and $\mathrm{H}_{\mathrm{L}}$ are the height of air incorporated liquid plus foam and the height of liquid at rest. The gas holdup is the volumetric fraction occupied in the aerated column by the gas and it is calculated according to the following equation by Euzen et.al. ${ }^{8}$

Gas holdup in the system $=\frac{H_{G+L}-H_{L}}{H_{G+L}}$

Thus, percent foaminess is approximately equal to $100 *$ (degree of air incorporated - gas holdup). 
This method of defining foaminess applies only to small scale experimental foam tests, where the objective is to determine if a solution subjected to air sparging has a tendency to foam. The data derived from this method is not directly scalable to full-size tanks equipped with nozzles, coils, and other auxiliary units. Lack of uniformity of the bubble size and other geometric difference between experimental foam columns and full-scale plant tanks preclude any attempt to scale the $\%$ foaminess data to the WTP tanks.

Figure 5 shows the results of the AY-102/C-106 mixed with AP-101 (campaign II, SIPP feed) simulant with different concentrations of insoluble solids from AY-102/C-106 sludge. Experiments with AY-102/C-106 supernate with no solid particles exhibited negligible foaming. Therefore, the foaminess in this simulant was due to the presence of insoluble solid particles. The percent foaminess increases with an increase of the air flux. The amount of foaminess increases (as shown in Figure 5) with the increase in concentration of insoluble solids in solution. The foaminess of the AY-102/C-106 simulant only (campaign I) is shown in Figure 6. The data show the foaminess for the AY-102/C-106 simulant only is significantly higher than that of AY-102/C-106 mixed with AP-101 (campaign II). The foam generated from both simulants was unstable and immediately collapsed after the air sparge was terminated. 
WSRC-TR-2004-00387, REVISION 0

SRNL-RPP-2004-00053, REVISION 0

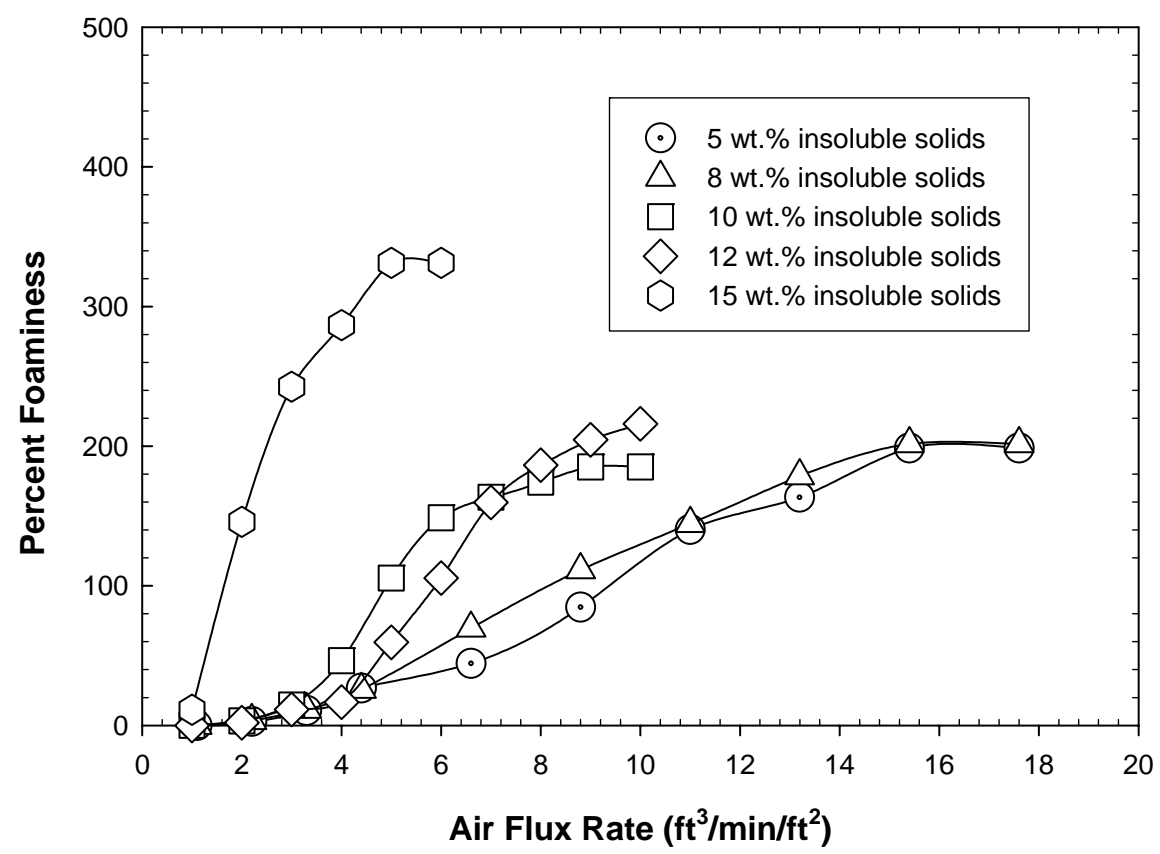

Figure 5. Effect of Solid Particles on Foaminess of AY-102/C-106 mixed with AP-101 (campaign II, SIPP feed) Simulant

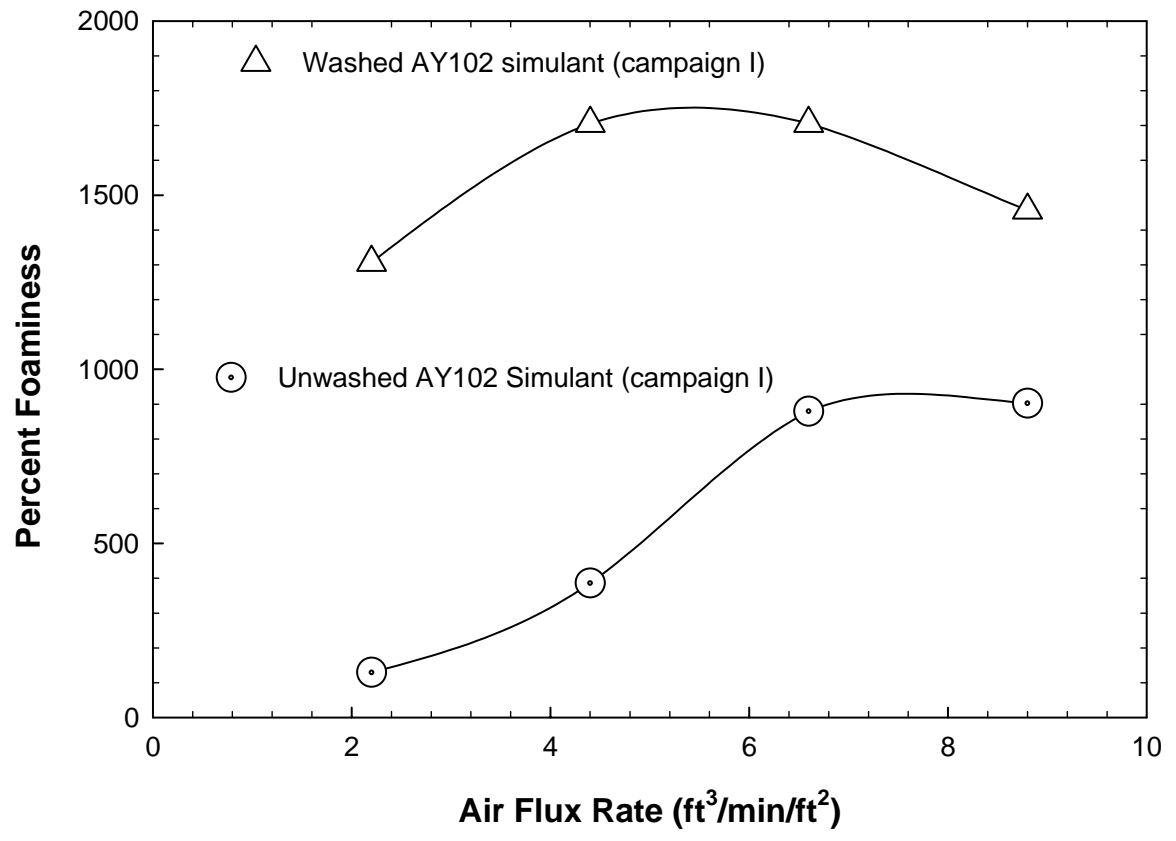

Figure 6. Foaminess of AY-102/C-106 (Campaign I-SIPP Feed) Simulant 
Figure 7 shows the results of the foam experiment with AP-101 simulant at various insoluble solid concentrations from AY-102/C-106 sludge. The results show that foaminess of the AP101 simulant is very similar to that of AY-102/C-106 mixed with AP-101 (about 4 parts to 1) from campaign II. In the presence of solid particles, the foaminess of the AP-101 simulant increased in a somewhat linear fashion with the increase in air sparging rate. The foam was unstable and collapsed immediately after the air sparing was terminated.

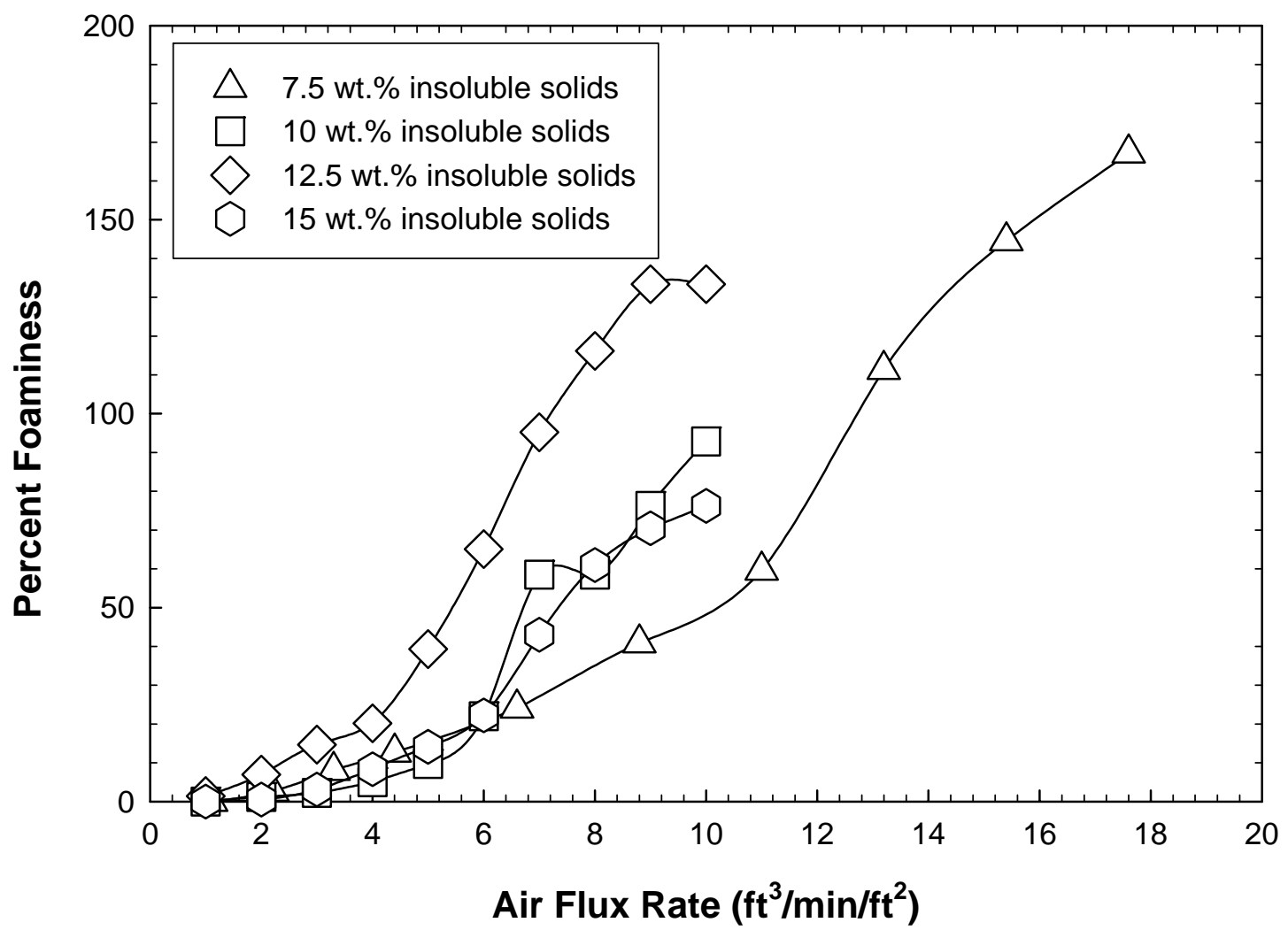

Figure 7. Effect of Solid Particles on Foaminess of AP-101 Simulant with AY-102 Sludge Solids 
Figure 8 shows the results of the foaming experiment of air-sparged AN-104 simulant. The results indicate that foaminess of the $\mathrm{AN}-104$ simulant significantly increased with the increase in the concentration of AY-102/C-106 insoluble solids particles from 3 to 9 wt. \% solids only when the air flux exceeded $5 \mathrm{ft}^{3} / \mathrm{min} / \mathrm{ft}^{2}$. At air fluxes below $5 \mathrm{ft}^{3} / \mathrm{min} / \mathrm{ft}^{2}$, the increase in the concentration of insoluble solids had limited effect on foaminess. At higher fluxes, the solution is concentrated due to evaporation, and the wt.\% insoluble solids may increase. The AN-104 simulant without insoluble solids exhibited negligible foaminess. The foam generated in the AP-101 simulant was unstable and collapsed within seconds after the air sparging of the system was terminated.

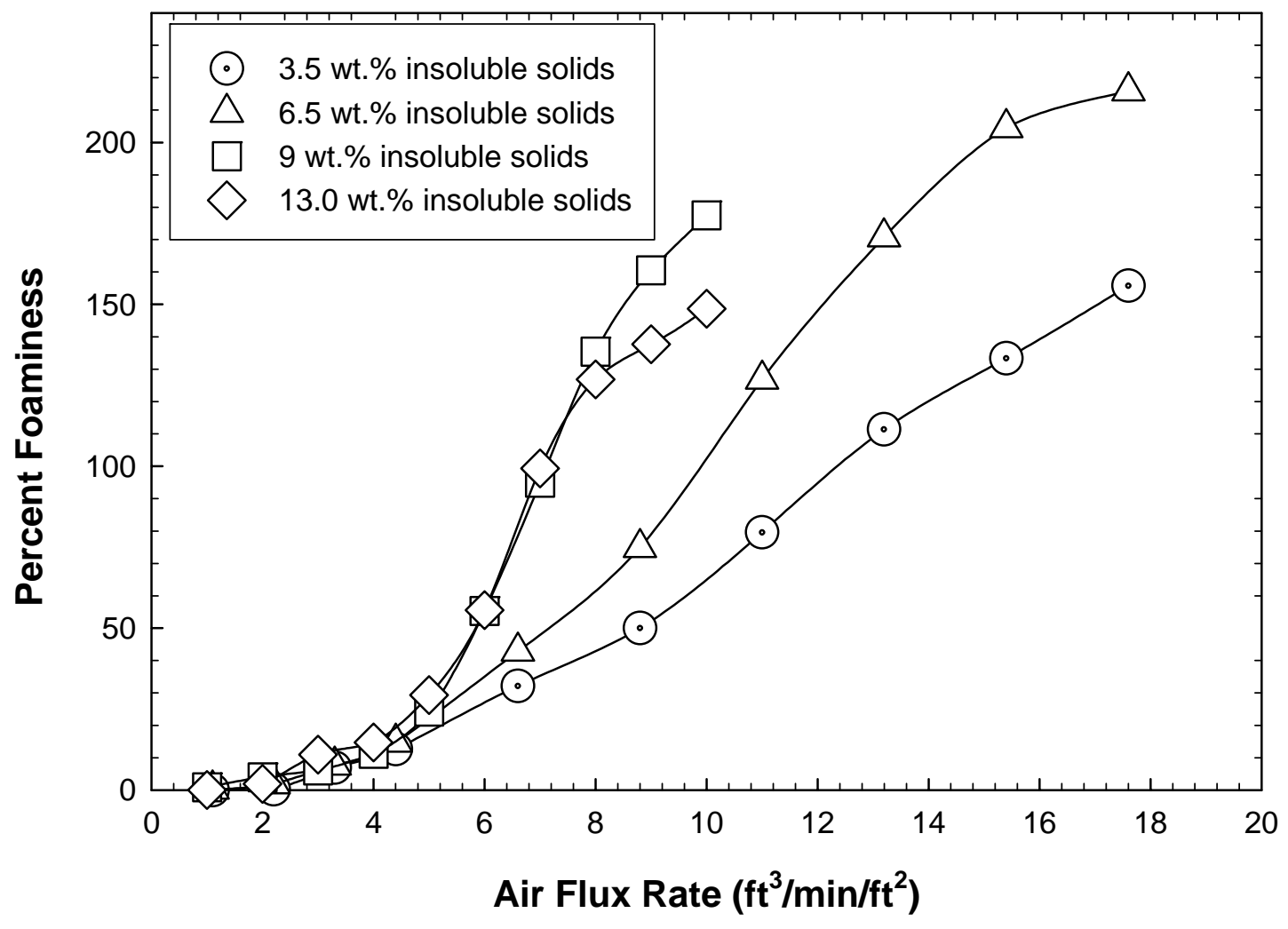

Figure 8. Effect of Solid Particles on Foaminess of AN-104 Simulant with AY-102 Sludge Solids 
Figure 9 shows the results of the foaming experiments with washed AZ-101 sludge simulant. To prepare the AZ-101 solution at different initial concentrations of insoluble solids, the AZ101 sludge system was diluted with inhibited water. The effect of the solid particles on the foaminess of the AZ-101 sludge system is clearly seen only after the air flux exceeded $4.4 \mathrm{ft}^{3} / \mathrm{min} / \mathrm{ft}^{2}$. The foaminess of this sample generally increased with air sparge rate. It was difficult to measure the height of the air entrained liquid for this sludge as the sludge tended to cling to the internal walls of the foam column.

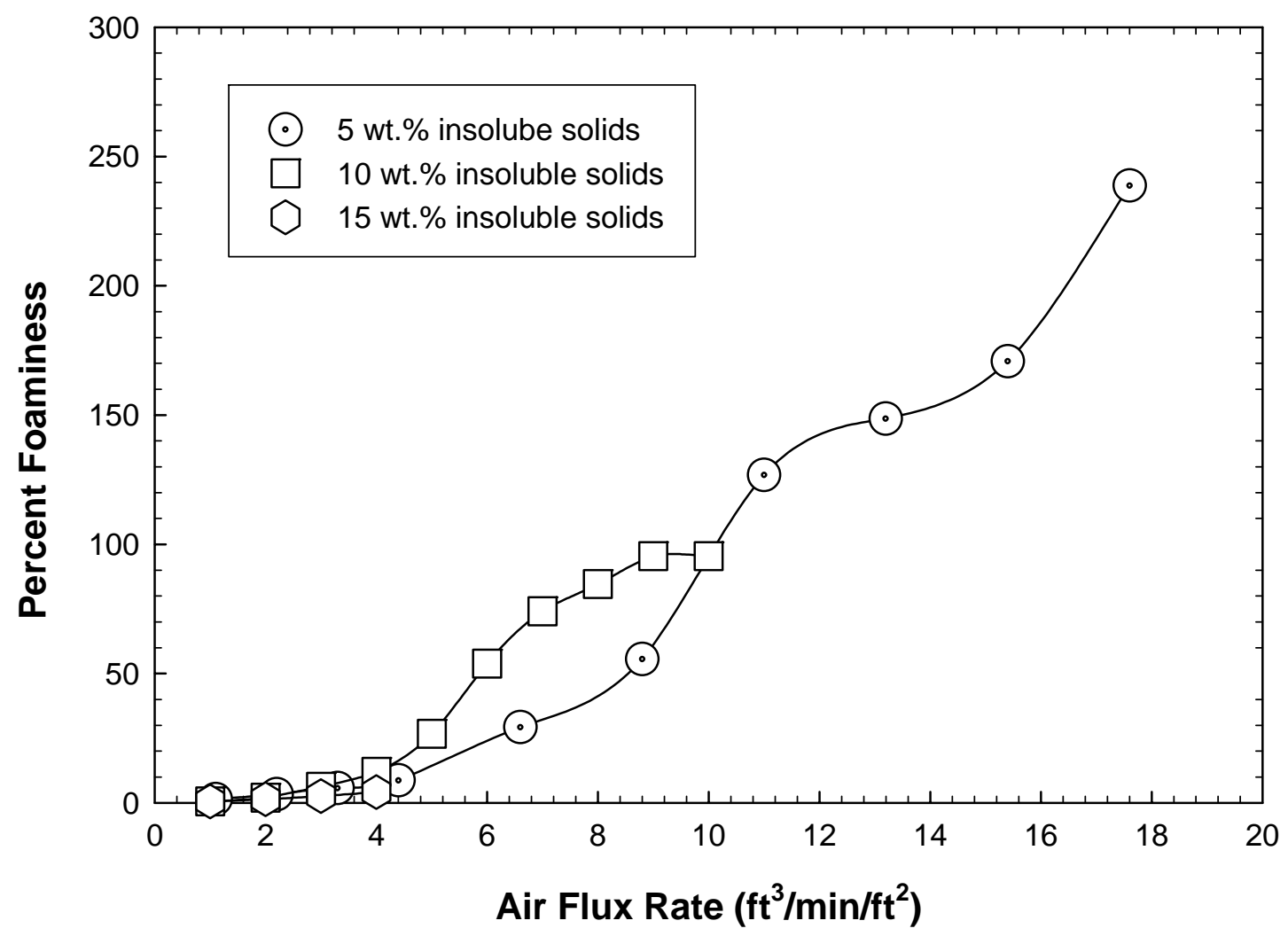

Figure 9. Effect of Solid Particles on Foaminess of Washed AZ-101 Simulant 


\subsection{SMALL-SCALE RADIOACTIVE TEST RESULTS}

Figure 10 and Figure 11 show the results of the foaminess experiment with actual Hanford waste (pretreated AN-104/SBS recycle solution) sparged with air at different fluxes.

Experiments with the as-received samples exhibited a strong tendency to foam. A maximum foaminess of $80 \%$ was observed with this sample at a flux of $4.4 \mathrm{ft}^{3} / \mathrm{min} / \mathrm{ft}^{2}$. At fluxes below $4.4 \mathrm{ft}^{3} / \mathrm{min} / \mathrm{ft}^{2}$, the foaminess of the solution increased almost linearly with flux with slow fluctuations at steady state. At fluxes above $4.4 \mathrm{ft}^{3} / \mathrm{min} / \mathrm{ft}^{2}$, the foaminess of the solution initially increased, then the bubbles at the top of the foam begin to collapse before the foam reached a steady state. Visual observations show that this foam breakdown into froth is due to increased turbulence in the liquid, which causes the bubbles on the top of the foam to rupture. Thus, the higher fluxes result in faster drainage and rupture of the bubbles.

The AN-104/SBS recycle had previously contained antifoam, and the solution was aged a number of months before testing. This particular solution was used for testing because of sample size limitations. It was evident from these tests that aged solutions previously treated with antifoam seem to lessen the effectiveness of new antifoam additions.

A steady increase of the foaminess of the AN-104/SBS recycle solution with increase in the concentration of the solid particles was noted at fluxes below $4.4 \mathrm{ft}^{3} / \mathrm{min} / \mathrm{ft}^{2}$. The foaminess of the system at different wt\% insoluble solids loadings decreased as the flux exceeded $4.4 \mathrm{ft}^{3} / \mathrm{min} / \mathrm{ft}^{2}$. The cause of this behavior for the real waste vs. simulant is not yet understood. The foam generated during the AN-104/SBS recycle solution testing was unstable and collapsed quickly upon termination of air sparging. 
WSRC-TR-2004-00387, REVISION 0

SRNL-RPP-2004-00053, REVISION 0

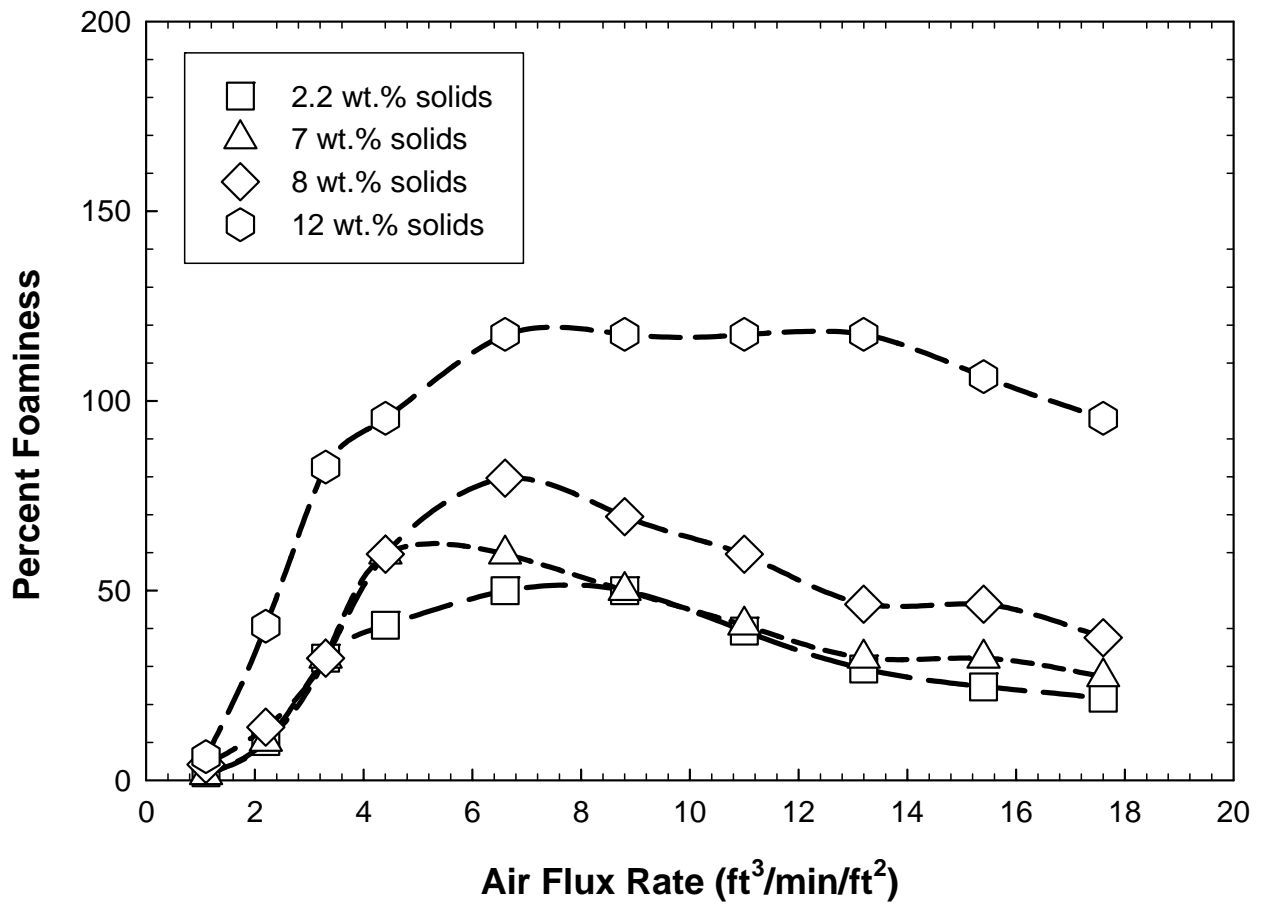

Figure 10. Effect of Solid Particles on Foaminess of Actual Hanford Waste (Pretreated AN-104/SBS Recycle Solution) with Simulated AY-102 Sludge Solids

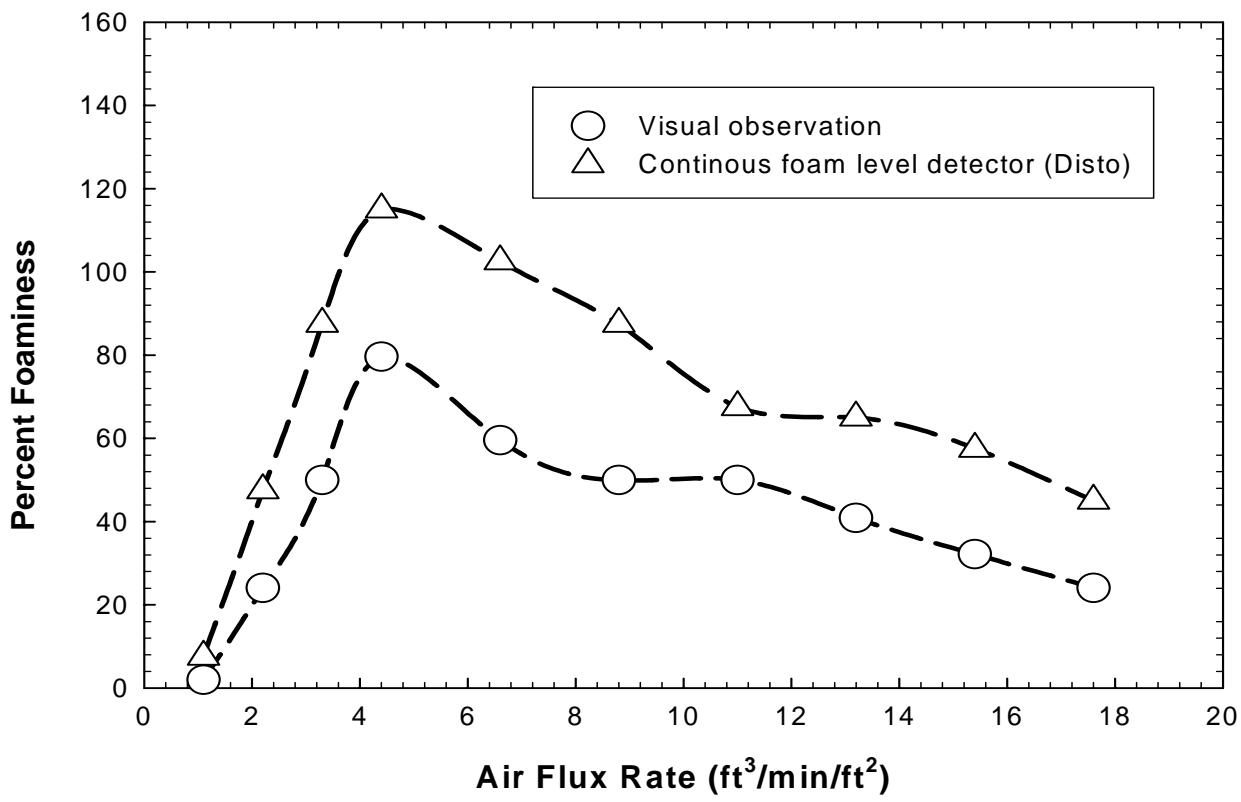

Figure 11. Foaming of AN-104/SBS Recycle Hanford Waste Sample with Simulated AY-102 Sludge Solids 
Figure 12 shows the results obtained for foaming of AN-104 Hanford waste sample that was previously treated through ion exchange columns that did not contain any antifoam. The solutions containing different weight percent solids were subjected to air sparging at fluxes of 1.1-4.4 $\mathrm{ft}^{3} / \mathrm{min} / \mathrm{ft}^{2}$. Higher fluxes have not been tested because of the excessive foaminess of the AN-104 sample.

From the results presented in Figure 12, it is clear that the extent of foaminess increased with increasing air flux over the range studied (except for the $6 \mathrm{wt} \%$ solids solution). The results show that maximum foaminess remains a function of the concentration of insoluble solids. The stability of the foam generated from the AN-104 actual waste sample (post ion exchange) was negligible. The foam collapsed as soon as the air sparging was terminated. It is speculated this is due to an insufficient quantity of surface active agents to create stable foam in the $5 \mathrm{M} \mathrm{Na}$ solution. The effect of the size of the insoluble solids has not been addressed in this study.

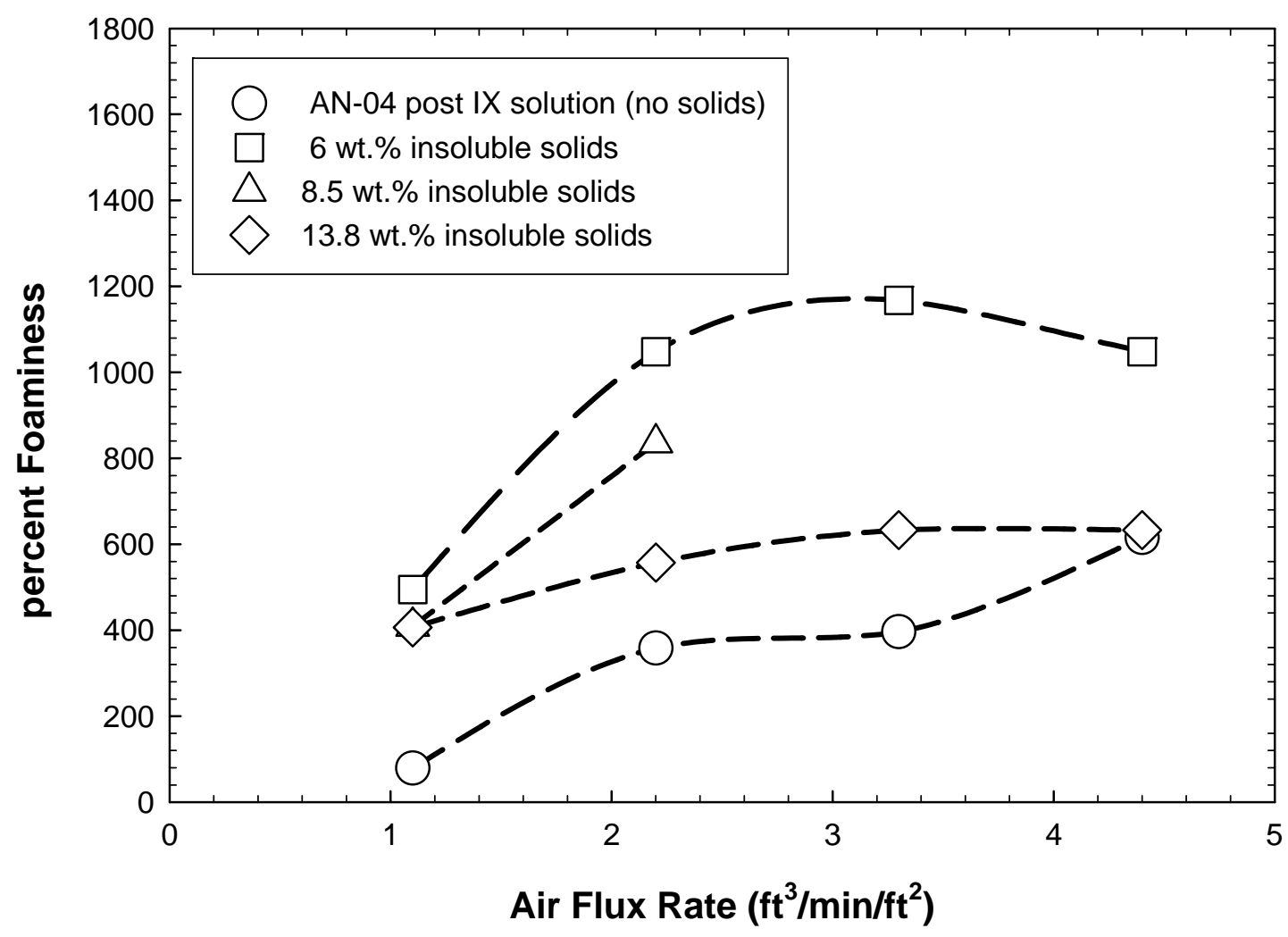

Figure 12. Effect of Solid Particles on Foaminess of Actual Hanford Waste (Pretreated AN-104/SBS Recycle Solution) with Simulated AY-102 Sludge Solids 
Figure 13 shows the effect of solid particles on foaminess of an AN-104 Hanford waste sample that was previously treated through ion exchange columns. The foaminess increased with an increase in the concentration of solid particles, and then went through a well-defined maximum. The maximum foaminess reached was approximately $1048 \%$ at an insoluble solids concentration of $6 \mathrm{wt} . \%$ and an air flux of $2.2 \mathrm{ft}^{3} / \mathrm{min} . \mathrm{ft}^{2}$. The sample exhibited a high tendency to foam even in the absence of solids, and the presence of solid particles contributed to the higher foaminess observed.

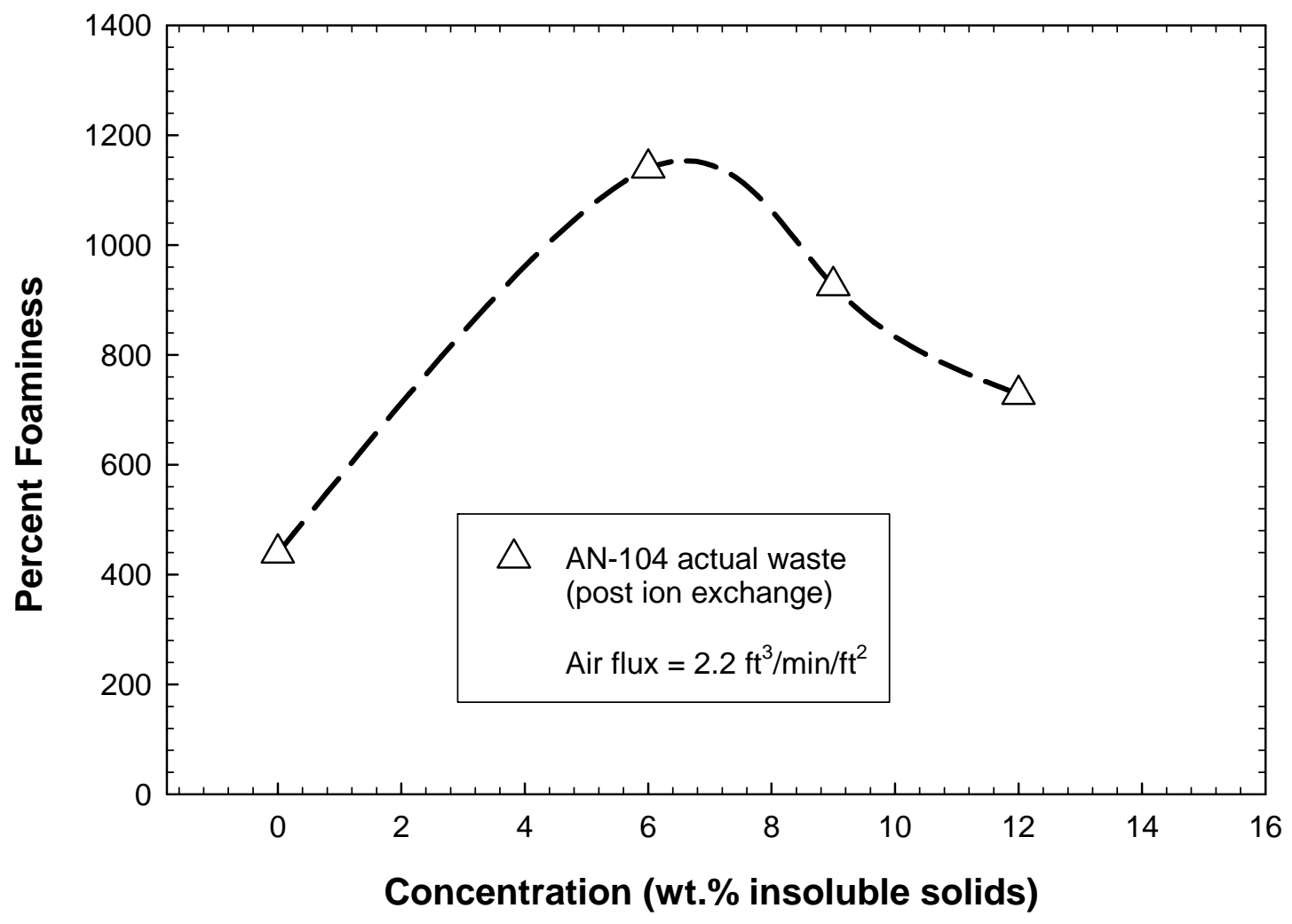

Figure 13. Effect of Solid Particles on Foaminess of Actual Hanford Waste (AN-104 Post IX Solution) during air sparging at $2.2 \mathrm{ft}^{3} / \mathrm{min} \mathrm{ft}^{2}$ 


\subsection{Q2 ANTIFOAM TEST RESULTS}

Figure 14 shows the effect of an initial charge of $315 \mathrm{mg} / \mathrm{L}$ of Q2-3183A antifoam on the percent foaminess of the AY-102/C-106 mixed with AP-101 (campaign II, SIPP feed) simulant as a function of time. The antifoam quickly destroyed and suppressed the foam for over 4 hours. Figure 15 shows the effect of the Q2 antifoam on the percent foaminess of AN-104/SBS Hanford waste sample solution as a function of the antifoam concentration. As shown, an initial charge of $345 \mathrm{mg} / \mathrm{L}$ Q2-3183A to the waste results in the immediate collapse of the foam. However, additional batches of the antifoam did not completely eliminate the foam. This is due to the fact that the AN-104/SBS contained antifoam from previous tests and the degraded components likely inhibited the performance of the fresh Q2-3183A added into solution. The antifoam components likely degrade into other surface active materials.

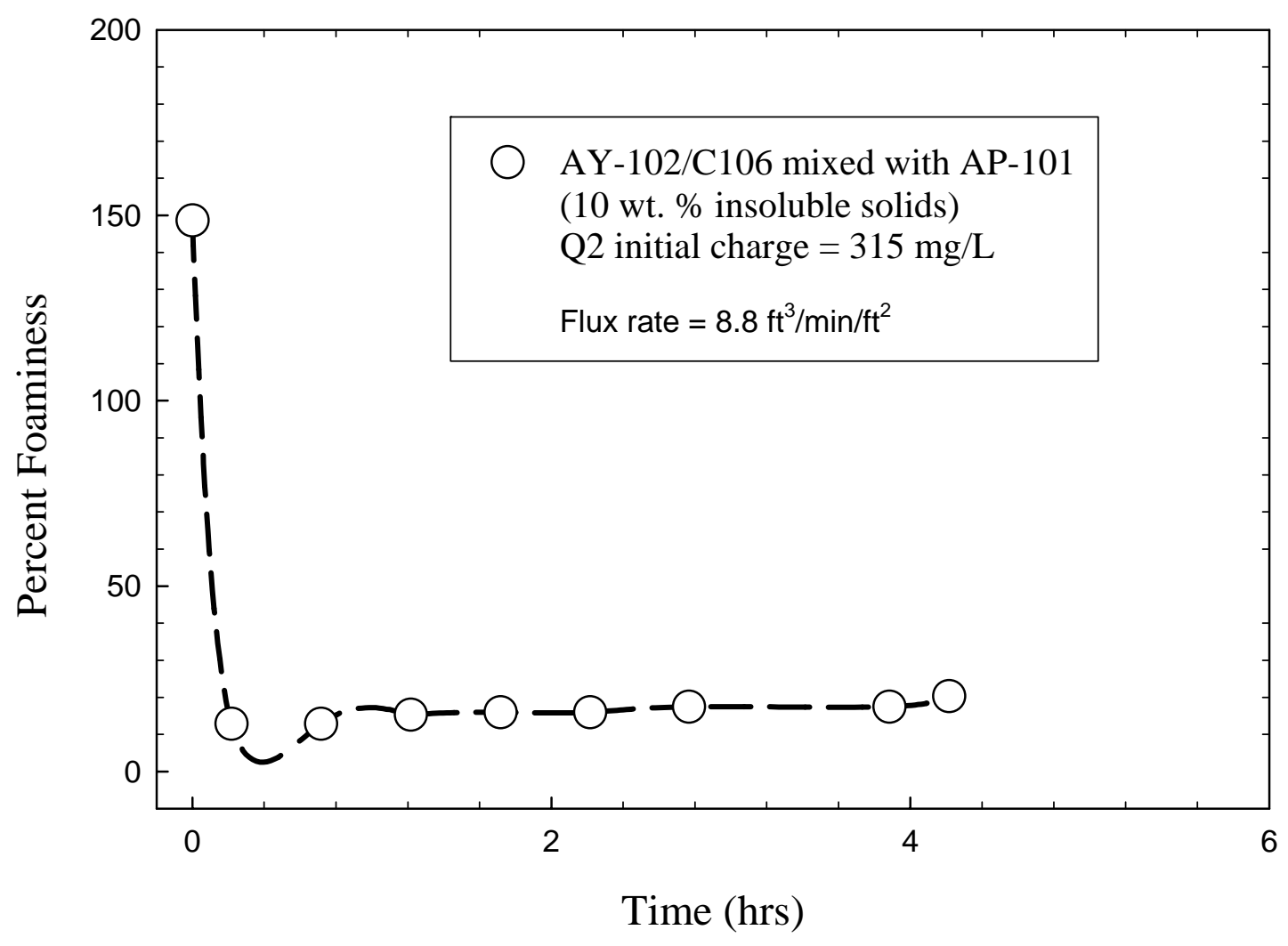

Figure 14. Effect of Q2 Antifoam on AY-102/C-106 Simulant 


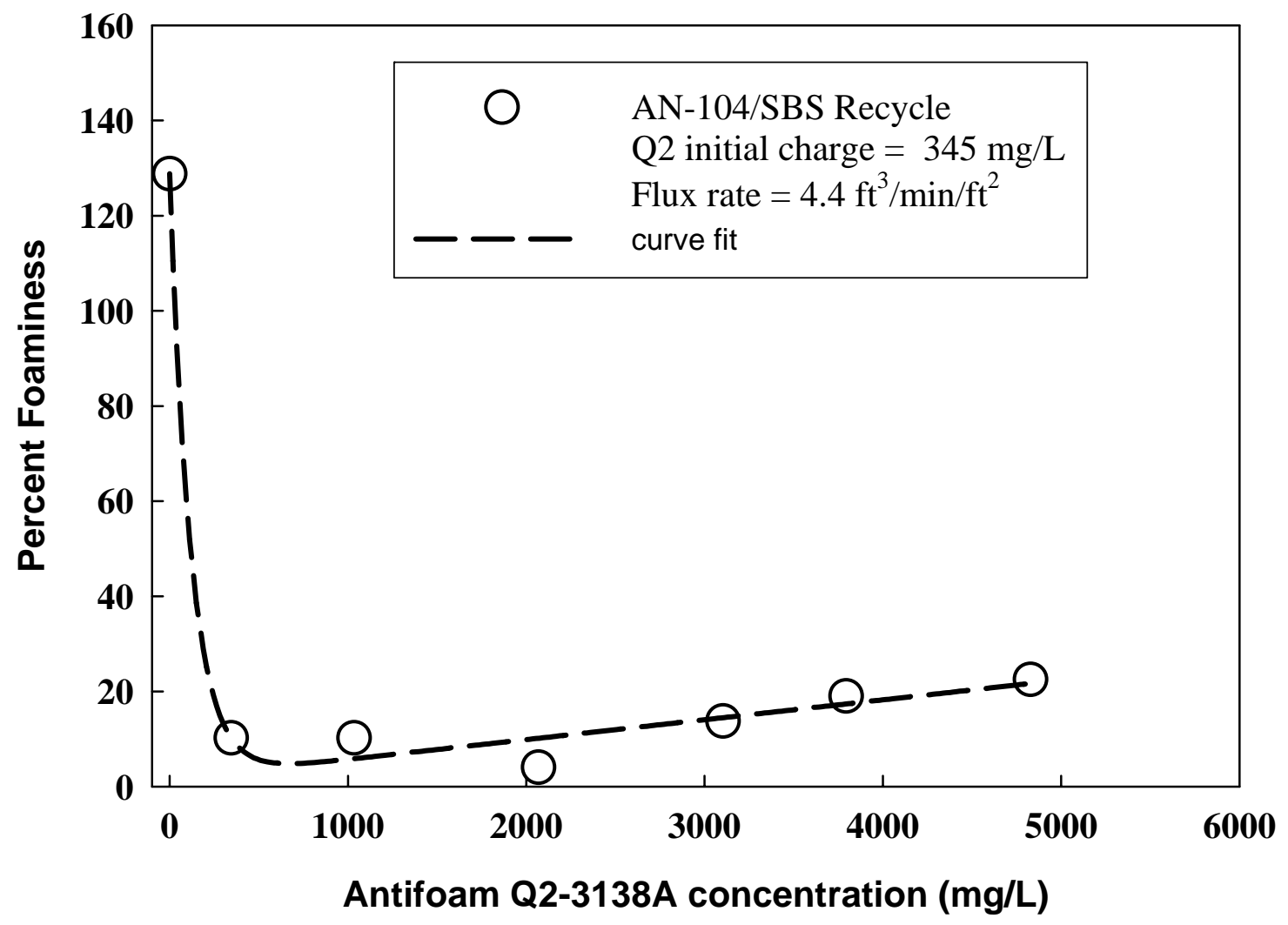

Figure 15. Effect of Q2 Antifoam on Actual Hanford Waste (Pretreated AN-104/SBS Recycle Solution) 
In Figure 16 and Figure 17, data are shown for the Q2-3183A effect on the foaminess of AN-104 Hanford waste sample (post ion exchange-no antifoam added) containing 9 wt.\% solids at air flux of $2.2 \mathrm{ft}^{3} / \mathrm{min} / \mathrm{ft}^{2}$. The data for the foaming solution without the antifoam are also shown in these figures. The percent foaminess obtained in the absence of the antifoam was $1127 \%$ after 8 minutes of air sparging (air flux $2.2 \mathrm{ft}^{3} / \mathrm{min} / \mathrm{ft}^{2}$ ). When $72 \mathrm{mg} / \mathrm{L}$ of the Q2-3183A was added to the foaming solution, the percent foaminess was reduced immediately to $122 \%$. With the solution still under a constant air sparging of $2.2 \mathrm{ft}^{3} / \mathrm{min} / \mathrm{ft}^{2}$, the foam increased gradually and after 63 minutes, the percent foaminess increased to 554\%. An increase of the concentration of the antifoam in solution to $144 \mathrm{mg} / \mathrm{L}$ resulted in reduction of the percent foaminess to $49 \%$. After addition, the foam in the solution under constant air sparge increased gradually and reached $241 \%$ after 117 minutes. The increase in the foam as a function of time indicates a reduction in the antifoam ability to suppress the foam. Further addition of $72 \mathrm{mg} / \mathrm{L}$ increments of the Q2-3183A into the solution successively reduced the percent foaminess. After a total of $345 \mathrm{mg} / \mathrm{L} \mathrm{Q2-3183A}$ was added to the solution, the percent foaminess of the solution was $13 \%$ after 5.7 hours. As demonstrated above by the incremental addition of the antifoam to foaming solution of AN-104 Hanford waste sample, the effectiveness of the antifoam decreases with time. This deactivation might be due to gradual breakdown of the antifoam as it spreads on the air/water surface under continuous air flow.

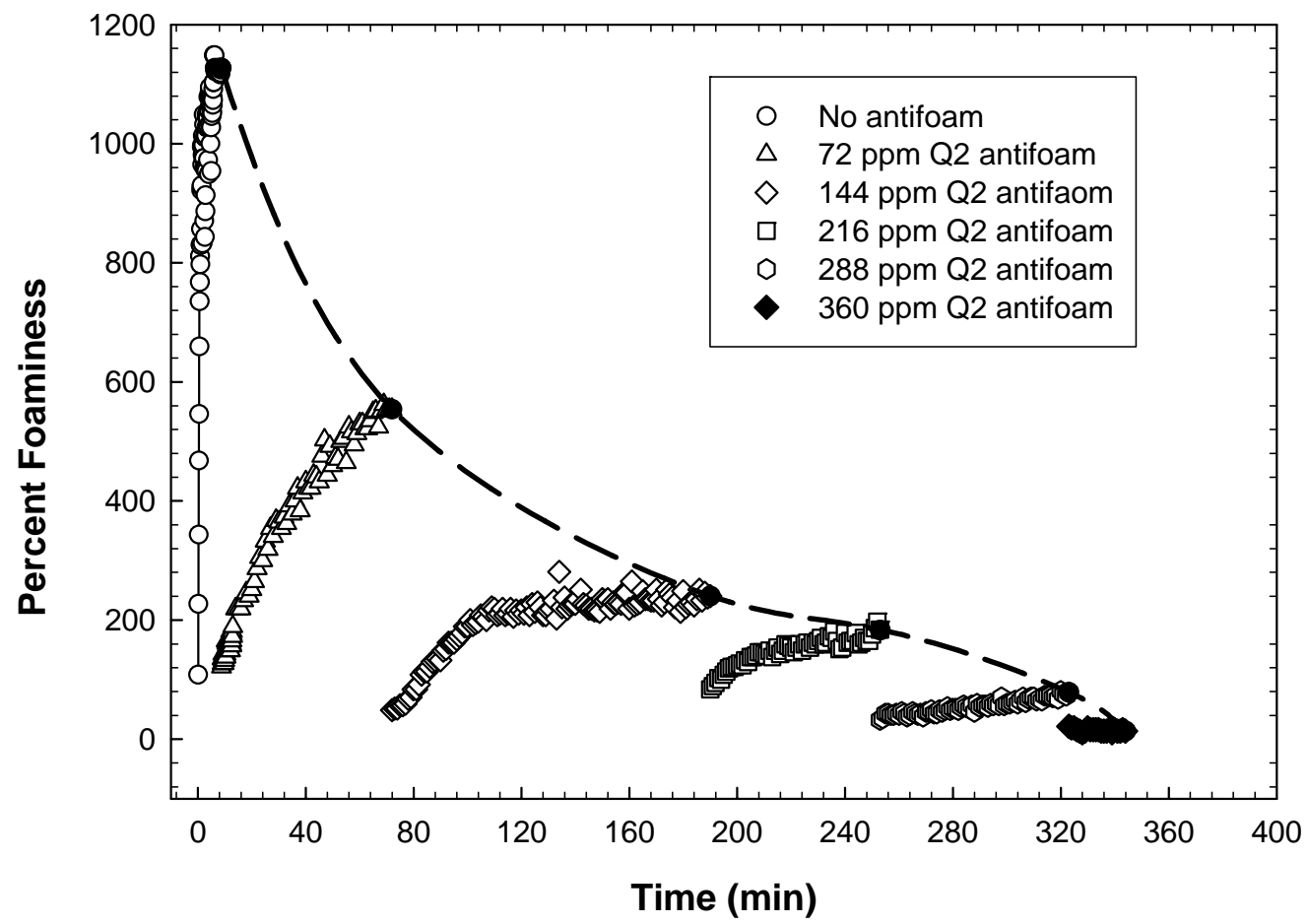

Figure 16. Evolution of the Foam with Time for Q2 Antifoam Addition to Actual Hanford Waste (Pretreated AN-104 Post Ion Exchange Solution) Disto data 
WSRC-TR-2004-00387, REVISION 0

SRNL-RPP-2004-00053, REVISION 0

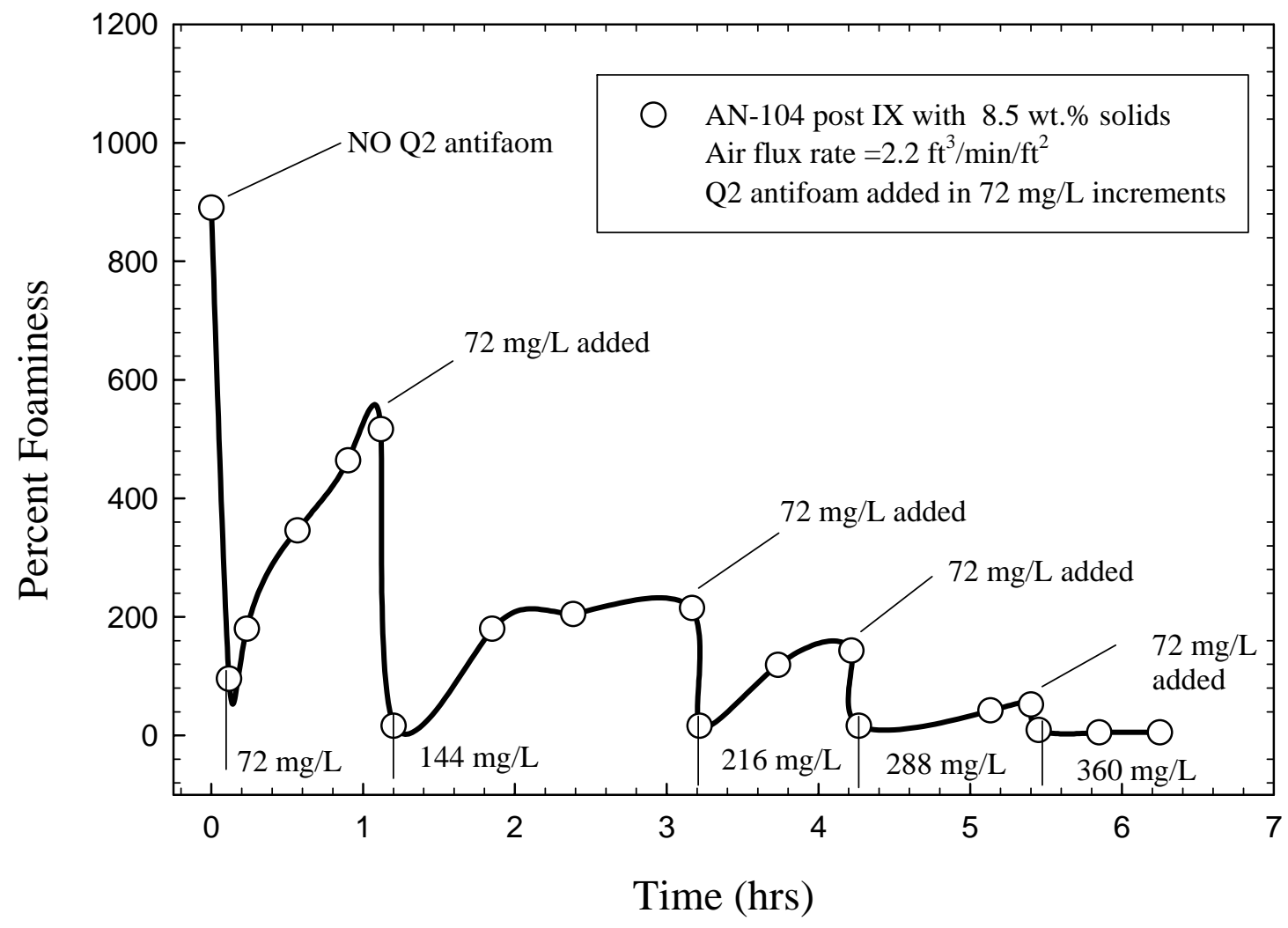

Figure 17. Evolution of the Foam with Time for Q2 Antifoam Addition to Actual Hanford Waste (Pretreated AN-104 Post Ion Exchange Solution) Visual data 
In Figure 18, data are shown for the foaming of AN-104 Hanford waste sample (post ion exchange) containing $6 \mathrm{wt}$. \% solids after an initial charge of $555 \mathrm{mg} / \mathrm{L} \mathrm{Q2-3183A}$ antifoam to the solution at rest. After the antifoam addition, the solution was sparged at a constant air flux of $2.2 \mathrm{ft}^{3} / \mathrm{min} / \mathrm{ft}^{2}$ and the evolution of the foam in the column was monitored. At time $=0$, the percent foaminess of 1048 equals to that of the foaming solution without antifoam added. As shown in Figure 19, the foam immediately collapsed after the initial charge of $555 \mathrm{mg} / \mathrm{L} \mathrm{Q}$. However, the foam slightly increased with time and after 27 hours, the percent foaminess was nearly $100 \%$. The increase in the foaminess may be due in part to evaporation and drying of the solution after overnight air sparging.

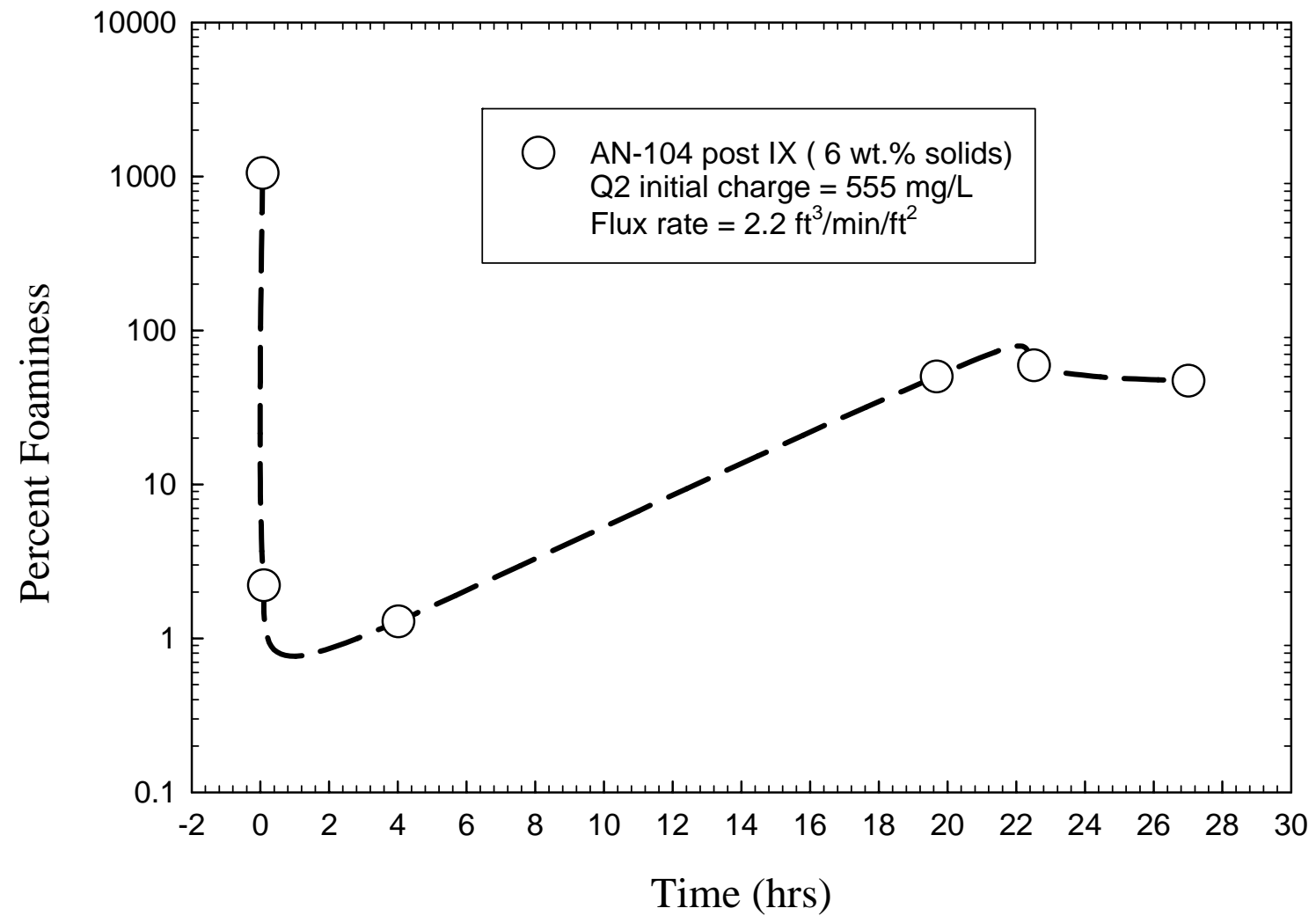

Figure 18. Effect of Initial $555 \mathrm{mg} / \mathrm{L} \mathrm{Q2} \mathrm{Antifoam} \mathrm{Addition} \mathrm{to} \mathrm{Actual} \mathrm{Hanford} \mathrm{Waste}$ (Pretreated AN-104 Post Ion Exchange Solution) 
WSRC-TR-2004-00387, REVISION 0

SRNL-RPP-2004-00053, REVISION 0

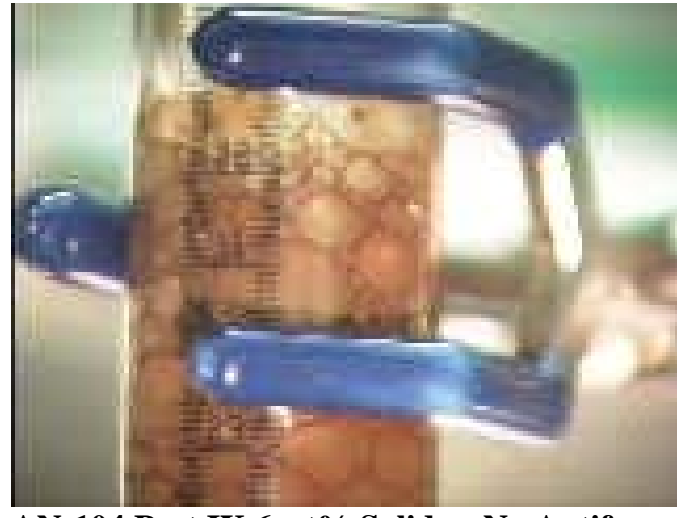

AN-104 Post IX 6 wt\% Solids - No Antifoam

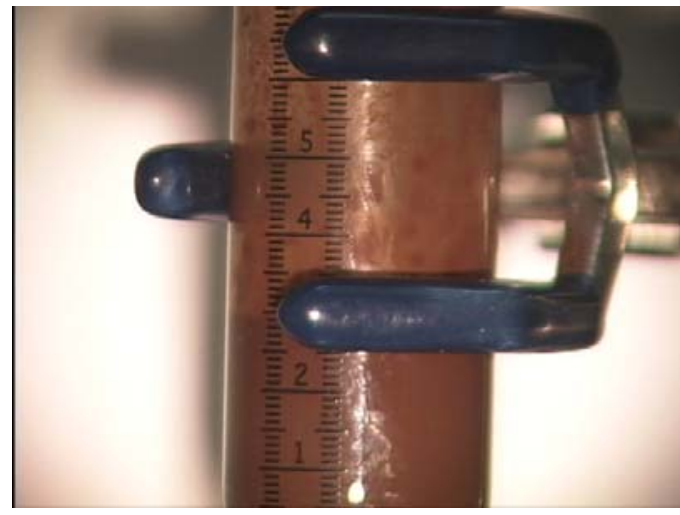

AN-104 Post IX 6 wt\% Solids -

Sparging After 555 mg/L Antifoam Addition

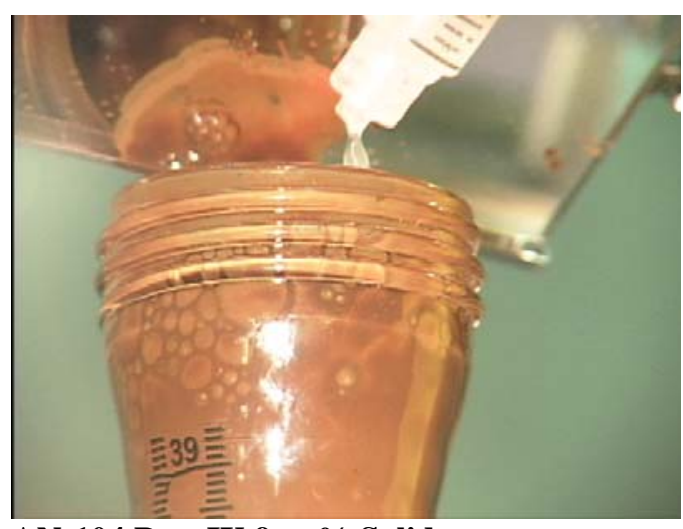

AN-104 Post IX 9 wt\% Solids -

Initial 70 mg/L Antifoam Addition

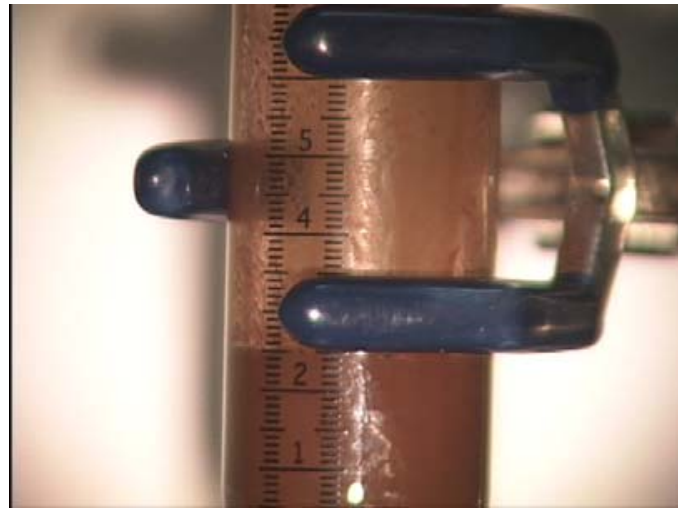

AN-104 Post IX 6 wt\% Solids -

At Rest Prior to 555 mg/L Antifoam Addition

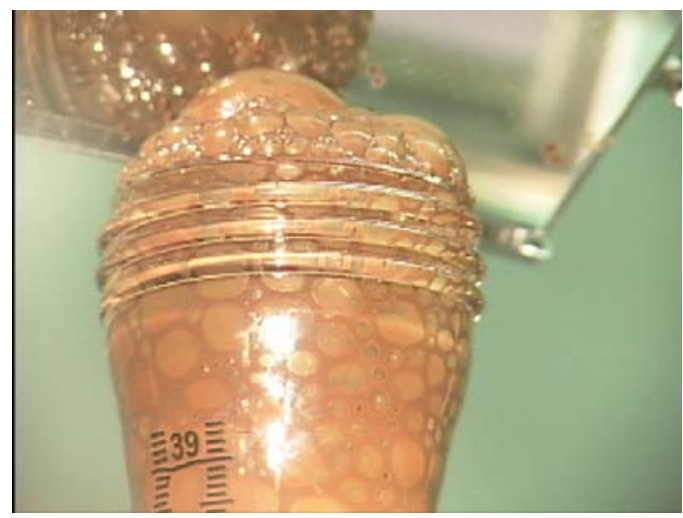

AN-104 Post IX 9 wt\% Solids No Antifoam Added

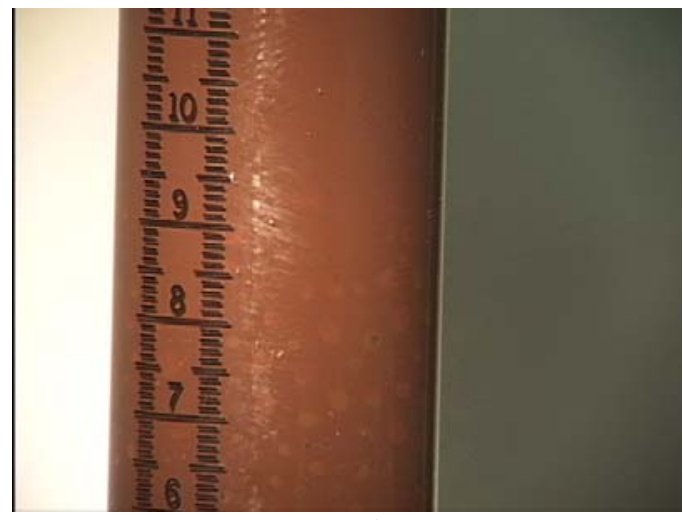

AN-104 Post IX 9 wt\% Solids -

Following Initial $70 \mathrm{mg} / \mathrm{L}$ Antifoam Addition

Figure 19. Effect of Dow Q2-3183A Antifoam Addition to Actual Hanford Waste 
WSRC-TR-2004-00387, REVISION 0

SRNL-RPP-2004-00053, REVISION 0

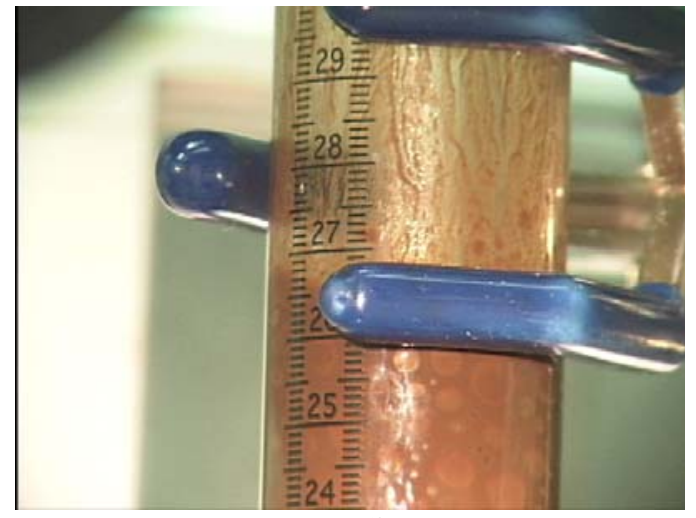

AN-104 Post IX 9 wt\% Solids -

Prior to Second $70 \mathrm{mg} / \mathrm{L}$ Antifoam Addition

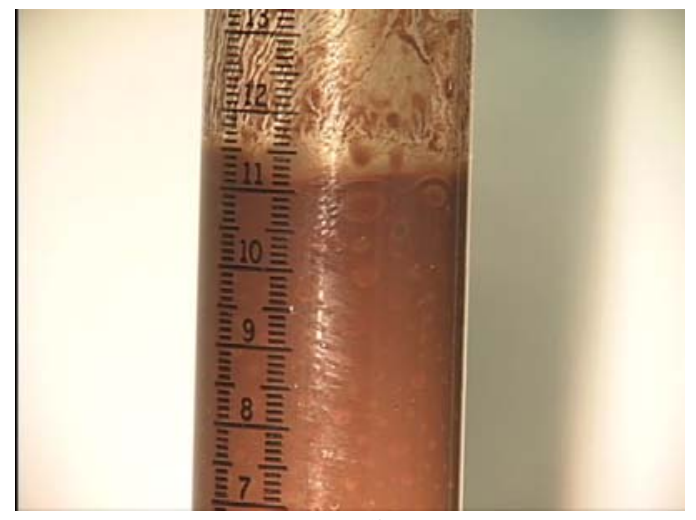

AN-104 Post IX 9 wt\% Solids -

Prior to Fourth 70 mg/L Antifoam Addition

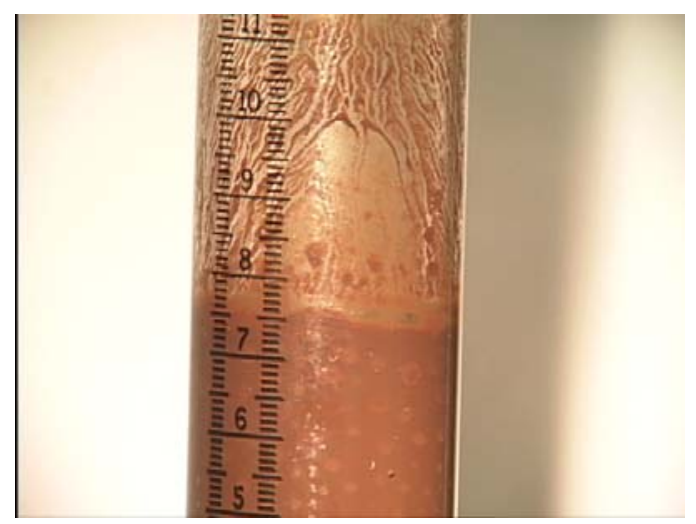

AN-104 Post IX 9 wt\% Solids -

Prior to Fifth $70 \mathrm{mg} / \mathrm{L}$ Antifoam Addition

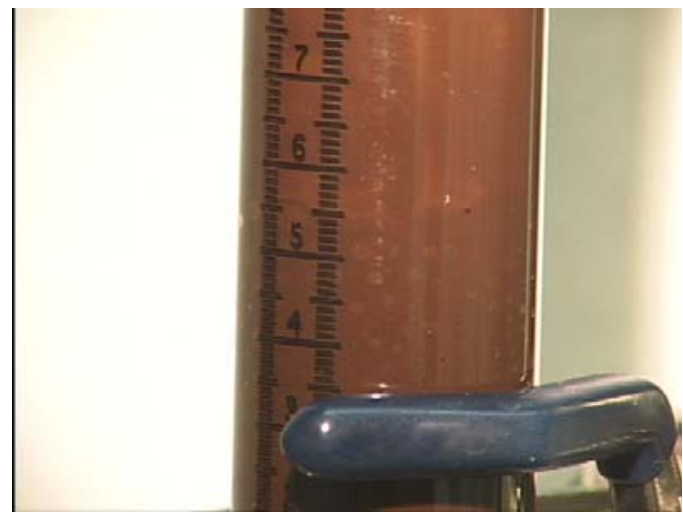

AN-104 Post IX 9 wt\% Solids -

Following Second $70 \mathrm{mg} / \mathrm{L}$ Antifoam Addition

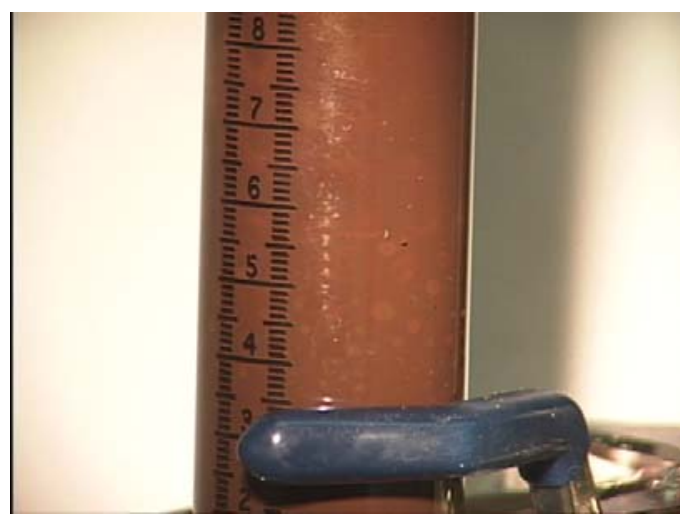

AN-104 Post IX 9 wt \% Solids -

Following Fourth $70 \mathrm{mg} / \mathrm{L}$ Antifoam Addition

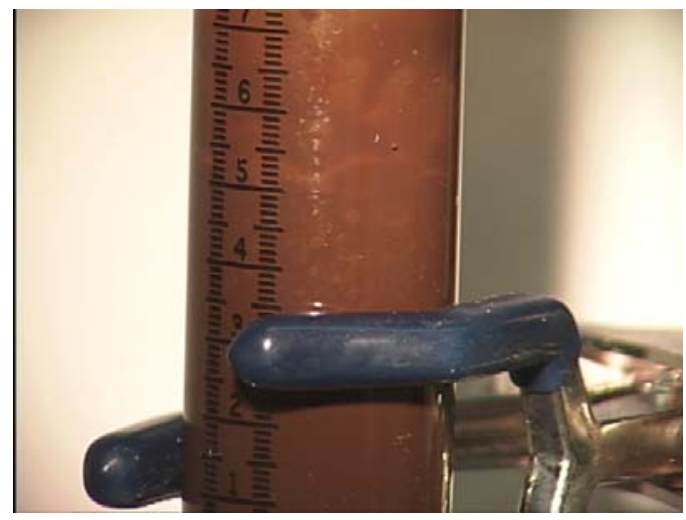

AN-104 Post IX 9 wt \% Solids -

Following Fifth $70 \mathrm{mg} / \mathrm{L}$ Antifoam Addition

Figure 19. (cont.) Effect of Dow Q2-3183A Antifoam Addition to Actual Hanford Waste 
WSRC-TR-2004-00387, REVISION 0

SRNL-RPP-2004-00053, REVISION 0

\subsection{RADIATION AND CHEMICAL STABILITY OF Q2-3183A}

The Q2-3183A antifoam has been found to degrade under radiation doses. Samples of LAW simulants spiked with $1500 \mathrm{mg} / \mathrm{L}$ Q2 were subjected to the maximum expected HLW radiation dose equivalent to a week of storage.

Analysis of these samples by Dow indicated a normalized degradation rate which follows first order kinetic decay. The equation which describes this decay follows:

\section{Equation 5-1 $\quad C=C_{0} \exp ^{(-0.0092 t)}$}

where

$\mathrm{C}$ is the concentration of antifoam at some time, $\mathrm{t}(\mathrm{hrs})$

$\mathrm{C}_{0}$ is the initial concentration at time $\mathrm{t}=0 \mathrm{hrs}$

$\mathrm{t}$ is in total time exposed to the maximum dose in hours

NOTE: Equation 5-1 was developed with only minimal data (6 points). Further investigation into the radiation stability of Q2 antifoam is recommended before applying this type of analysis to the design of the antifoam system. Therefore additional kinetics testing with Q2 is recommended.

Equation 5-1 predicts that 20\% of the Q2 antifoam would degrade in 24 hours at the maximum radiation dose. To maintain the $350 \mathrm{mg} / \mathrm{L}$ recommended dose, an initial charge of $350 \mathrm{mg} / \mathrm{L}$ would be required as the tank is filled, and an additional batch charge of $70 \mathrm{mg} / \mathrm{L}$ every 24 hours to offset the amount of Q2 destroyed by radiation.

Previous investigations into the stability of Dow Q2-3183A antifoam have demonstrated very good chemical stability with little or no degradation observed at $50^{\circ} \mathrm{C}$ in 3 molar caustic for periods as long as a week. ${ }^{4}$ Chemical stability of Q2-3183A at temperatures above $50^{\circ} \mathrm{C}$ has not been investigated. Discussion with Dow technical personnel indicate that Q2-3183A will likely break down at temperatures above $80^{\circ} \mathrm{C}$. Therefore, it should be assumed that during leaching operations the antifoam may have to be added continuously to the UFP tanks. Since this study did not address leaching, it is recommended that future R\&T studies investigate the foaminess of leached HLW sludge and antifoam performance and degradation during chemical leaching of HLW sludge. The stability and the performance of Q2-3183A in acidic conditions are also unknown. Surfactants of this type are usually tailored for specific $\mathrm{pH}$ ranges. The fate of Q2-3183A across the WTP pretreatment process has not been investigated. It will be included in the Semi-Integrated Pilot Plant tasks and reported separately from this task. 


\subsection{PROCESS DESIGN CONSIDERATIONS}

- Q2-3183A has a quoted viscosity of between 1800 - $3500 \mathrm{cps}$. While somewhat thick, it pours easily at room temperature. The antifoam behaves as a Newtonian fluid. No yield stress has been observed or measured by SRNL. The actual viscosity of the sample used by SRNL was $1150 \mathrm{cps}$ at $25^{\circ} \mathrm{C}$.

- The measured viscosity of 10 and $25 \mathrm{wt} \%$ antifoam was 1.7 and $5.0 \mathrm{cps}$, respectively, as shown in Figure 20. Dilution reduces the viscosity significantly, and allows fine silica solids to settle out of the suspension. The particles are readily suspended when agitated. However, if left standing in dead legs of transfer piping, the fine silica solids (mean particle size of 15 microns) may accumulate over time. Therefore, SRNL recommends that diluted antifoam transfer piping should be designed to minimize low points that may allow solids to accumulate over time.

\begin{tabular}{|c|c|}
\hline Weight \% Antifoam & Viscosity, Centipoise \\
\hline $\mathbf{1}$ & 1.2 \\
\hline $\mathbf{5}$ & 1.4 \\
\hline $\mathbf{1 0}$ & 1.7 \\
\hline $\mathbf{2 5}$ & 5.0 \\
\hline $\mathbf{5 0}$ & 41.7 \\
\hline
\end{tabular}

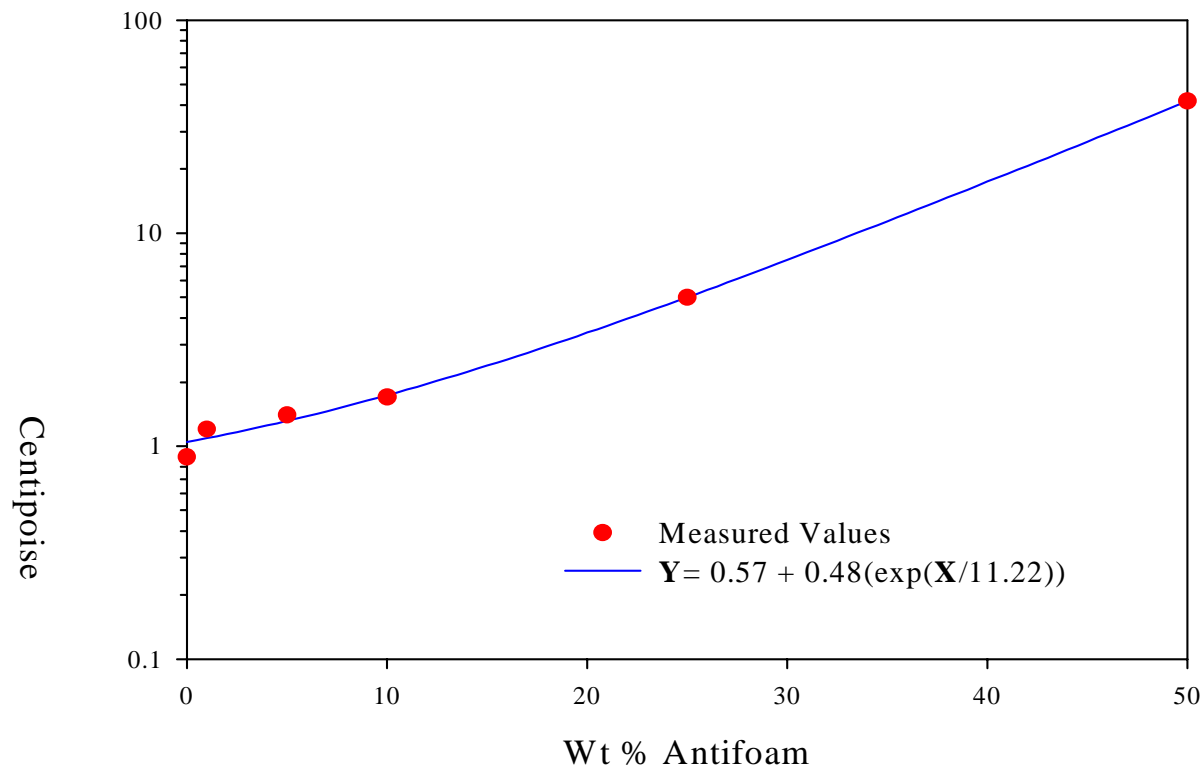

Figure 20. Q2-3183A Antifoam Viscosity vs. Concentration 
- No segregation has been observed with undiluted antifoam. Addition to the process without dilution should be considered.

- The antifoam has a shelf life of 12 months when maintained at or below $32^{\circ} \mathrm{C}$.

\subsection{TWENTY-DAY AIR SPARGING RESULTS}

The analytical data for the samples taken on day $0,7,14$, and 20 for the 4-cm and 5-cm air sparging columns are shown in Table 8 and Table 9 located in Appendix A.

To examine the potential impact of air sparging on the $\mathrm{pH}$ or chemical composition of the sludge, the data was plotted over the course of the study for the 4-cm and 5-cm columns as shown in Figure 21 and Figure 22. The $\mathrm{pH}$ for the 4-cm and 5-cm columns is constant over the 20 days. The total inorganic carbon (TIC) for the $4-\mathrm{cm}$ and $5-\mathrm{cm}$ columns does change over the 20 days but its variation is within the measurement error. Looking at the iron and anion analytical data in Table 9 the chemical composition of the sludge does not appear to be changing.

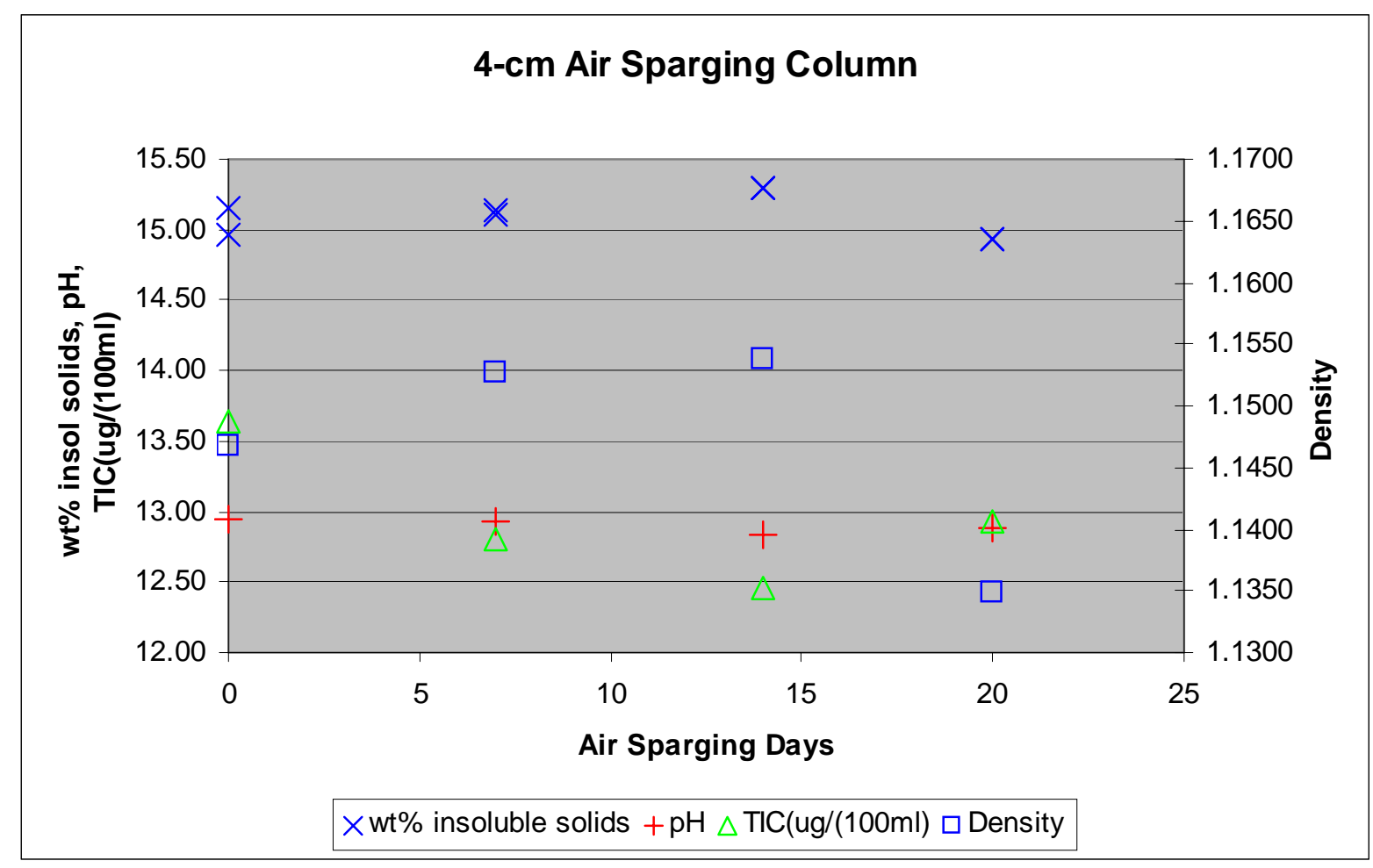

Figure 21. 4-cm Air Sparging Column Analytical Data vs. Time 


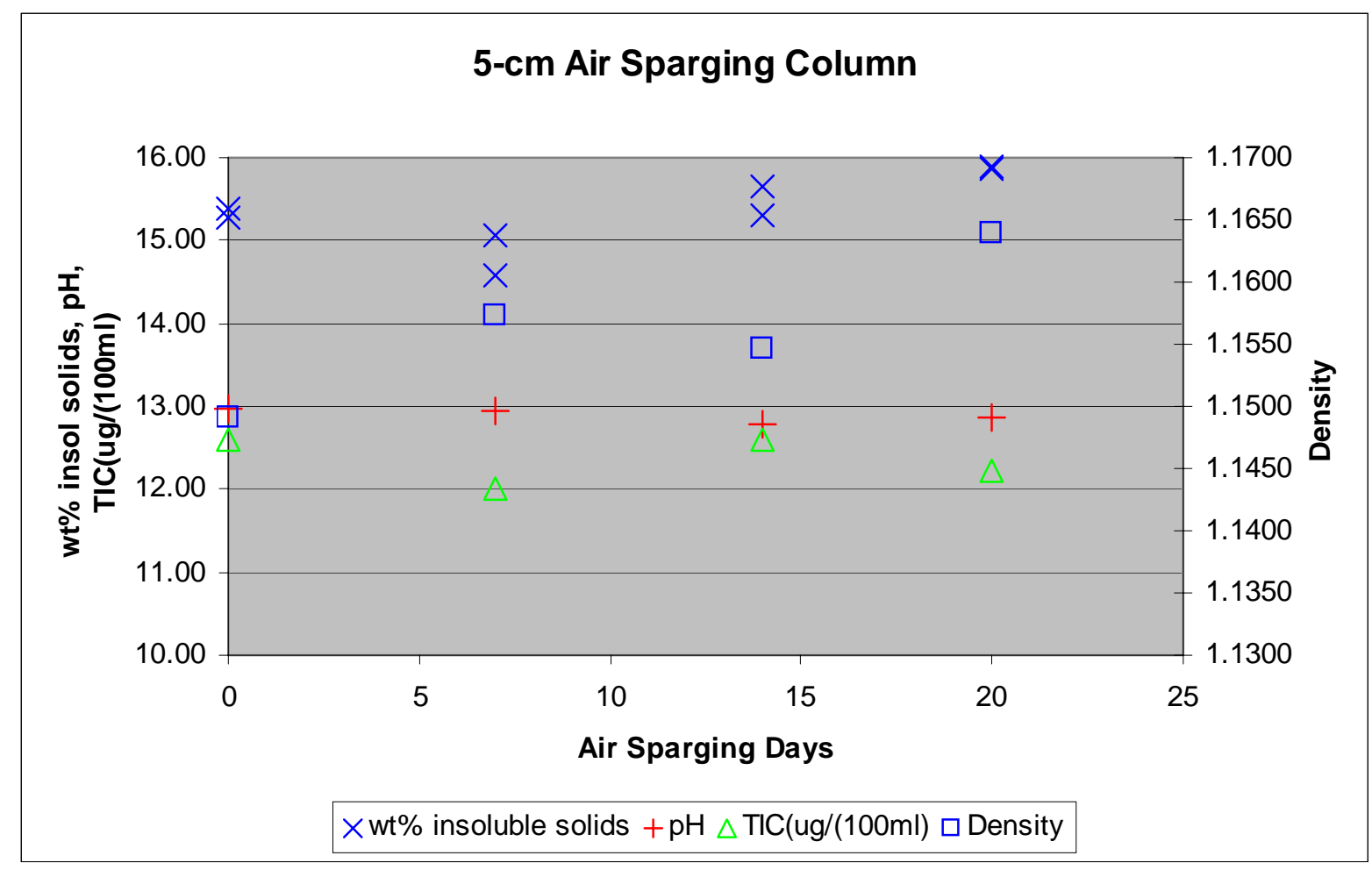

Figure 22. 5-cm Air Sparging Column Analytical Data vs. Time

To examine the impact of air sparging on the rheology of the sludge, rheological properties were measured for the samples taken during the 20 day air sparging test of the HLW Precipitated Hydroxide Simulant 15 wt\% AZ-101 sludge. These rheological properties were measured using a flow curve (shear stress-shear rate) and analyzed using various rheological models. The 4-cm and 5-cm columns were analyzed for day 0 , day 7, day 14 and day 20 of continuous sparging.

The rheology results are summarized in Table 10 and Table 11, shown in Appendix A.

The average results of the up curve Bingham Plastic model parameters are shown in Figure 23 and Figure 24 for the $4-\mathrm{cm}$ and $5-\mathrm{cm}$ column air sparging tests respectively. There is no significant rheological change for the 4-cm column test over the 20 days of air sparging. For the 5-cm column, the air sparging appears to impact the yield stress but after inspecting the other analyses (anion, iron, weight percent solids, density) the increase is most likely due to slight changes in the $\mathrm{pH}$ and density due to loss of solids on the walls of the column rather than air sparging. 


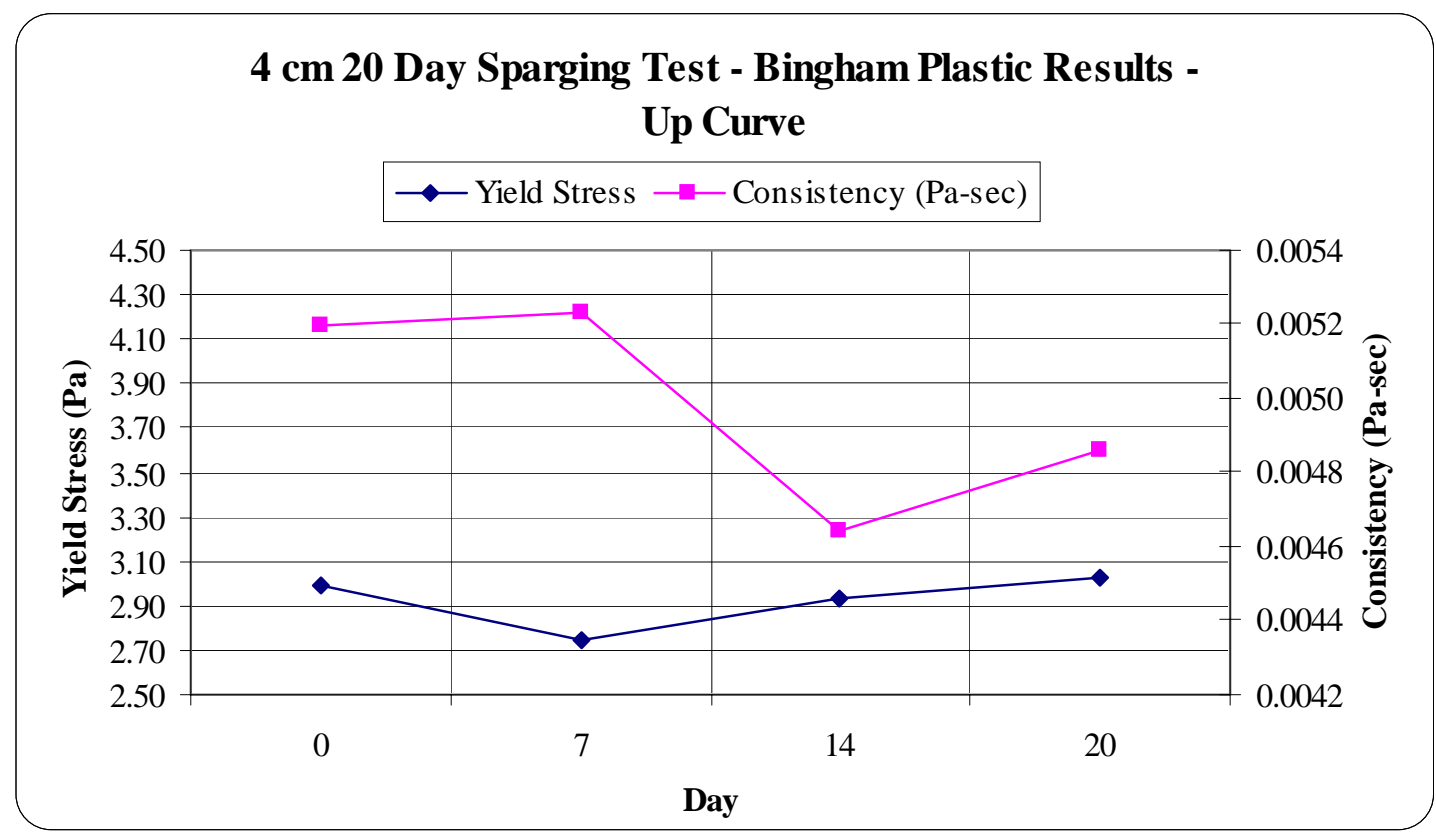

Figure 23. Bingham Plastic Parameters From 4-cm Air Sparing Test

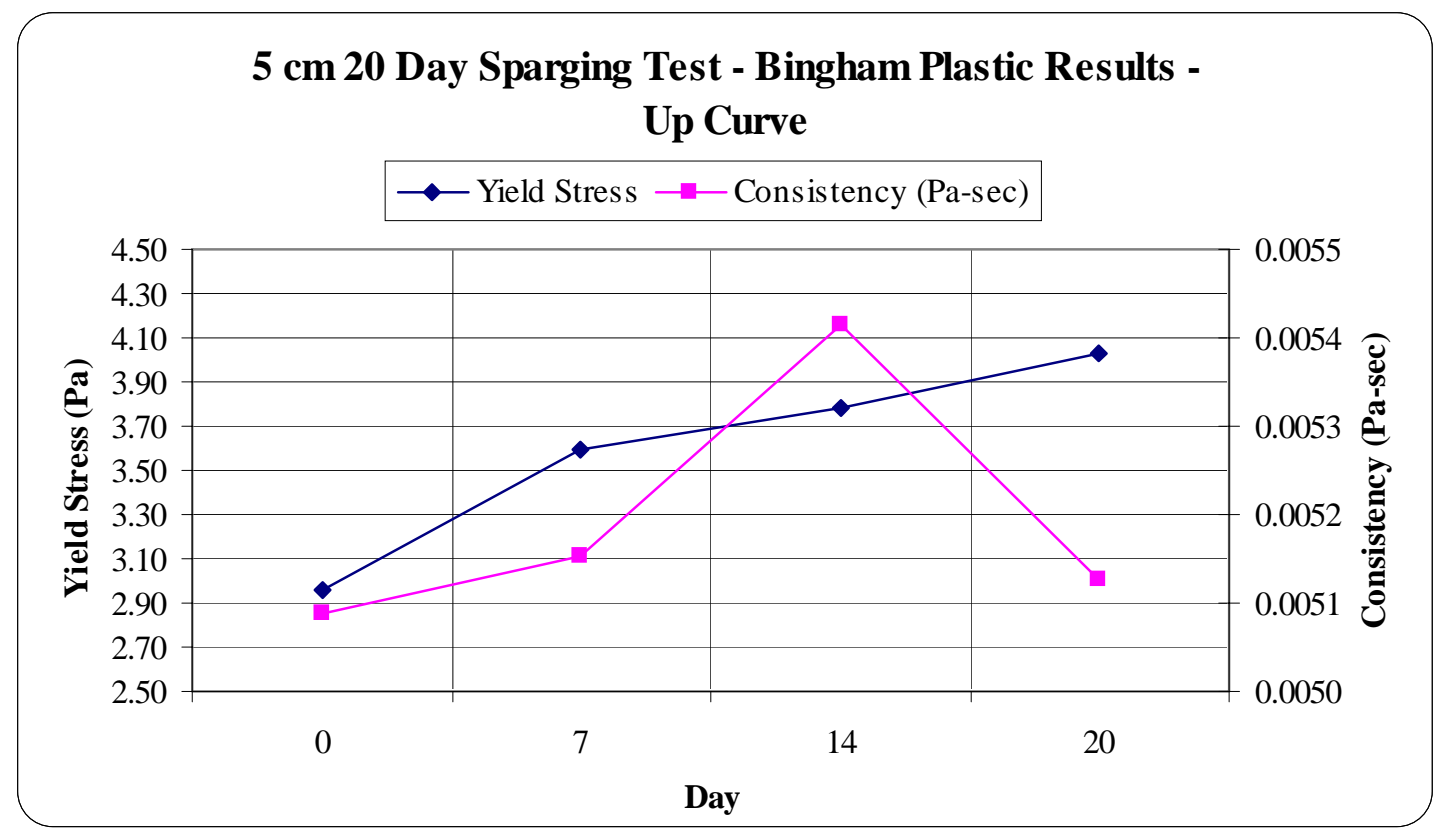

Figure 24. Bingham Plastic Parameters From 5-cm Air Sparing Test 
To analyze how the rheological properties were impacted by sparging, the Bingham yield stress and consistency were plotted versus the weight percent solids, $\mathrm{pH}$, total inorganic carbon (TIC), and density analyses for the 4-cm and 5-cm columns as shown in Figure 29 through Figure 36 located in Appendix A. From the data collected and considering measurement variance, no direct link can be derived between the rheology (yield stress and consistency) of the sparged material and its wt\% insoluble solids, $\mathrm{pH}$, TIC, density, anion, and $\mathrm{Fe}$ measurements for the 4- $\mathrm{cm}$ and 5-cm air sparging columns. There is some evidence that the 5-cm column material yield stress decreases as its $\mathrm{pH}$ increases and increases as its density increases. However, this data is very limited and would need to be further investigated before drawing any conclusions.

To maintain the weight percent solids throughout the 20 days, de-ionized water was added back to each column before taking samples on day 7, 14, and 20. Due to material being stuck to the inside of the column walls and some material spattering out of the columns, the mass of water added back may have been artificially inflated. The spattering was more pronounced in the 5-cm column than the 4-cm column and this helps explain the 14.6-15.9 wt- $\%$ insoluble solids variance for the 5-cm column versus the 14.9-15.3 wt-\% insoluble solids variance for the 4-cm column. The air sparging with the dry cylinder air was causing about $30 \mathrm{~g}$ of water loss from the $4-\mathrm{cm}$ column and $50 \mathrm{~g}$ loss from the 5 -cm column per 24 hours. These measured water losses matched closely with calculated values of 34 gram and 54 grams per 24 hours for the 4-cm and 5-cm columns using ideal gas compressibility factors, respectively. The dry air rate was set in both columns to deliver $2.5 \mathrm{ft}^{3} / \mathrm{min} / \mathrm{ft}^{2}$ air sparge rate. If dry or conditioned air is going to be used in a plant situation then some means of maintaining the weight percent solids with water addition during sparging must be considered.

In summary, the rheology does not appear impacted by air sparging other than by the loss of water due to evaporation by the dry sparge air. For the Ultrafiltration Feed Process Vessels (UFP-VSL-00002A/2B) assuming a dry air flux of $2.508 \mathrm{scfm} / \mathrm{ft}^{2}$ and tank diameter of 14 feet gives $1,871 \mathrm{lb} / \mathrm{hr}$ of dry air into the vessel. It is assumed that the dry air has $0 \%$ relative humidity coming in and after sparging through the vessel exits at $100 \%$ saturated at $40{ }^{\circ} \mathrm{C}$ and $1 \mathrm{~atm}$. The 4-cm and 5-cm column air sparging tests showed the dry air exiting the top of the columns to be saturated throughout the 20 days of testing. For the exit conditions using the ideal gas law and water vapor pressure data, the mass ratio of water to air is $0.04902 \mathrm{lb} \mathrm{H}_{2} \mathrm{O} / \mathrm{lb}$ dry air. This mass ratio would amount to $91.74 \mathrm{lb} \mathrm{H}_{2} \mathrm{O} / \mathrm{hr}$ going out the top of the Ultrafiltration Feed Process vessels. Assuming the Ultrafiltration Feed Process Vessel has an initial 29,364 gallons of a $15 \mathrm{wt} \%$ total solids and $1.1467 \mathrm{~kg} / \mathrm{L}$ density sludge, the initial solids mass is $42,151 \mathrm{lb}$ and initial water mass of 238,853 lb. Using all these values the wt-\% solids for the sludge over time without any water addition can be represented as:

$$
\text { Wt\%-Solids }=42151 /(42151+238853-91.74 * \text { time}[\mathrm{hr}])
$$

A plot of the above equation is shown in Figure 25 over a period of 100 days. 


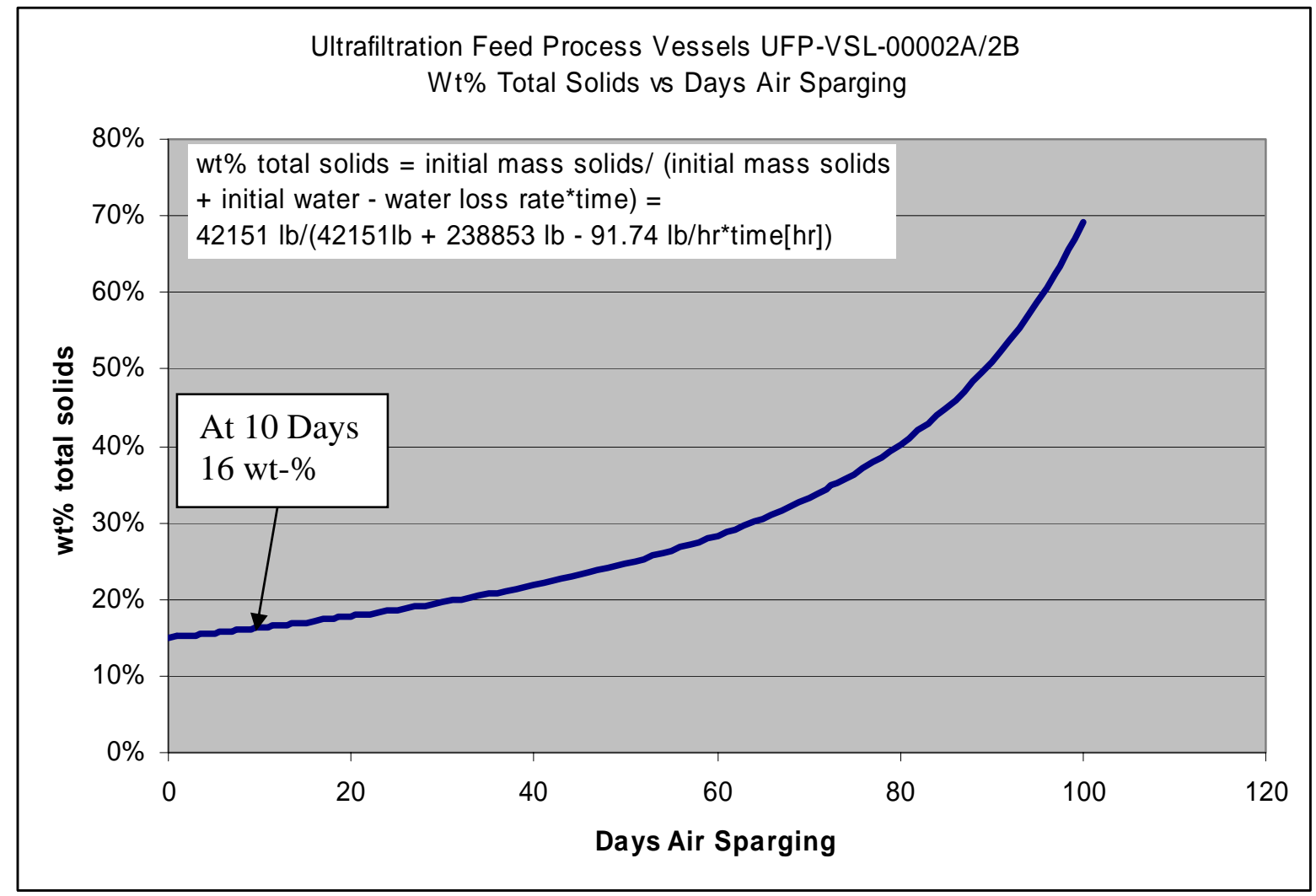

Figure 25. Ultrafiltration Feed Process Vessels Wt\% Total Solids versus Days of Air Sparging

For the HLW Lag Storage Vessels (HLP-VSL-00027A/B) assuming a dry air flux of 2.575 $\mathrm{scfm} / \mathrm{ft}^{2}$ and tank diameter of 25 feet gives $6,126 \mathrm{lb} / \mathrm{hr}$ of dry air into the vessel. It is assumed that the dry air has $0 \%$ relative humidity coming in and after sparging through the vessel exits at $100 \%$ saturated at $40^{\circ} \mathrm{C}$ and $1 \mathrm{~atm}$. The $4-\mathrm{cm}$ and $5-\mathrm{cm}$ column air sparging tests showed the dry air exiting the top of the columns to be saturated throughout the 20 days of testing. For the exit conditions using ideal gas law the mass ratio of water to air is $0.04902 \mathrm{lb}$ $\mathrm{H}_{2} \mathrm{O} / \mathrm{lb}$ dry air. For the air flux for the HLW Lag Storage Vessels that amounts to $300.34 \mathrm{lb}$ $\mathrm{H} 2 \mathrm{O} / \mathrm{hr}$ going out the top of the vessel. Assuming the HLW Lag Storage Vessel has an initial 100,673 gallons of a 15 -wt $\%$ total solids and $1.1467 \mathrm{~kg} / \mathrm{L}$ density sludge, the initial solids mass is $144,511 \mathrm{lb}$ and initial water mass of $818,897 \mathrm{lb}$. Using all these values the wt \% solids for the sludge over time without any water addition can be represented as:

$$
\mathrm{Wt} \% \text {-Solids }=144511 /(144511+818897-300.34 * \text { time }[\mathrm{hr}])
$$

A plot of the above equation is shown in over a period of 100 days. 


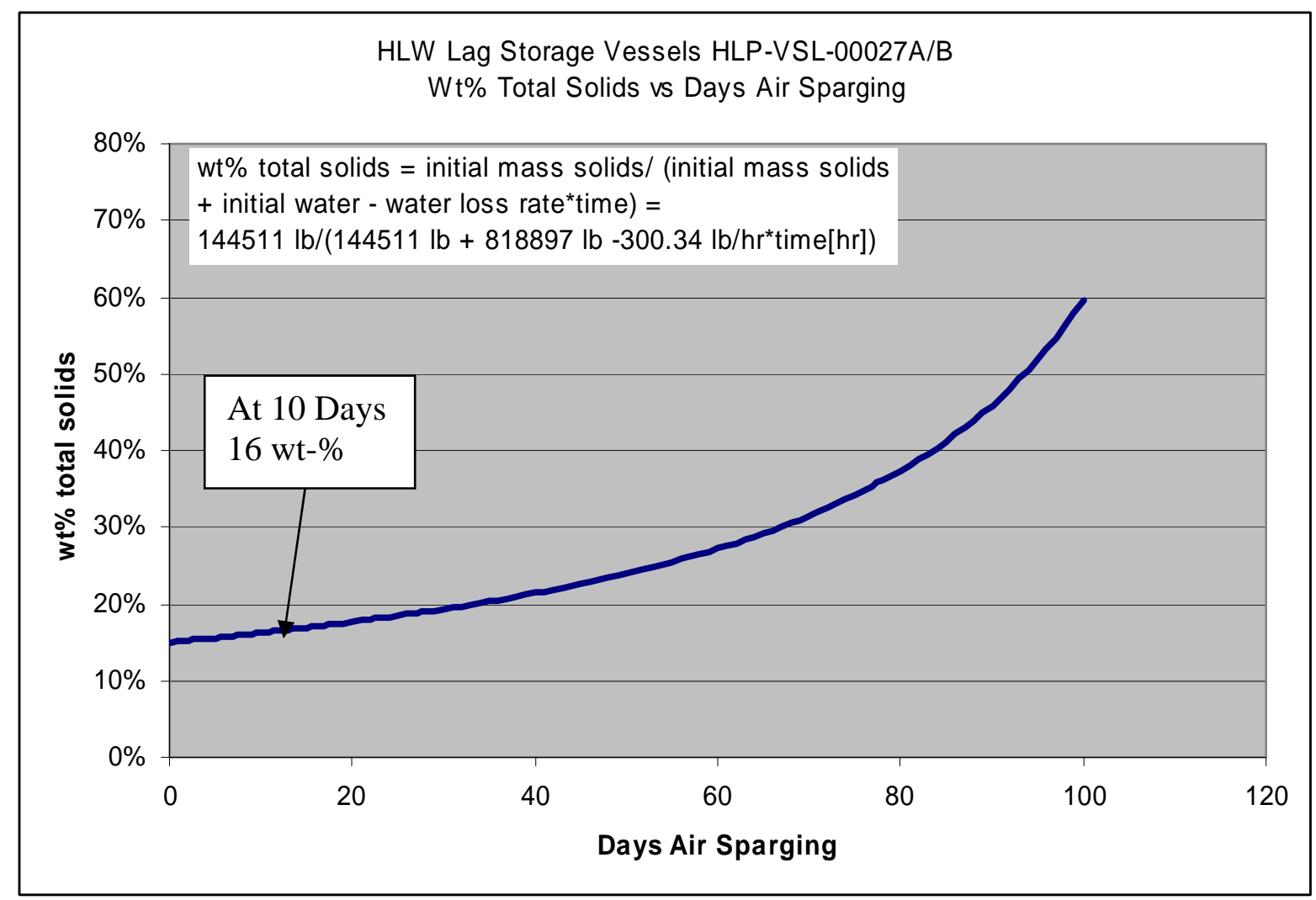

Figure 26. HLW Lag Storage Vessels Wt\% Total Solids versus Days of Air Sparging

\subsection{FATE OF ANTIFOAM IN WTP PROCESS}

Discussion with Dow technical personnel and previous work at SRNL (Waste Treatment Plant LAW Evaporation: Antifoam Performance [WSRC-TR-2003-00216, Rev.0]) indicate that Q2-3183A will likely break down at temperatures above $80^{\circ} \mathrm{C}$. This prompts a concern about the formation of dimethylmercury in the UFP system during the leaching process, in which temperature may exceed $80^{\circ} \mathrm{C}$. In this study, the antifoam was tested at a temperature of $25 \pm 2$ degrees Celsius, in which the antifoam decomposition was not expected. However, literature data for vapor pressure of dimethylmercury between 20.5 and $78.7^{\circ} \mathrm{C}$ was obtained and presented in Figure 27. The data show that the vapor pressure of dimethylmercury in the UFP tank will be approximately $400 \mathrm{mmHg}$ at $80^{\circ} \mathrm{C}$. SRNL researchers (Wilmarth 2003) investigated the formation of dimethylmercury in HLW systems. At temperatures above $100^{\circ} \mathrm{C}$, dimethylmercury formed in simulated HLW salt solutions mixed with Dow antifoams (polymethylsiloxanes, similar to Q2-3183A) and other organic compounds. At temperature below $50^{\circ} \mathrm{C}$, dimethylmercury did not form in the test solutions. Unfortunately no studies were performed at temperatures between 50 and $100^{\circ} \mathrm{C}$. However, given the vapor pressure data and the potential for formation of dimethylmercury in HLW salt solutions, evaluation of the vapor mitigation systems within the WTP should be conducted. 


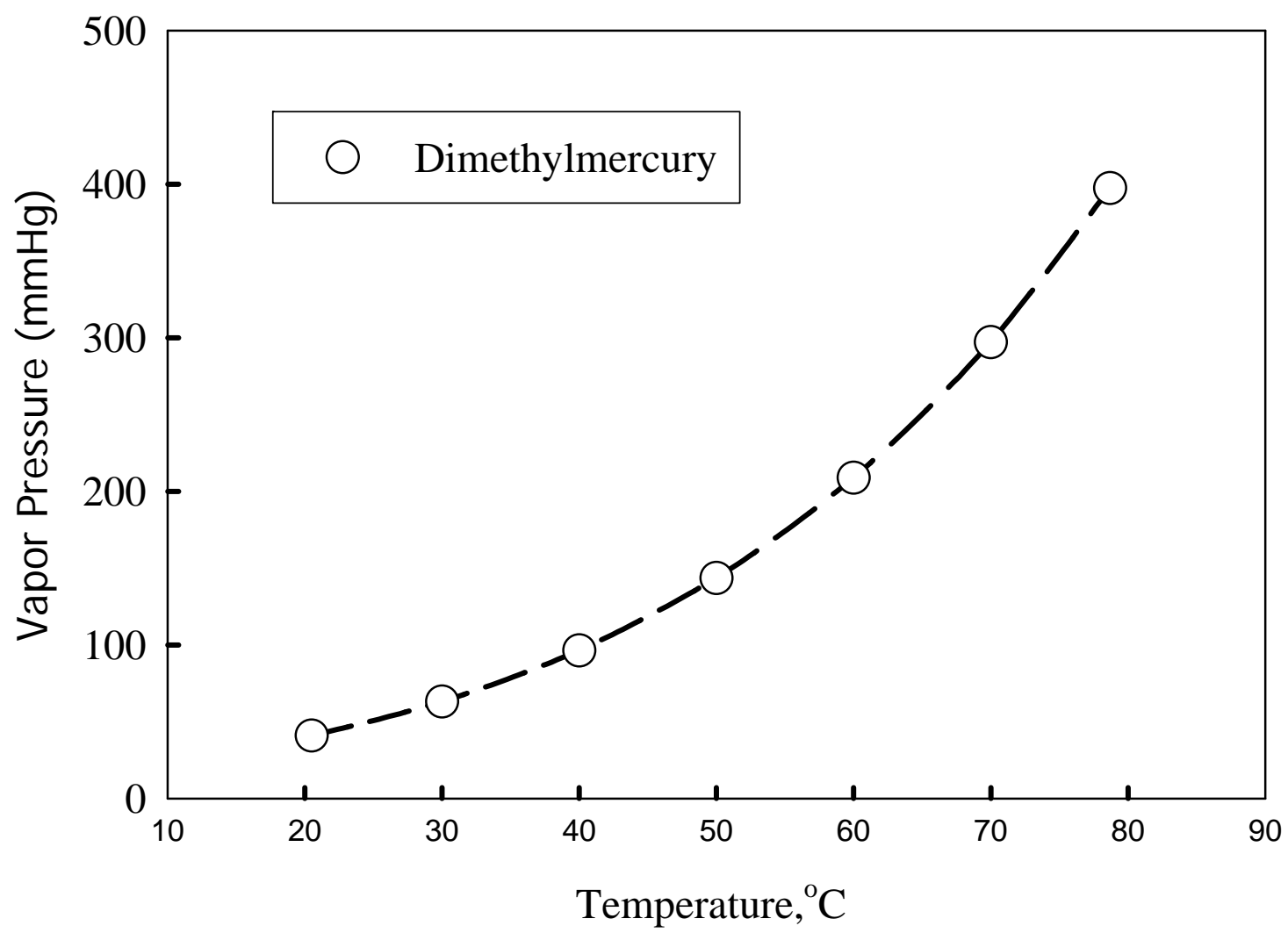

Figure 27. Vapor pressure of Dimethylmercury (ref. Thompson, W. H and Linnett, J. W., Trans. Faraday Soc. (1936), 32, 681-685)

At temperatures above $80^{\circ} \mathrm{C}$, the Q2-3183A will likely be degraded in the Hanford tank waste solutions. While the actual degradation mechanism is not known, literature sources reveal one potential pathway and the possible breakdown products. University of Minnesota (Feng 2002) researchers investigated the degradation pathways of organosilicone in the presence of microorganisms. Dimethylsilanediol (DMSD) is the main degradation product of polydimethylsiloxane (PDMS, one of the active ingredients in Q2-3183A). The DMSD degradation pathway is presented in Figure 28. While the exact degradation pathway of PDMS is unknown for radioactive caustic solutions, the pathway proposed by Feng does provide some insight into the potential degradation compounds that could occur. It should be noted that reaction kinetics for systems concerning microorganisms are likely to be much different (i.e., generally faster in normal environmental conditions) than systems without microorganisms. 


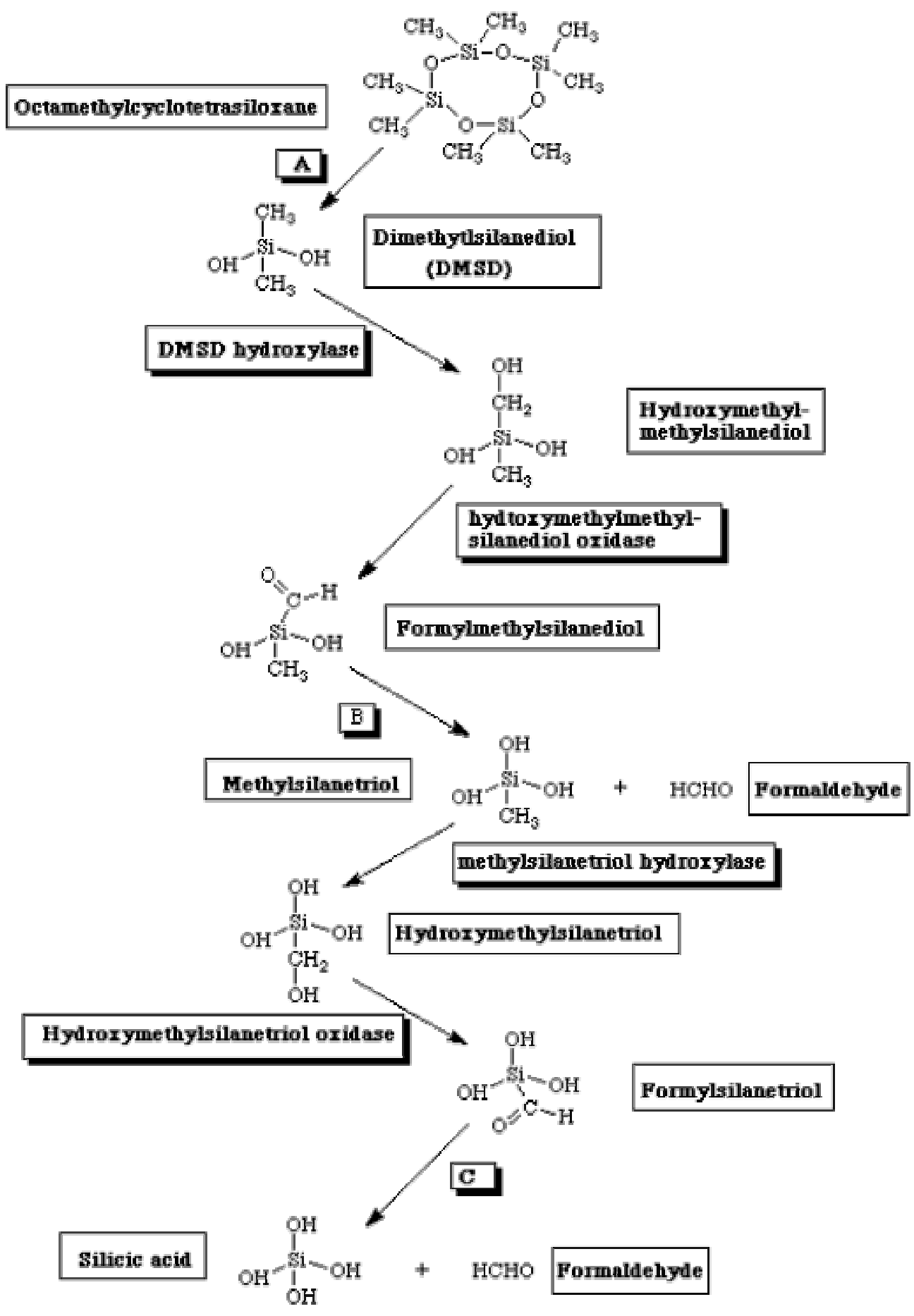

Figure 28. Degradation Pathway of Organosilicones in the Presence of Bacteria (Feng 2002) 
Over-addition of antifoam agent could cause secondary phase to form. This has occurred in the HLW tank farm at SRS. It is not expected that an organic phase will form at the concentration proposed by this report. However, in the leaching case, further investigation is warranted to determine the actual fate of the antifoam during leaching operations.

The fate of the antifoam that is left after transferring a batch of washed sludge is unknown. It is unlikely that current analytical methods would detect the concentration of antifoam left in the heel after it was diluted with a new batch of HLW. 
WSRC-TR-2004-00387, REVISION 0

SRNL-RPP-2004-00053, REVISION 0

\subsection{REFERENCES}

1. K. Adu-Wusu and N. M. Hassan, Cesium Ion Exchange Using Tank 241-AN-104 Supernate, WSRC-TR-2003-00311, Rev.0, Westinghouse Savannah River Company, October, 2003.

2. R. E. Eibling et al., Hanford Waste Simulants Created to Support the Research and Development on the River Protection Project - Hanford Waste Treatment Plant, WSRCTR-2000-00338, Rev.0, Westinghouse Savannah River Company, September 2000.

3. Crowder, M.L., E.K. Hansen, C.L. Crawford, W.E. Daniel, Jr., R.F. Schumacher, P. R. Burket, and J.L. Siler, Evaporation, Rheology and Vitrification of a Radioactive Hanford Tank AN-104 Sample Mixed with Recycle, WSRC-TR-2004-00232 (SRNL-RPP-200400044), Westinghouse Savannah River Company, Aiken, SC 29808 (in press, expected June 2004).

4. Baich, M. A., Stone, M. E., White, T. L., Calloway, T. B., "Waste Treatment Plant Evaporation: Antifoam Performance (U)," WSRC-TR-2003-00216, Rev. 0, Westinghouse Savannah River Company, August 2003.

5 Calloway, T. B., Baich, M. A. \& Lambert, D. P., March 31, 2001, Fate of IIT B52 Antifoam Agent Across the Small Tank Tetraphenylborate Process, WSRC-TR-200100102, Westinghouse Savannah River Company, Aiken SC 29808.

6. Pilon, L., Fedrov, A. G., Viskanat, R. (2001) Steady State Foam Thickness of Liquid-Gas Foams, Journal of Colloidal and Interface Science, 242, 425-436.

7. Haake Rheowin Version 3.14, Thermo Electron Corporation, 2004.

8. Feng, J., 2002, “Organosilicone (an/aerobic) Degradation Pathway Map," http://umbbd.ahc.umn.edu/osi/osi_map.html, University of Minnesota.

9. Euzen, J. P., Trambouze, P., Wauquier, J. P., Scale-Up Methodology for Chemical Processes, Gulf Publishing Company, Houston, Texas (1993) p. 130.

10. Zamecnik, J. R., P. R. Burket, R. E. Eibling, and M. R. Poirier, "Tank 241-AY-102 Simulant Development, Ultrafiltration and Washing," WSRC-TR-2003-00547, Rev.0. Westinghouse Savannah River Company, Aiken, SC. March 2004.

11. Wilmarth, W. R. \& S. W. Rosencrance, "Studies of Mercury in High Level Waste Systems," WSRC-TR-2003-00238, Westinghouse Savannah River Company, Aiken, SC. June 2003. 
WSRC-TR-2004-00387, REVISION 0

SRNL-RPP-2004-00053, REVISION 0

This page intentionally left blank. 
WSRC-TR-2004-00387, REVISION 0

SRNL-RPP-2004-00053, REVISION 0

\section{APPENDIX A. 20-DAY AIR SPARGING DATA}


Table 8. 20-Day Air Sparging Analytical Results

\begin{tabular}{|c|c|c|c|c|c|c|c|c|c|c|}
\hline Sample & $\begin{array}{c}\text { wt } \% \\
\text { total } \\
\text { solids }\end{array}$ & $\begin{array}{c}\text { wt } \% \\
\text { soluble } \\
\text { solids }\end{array}$ & $\begin{array}{c}\text { wt } \% \\
\text { insoluble } \\
\text { solids } \\
\end{array}$ & Density & pH & $\begin{array}{c}\text { TC } \\
{[\mu g / m l]}\end{array}$ & 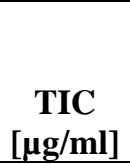 & $\begin{array}{c}\text { TOC } \\
{[\mu g / m l]}\end{array}$ & $\begin{array}{c}\text { Bingham } \\
\text { Yield } \\
\text { Stress } \\
\text { [Pa] }\end{array}$ & $\begin{array}{c}\text { Bingham } \\
\text { Consistency } \\
\text { [Pa-sec] }\end{array}$ \\
\hline 4-cm Day 0 & 17.92 & 2.86 & 15.06 & 1.1467 & 12.95 & 1697 & 1365 & 333 & 2.99 & 0.0052 \\
\hline 4-cm Day 7 & 17.91 & 2.78 & 15.13 & 1.1527 & 12.93 & 1450 & 1280 & $<200$ & 2.75 & 0.0052 \\
\hline 4-cm Day 14 & 17.80 & 2.50 & 15.30 & 1.1538 & 12.83 & 1592 & 1246 & 346 & 2.93 & 0.0046 \\
\hline 4-cm Day 20 & 17.52 & 2.58 & 14.94 & 1.1349 & 12.88 & 2009 & 1294 & 715 & 3.03 & 0.0049 \\
\hline 5-cm Day 0 & 18.02 & 2.69 & 15.33 & 1.1491 & 12.97 & 1440 & 1260 & $<200$ & 2.96 & 0.0051 \\
\hline 5-cm Day 7 & 17.58 & 2.76 & 14.83 & 1.1573 & 12.95 & 1360 & 1200 & $<200$ & 3.59 & 0.0052 \\
\hline 5-cm Day 14 & 18.04 & 2.56 & 15.48 & 1.1547 & 12.79 & 1248 & 1260 & 2136 & 3.78 & 0.0054 \\
\hline 5-cm Day 20 & 18.57 & 2.71 & 15.86 & 1.1639 & 12.87 & 1234 & 1222 & 1110 & 4.03 & 0.0051 \\
\hline
\end{tabular}

Table 9. 20-Day Air Sparging Analytical Results Continued

\begin{tabular}{|c|c|c|c|c|c|c|c|c|c|c|c|}
\hline Sample & $\begin{array}{c}\text { Fe } \\
{[\mathrm{mg} / \mathrm{L}]}\end{array}$ & $\begin{array}{c}F \\
{[\mathrm{mg} / \mathrm{L}]}\end{array}$ & $\begin{array}{c}\mathrm{Cl} \\
{[\mathrm{mg} / \mathrm{L}]}\end{array}$ & $\begin{array}{c}\mathrm{NO2} \\
{[\mathrm{mg} / \mathrm{l}]}\end{array}$ & $\begin{array}{c}\text { NO3 } \\
\text { [mg/L] }\end{array}$ & $\begin{array}{c}\text { SO4 } \\
\text { [mg/L] }\end{array}$ & $\begin{array}{c}\text { PO4 } \\
{[\mathrm{mg} / \mathrm{L}]}\end{array}$ & $\begin{array}{l}\mathrm{HCO}_{2} \\
{[\mathrm{mg} / \mathrm{L}]}\end{array}$ & $\begin{array}{c}\mathrm{C} 204 \\
{[\mathrm{mg} / \mathrm{L}]}\end{array}$ & $\begin{array}{c}\text { Bingham } \\
\text { Yield } \\
\text { Stress } \\
\text { [Pa] } \\
\end{array}$ & $\begin{array}{c}\text { Bingham } \\
\text { Consistency } \\
\text { [Pa-sec] }\end{array}$ \\
\hline 4-cm Day 0 & 49700 & $<100$ & 195 & 1570 & 15600 & 648 & 170 & $<100$ & $<100$ & 2.99 & 0.0052 \\
\hline 4-cm Day 7 & 49000 & $<100$ & 189 & 1580 & 14300 & 623 & 157 & $<100$ & $<100$ & 2.75 & 0.0052 \\
\hline 4-cm Day 14 & 46100 & $<100$ & 193 & 1540 & 12800 & 641 & 175 & $<100$ & $<100$ & 2.93 & 0.0046 \\
\hline 4-cm Day 20 & 48000 & $<100$ & 201 & 1540 & 13700 & 631 & 173 & $<100$ & $<100$ & 3.03 & 0.0049 \\
\hline 5-cm Day 0 & 50800 & $<100$ & 191 & 1570 & 12900 & 639 & 189 & $<100$ & $<100$ & 2.96 & 0.0051 \\
\hline 5-cm Day 7 & 48600 & $<100$ & 188 & 1590 & 13400 & 623 & 171 & $<100$ & $<100$ & 3.59 & 0.0052 \\
\hline 5-cm Day 14 & 50900 & $<100$ & 175 & 1660 & 13300 & 622 & 140 & $<100$ & $<100$ & 3.78 & 0.0054 \\
\hline 5-cm Day 20 & 50500 & $<100$ & 185 & 1462 & 11800 & 636 & 167 & $<100$ & $<100$ & 4.03 & 0.0051 \\
\hline
\end{tabular}


WSRC-TR-2004-00387, REVISION 0

SRNL-RPP-2004-00053, REVISION 0

Table 10. Rheological Results of 4-cm Column 20-Day Air Sparing of 15 wt\% HLW Precipitated Hydroxide Simulant AZ-101 at $25^{\circ} \mathrm{C} *$

\begin{tabular}{|c|c|c|c|c|c|c|c|c|c|c|c|c|c|c|c|c|}
\hline \multirow{3}{*}{\begin{tabular}{|c} 
Rheological Model \\
Ostwald (or Power Law):
\end{tabular}} & \multicolumn{4}{|c|}{ Initial } & \multicolumn{4}{|c|}{ Day 7} & \multicolumn{4}{|c|}{ Day 14} & \multicolumn{4}{|c|}{ Day 20} \\
\hline & \multicolumn{2}{|c|}{ Up } & \multicolumn{2}{|c|}{ Down } & \multicolumn{2}{|c|}{ Up } & \multicolumn{2}{|c|}{ Down } & \multicolumn{2}{|c|}{ Up } & \multicolumn{2}{|c|}{ Down } & \multicolumn{2}{|c|}{ Up } & \multicolumn{2}{|c|}{ Down } \\
\hline & Run 1 & Run 2 & Run 1 & Run 2 & Run 1 & Run 2 & Run 1 & Run 2 & Run 1 & Run 2 & Run 1 & Run 2 & Run 1 & Run 2 & Run 1 & Run 2 \\
\hline $\mathrm{m}-$ consistency coefficient $\left(\mathrm{Pa}-\mathrm{sec}^{\mathrm{n}}\right)$ & 0.670 & 0.567 & 0.479 & 0.577 & 0.546 & 0.475 & 0.473 & 0.593 & 0.953 & 0.956 & 0.745 & 0.737 & 0.651 & 0.683 & 0.497 & 0.512 \\
\hline $\mathrm{n}$ - power law coefficient & 0.349 & 0.378 & 0.399 & 0.381 & 0.372 & 0.403 & 0.394 & 0.378 & 0.317 & 0.317 & 0.356 & 0.358 & 0.351 & 0.343 & 0.391 & 0.386 \\
\hline $\mathrm{R}^{2}-$ correlation coefficient & 0.9661 & 0.9620 & 0.9683 & 0.9738 & 0.9694 & 0.9598 & 0.9722 & 0.9763 & 0.9551 & 0.9543 & 0.9683 & 0.9667 & 0.9629 & 0.9647 & 0.9734 & 0.9732 \\
\hline \multicolumn{17}{|l|}{ Bingham Plastic (BP): } \\
\hline$\tau_{\mathrm{BP}}-\mathrm{BP}$ yield stress $(\mathrm{Pa})$ & 3.05 & 2.94 & 2.72 & 3.03 & 2.75 & 2.74 & 2.63 & 3.06 & 3.78 & 3.78 & 3.50 & 3.49 & 3.00 & 3.06 & 2.74 & 2.75 \\
\hline$\eta_{\mathrm{BP}}-\mathrm{BP}$ viscosity (Pa-sec) & 0.0050 & 0.0054 & 0.0054 & 0.0056 & 0.0049 & 0.0055 & 0.0051 & 0.0056 & 0.0054 & 0.0054 & 0.0058 & 0.0059 & 0.0049 & 0.0048 & 0.0052 & 0.0052 \\
\hline $\mathrm{R}^{2}-$ correlation coefficient & 0.9817 & 0.9878 & 0.9864 & 0.9829 & 0.9837 & 0.9914 & 0.9837 & 0.9795 & 0.9857 & 0.9857 & 0.9868 & 0.9878 & 0.9896 & 0.9882 & 0.9902 & 0.9882 \\
\hline \multicolumn{17}{|l|}{ Herschel-Bulkley (HB): } \\
\hline$\tau_{\mathrm{HB}}-\mathrm{HB}$ yield stress $(\mathrm{Pa})$ & 2.28 & 2.36 & 2.09 & 2.15 & 2.04 & 2.32 & 1.91 & 2.07 & 3.12 & 3.15 & 2.67 & 2.71 & 2.41 & 2.41 & 2.09 & 2.05 \\
\hline $\mathrm{k}-\mathrm{HB}$ consistency coefficient $\left(\mathrm{Pa}-\mathrm{sec}^{\mathrm{n}}\right)$ & 0.049 & 0.031 & 0.035 & 0.056 & 0.044 & 0.021 & 0.044 & 0.069 & 0.037 & 0.035 & 0.050 & 0.046 & 0.033 & 0.038 & 0.037 & 0.041 \\
\hline $\mathrm{b}-\mathrm{HB}$ power law coefficient & 0.6822 & 0.7563 & 0.7391 & 0.6796 & 0.6949 & 0.8109 & 0.7008 & 0.6515 & 0.7306 & 0.7401 & 0.7008 & 0.7134 & 0.7335 & 0.7135 & 0.7285 & 0.7106 \\
\hline $\mathrm{R}^{2}-$ correlation coefficient & 0.9950 & 0.9950 & 0.9954 & 0.9970 & 0.9958 & 0.9956 & 0.9960 & 0.9968 & 0.9946 & 0.9938 & 0.9988 & 0.9988 & 0.9990 & 0.9992 & 1.0000 & 0.9994 \\
\hline
\end{tabular}

*Blanks in Table are intentional 
WSRC-TR-2004-00387, REVISION 0

SRNL-RPP-2004-00053, REVISION 0

Table 11. Rheological Results of 5-cm Column 20-Day Air Sparing of 15 wt\% HLW Precipitated Hydroxide Simulant AZ-101 at $25^{\circ} \mathrm{C}^{*}$

\begin{tabular}{|c|c|c|c|c|c|c|c|c|c|c|c|c|c|c|c|c|}
\hline \multirow{3}{*}{$\begin{array}{r}\text { Rheological Model } \\
\text { Ostwald (or Power Law): }\end{array}$} & \multicolumn{4}{|c|}{ Initial } & \multicolumn{4}{|c|}{ Day 7} & \multicolumn{4}{|c|}{ Day 14} & \multicolumn{4}{|c|}{ Day 20} \\
\hline & \multicolumn{2}{|c|}{ Up } & \multicolumn{2}{|c|}{ Down } & \multicolumn{2}{|c|}{ Up } & \multicolumn{2}{|c|}{ Down } & \multicolumn{2}{|c|}{ Up } & \multicolumn{2}{|c|}{ Down } & \multicolumn{2}{|c|}{ Up } & \multicolumn{2}{|c|}{ Down } \\
\hline & Run 1 & Run 2 & Run 1 & Run 2 & Run 1 & Run 2 & Run 1 & Run 2 & Run 1 & Run 2 & Run 1 & Run 2 & Run 1 & Run 2 & Run 1 & Run 2 \\
\hline $\begin{array}{c}\mathrm{m}-\begin{array}{c}\text { consistency coefficient } \\
\left(\mathrm{Pa}-\mathrm{Sec}^{\mathrm{n}}\right)\end{array} \\
\end{array}$ & 0.574 & 0.673 & 0.541 & 0.483 & 0.906 & 0.916 & 0.669 & 0.656 & 0.953 & 0.956 & 0.745 & 0.737 & 1.085 & 1.210 & 0.748 & 0.769 \\
\hline $\mathrm{n}$ - power law coefficient & 0.374 & 0.355 & 0.386 & 0.396 & 0.317 & 0.316 & 0.363 & 0.366 & 0.317 & 0.317 & 0.356 & 0.358 & 0.299 & 0.281 & 0.355 & 0.347 \\
\hline $\mathrm{R}^{2}-$ correlation coefficient & 0.9631 & 0.9659 & 0.9716 & 0.9714 & 0.9612 & 0.9557 & 0.9675 & 0.9677 & 0.9551 & 0.9543 & 0.9683 & 0.9667 & 0.9946 & 0.9584 & 0.9663 & 0.9673 \\
\hline \multicolumn{17}{|l|}{ Bingham Plastic (BP): } \\
\hline$\tau_{\mathrm{BP}}-\mathrm{BP}$ yield stress $(\mathrm{Pa})$ & 2.94 & 2.97 & 2.90 & 2.71 & 3.59 & 3.60 & 3.26 & 3.23 & 3.78 & 3.78 & 3.50 & 3.49 & 3.96 & 4.11 & 3.52 & 3.49 \\
\hline$\eta_{\mathrm{BP}}-\mathrm{BP}$ viscosity (Pa-sec) & 0.0052 & 0.0050 & 0.0054 & 0.0053 & 0.0052 & 0.0052 & 0.0056 & 0.0056 & 0.0054 & 0.0054 & 0.0058 & 0.0059 & 0.0053 & 0.0050 & 0.0058 & 0.0056 \\
\hline $\mathrm{R}^{2}-$ correlation coefficient & 0.9934 & 0.9825 & 0.9839 & 0.9857 & 0.9797 & 0.9805 & 0.9851 & 0.9857 & 0.9857 & 0.9857 & 0.9868 & 0.9878 & 0.9819 & 0.9823 & 0.9908 & 0.9862 \\
\hline \multicolumn{17}{|l|}{ Herschel-Bulkley (HB): } \\
\hline$\tau_{\mathrm{HB}}-\mathrm{HB}$ yield stress $(\mathrm{Pa})$ & 2.43 & 2.24 & 2.13 & 2.01 & 2.74 & 2.85 & 2.50 & 2.47 & 3.12 & 3.15 & 2.67 & 2.71 & 3.22 & 3.29 & 2.83 & 2.67 \\
\hline $\begin{array}{c}\text { k - HB consistency coefficient } \\
\left(\mathrm{Pa}-\mathrm{Sec}^{\mathrm{n}}\right)\end{array}$ & 0.026 & 0.046 & 0.047 & 0.041 & 0.057 & 0.047 & 0.045 & 0.045 & 0.037 & 0.035 & 0.050 & 0.046 & 0.045 & 0.054 & 0.039 & 0.051 \\
\hline$b-$ HB power law coefficient & 0.7738 & 0.6907 & 0.7011 & 0.7142 & 0.6662 & 0.6922 & 0.7094 & 0.7095 & 0.7306 & 0.7401 & 0.7008 & 0.7134 & 0.7028 & 0.6708 & 0.7359 & 0.6954 \\
\hline $\mathrm{R}^{2}$ - correlation coefficient & 0.9998 & 0.9950 & 0.9960 & 0.9983 & 0.9936 & 0.9926 & 0.9964 & 0.9970 & 0.9946 & 0.9938 & 0.9988 & 0.9988 & 0.9926 & 0.9964 & 0.9998 & 0.9986 \\
\hline
\end{tabular}

*Blanks in Table are intentional 
WSRC-TR-2004-00387, REVISION 0

SRNL-RPP-2004-00053, REVISION 0

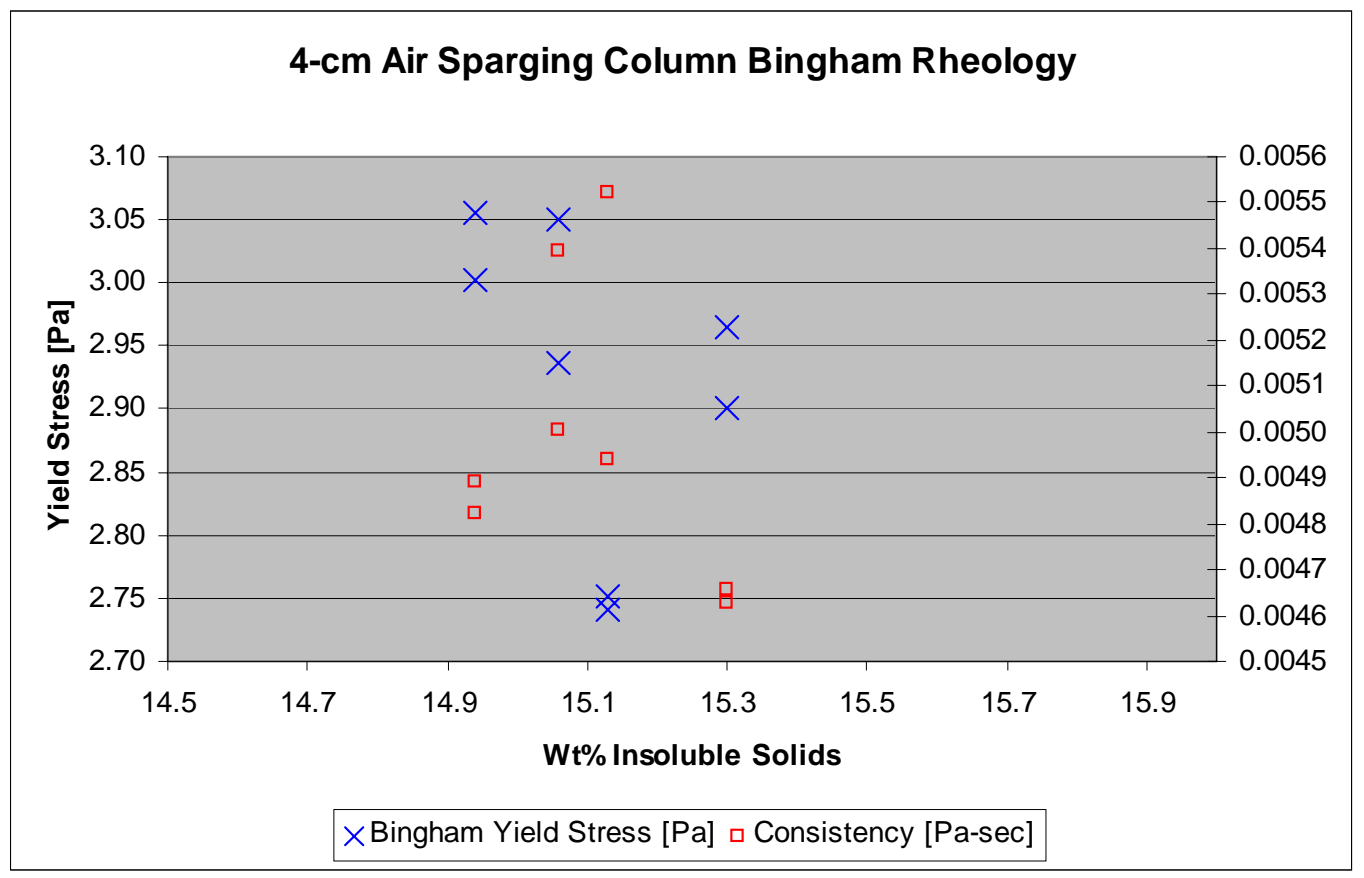

Figure 29. 4-cm Air Sparging Column Bingham Rheology vs. wt\% Insoluble Solids

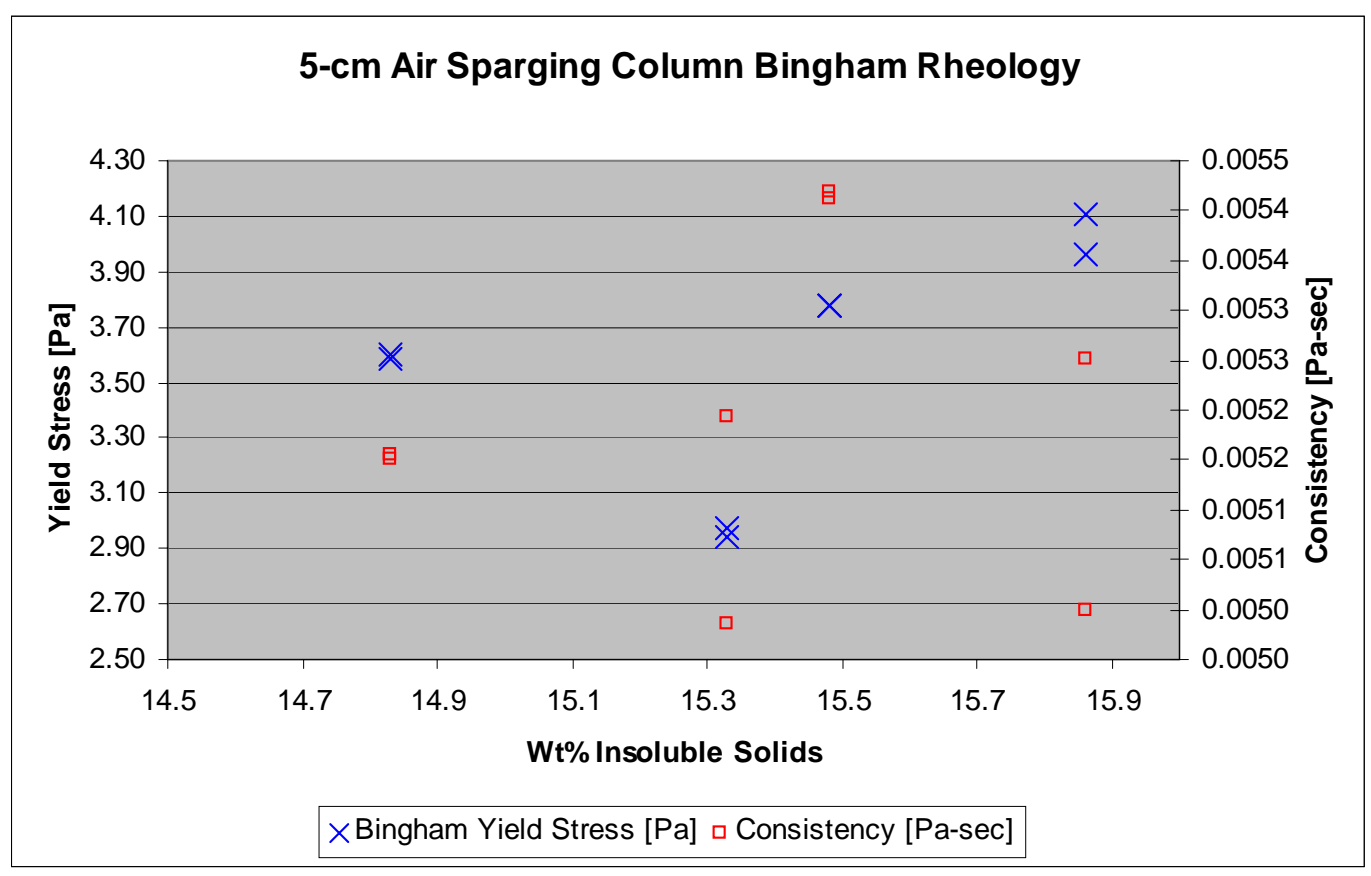

Figure 30. 5-cm Air Sparging Column Bingham Rheology vs. wt\% Insoluble Solids 
WSRC-TR-2004-00387, REVISION 0

SRNL-RPP-2004-00053, REVISION 0

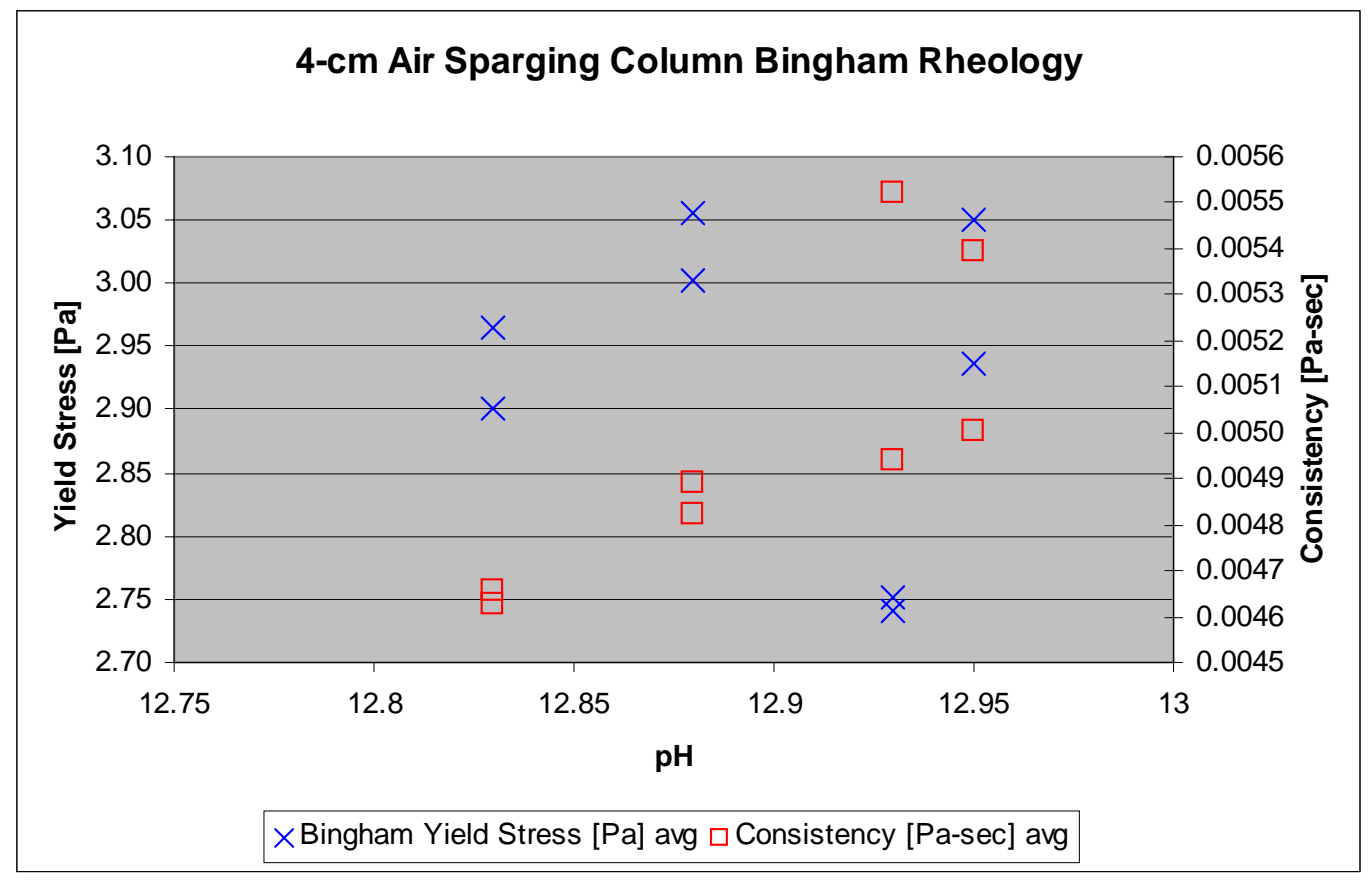

Figure 31. 4-cm Air Sparging Column Bingham Rheology vs. pH

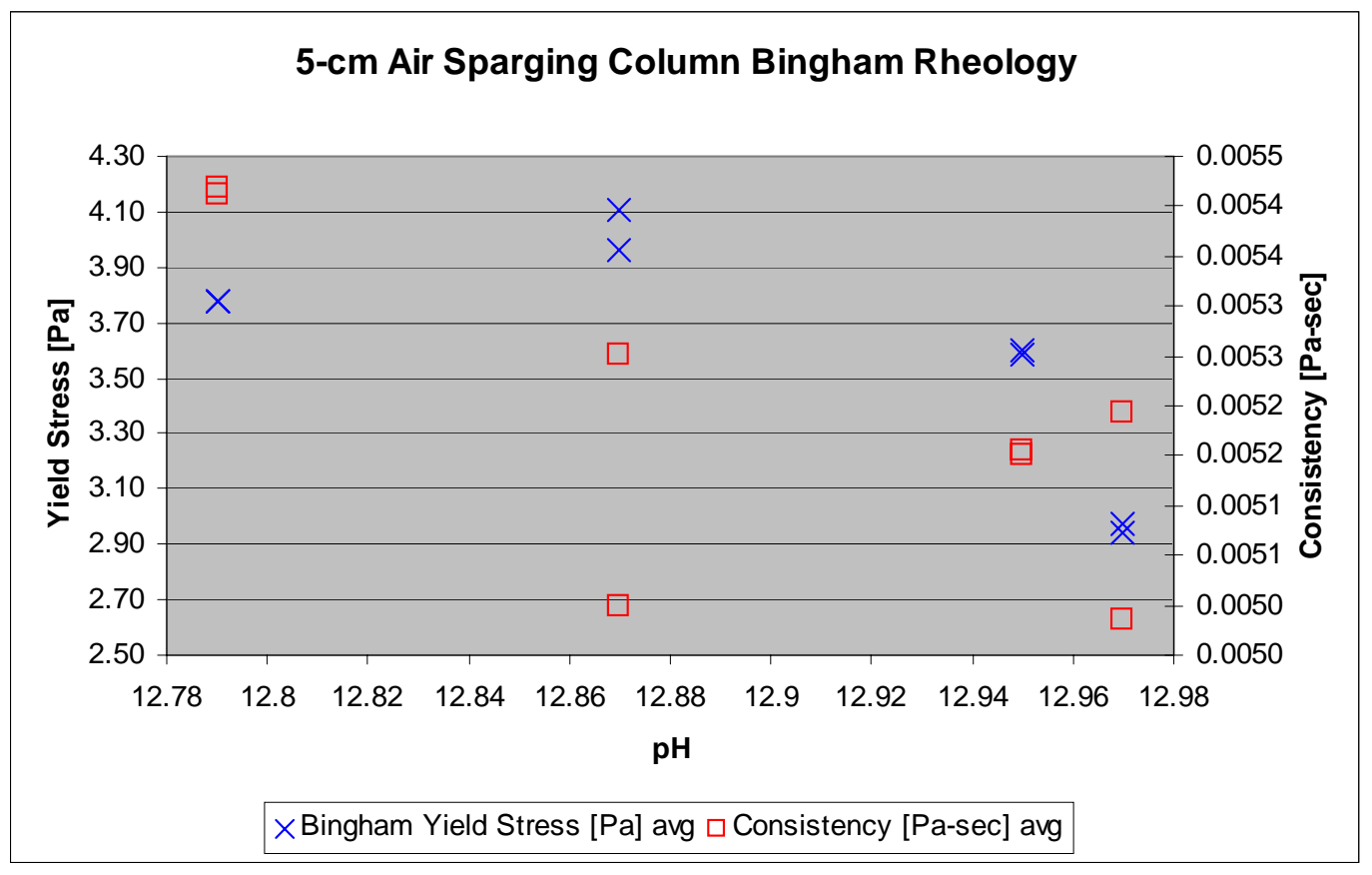

Figure 32. 5-cm Air Sparging Column Bingham Rheology vs. pH 
WSRC-TR-2004-00387, REVISION 0

SRNL-RPP-2004-00053, REVISION 0

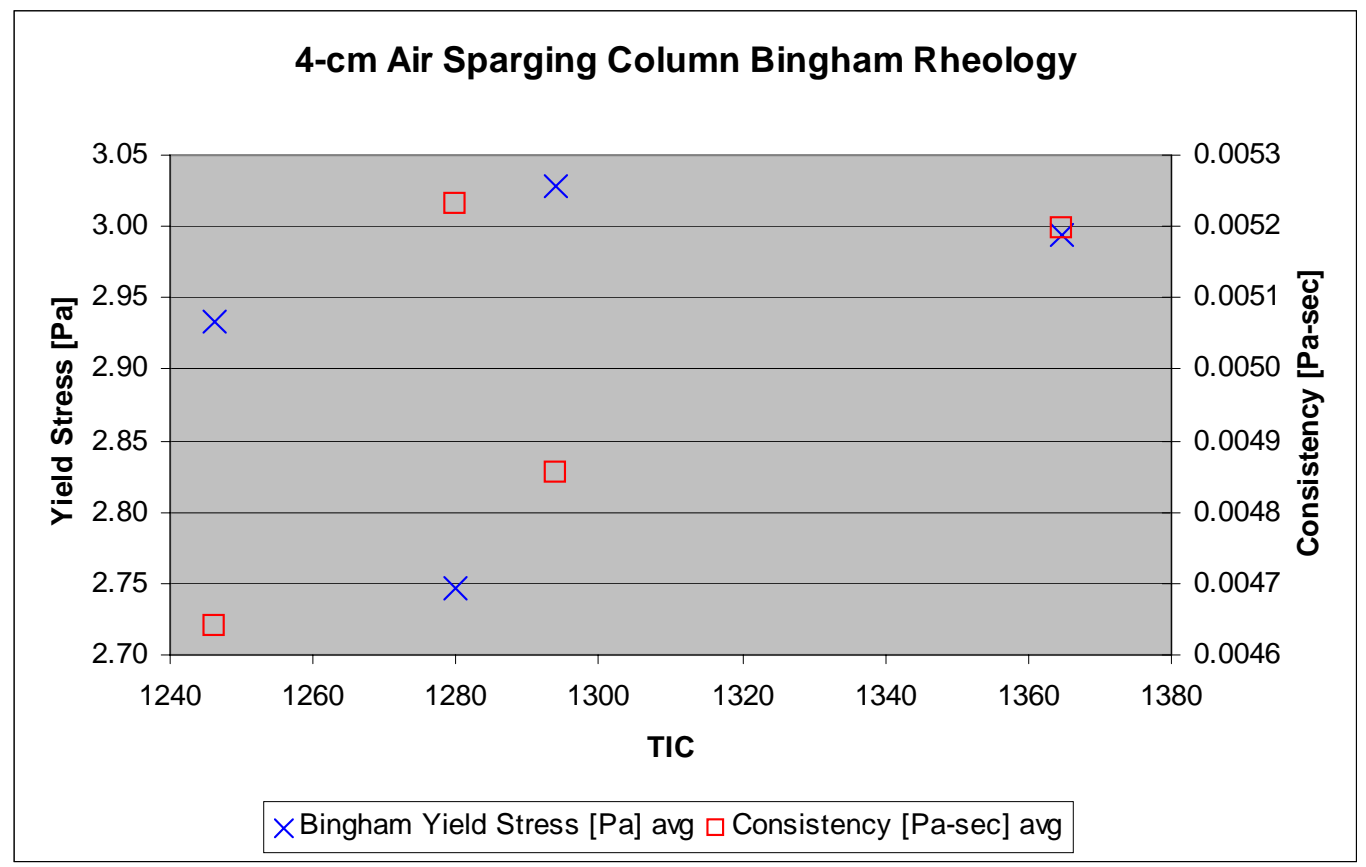

Figure 33. 4-cm Air Sparging Column Bingham Rheology vs. TIC

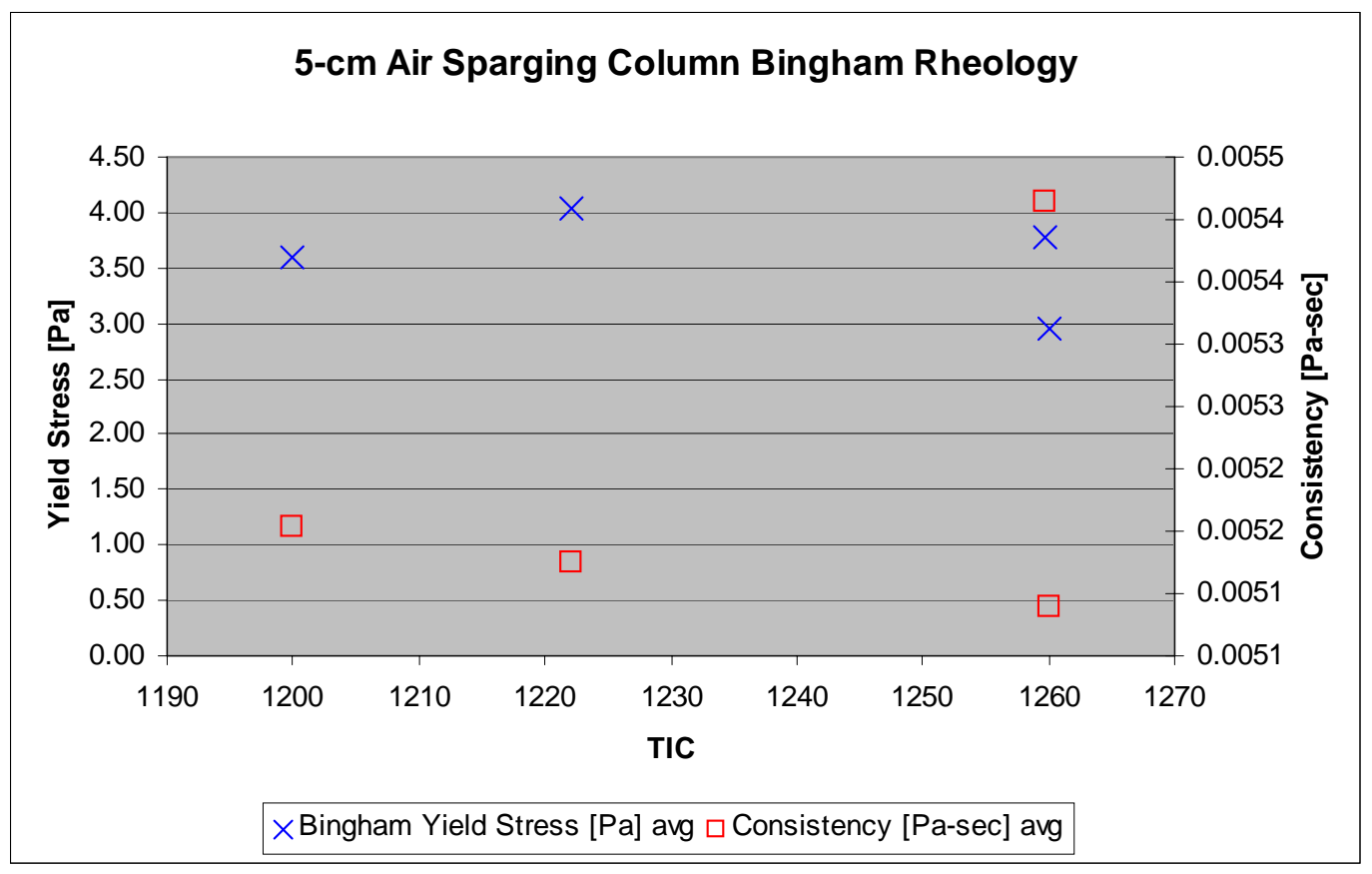

Figure 34. 5-cm Air Sparging Column Bingham Rheology vs. TIC 
WSRC-TR-2004-00387, REVISION 0

SRNL-RPP-2004-00053, REVISION 0

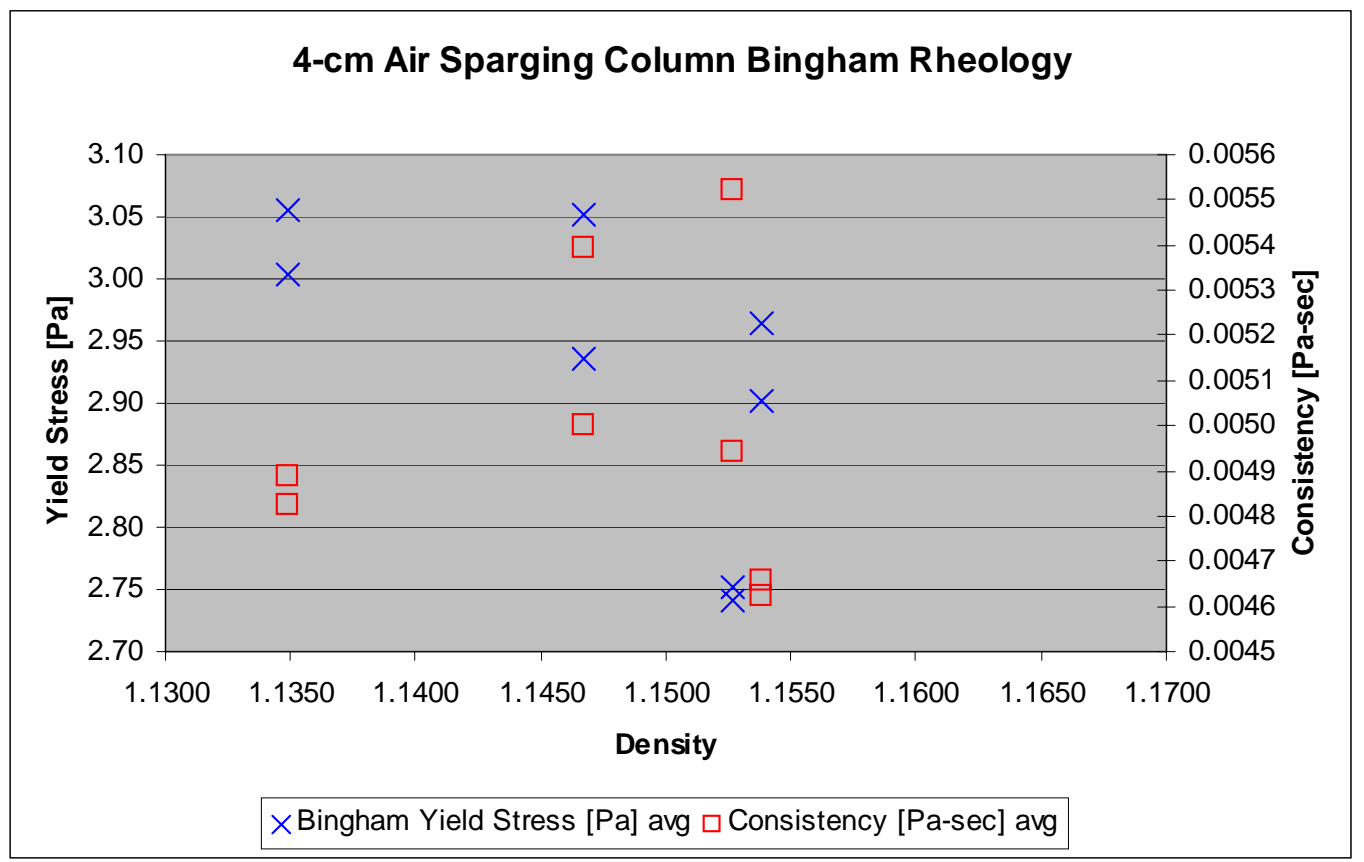

Figure 35. 4-cm Air Sparging Column Bingham Rheology vs. Density

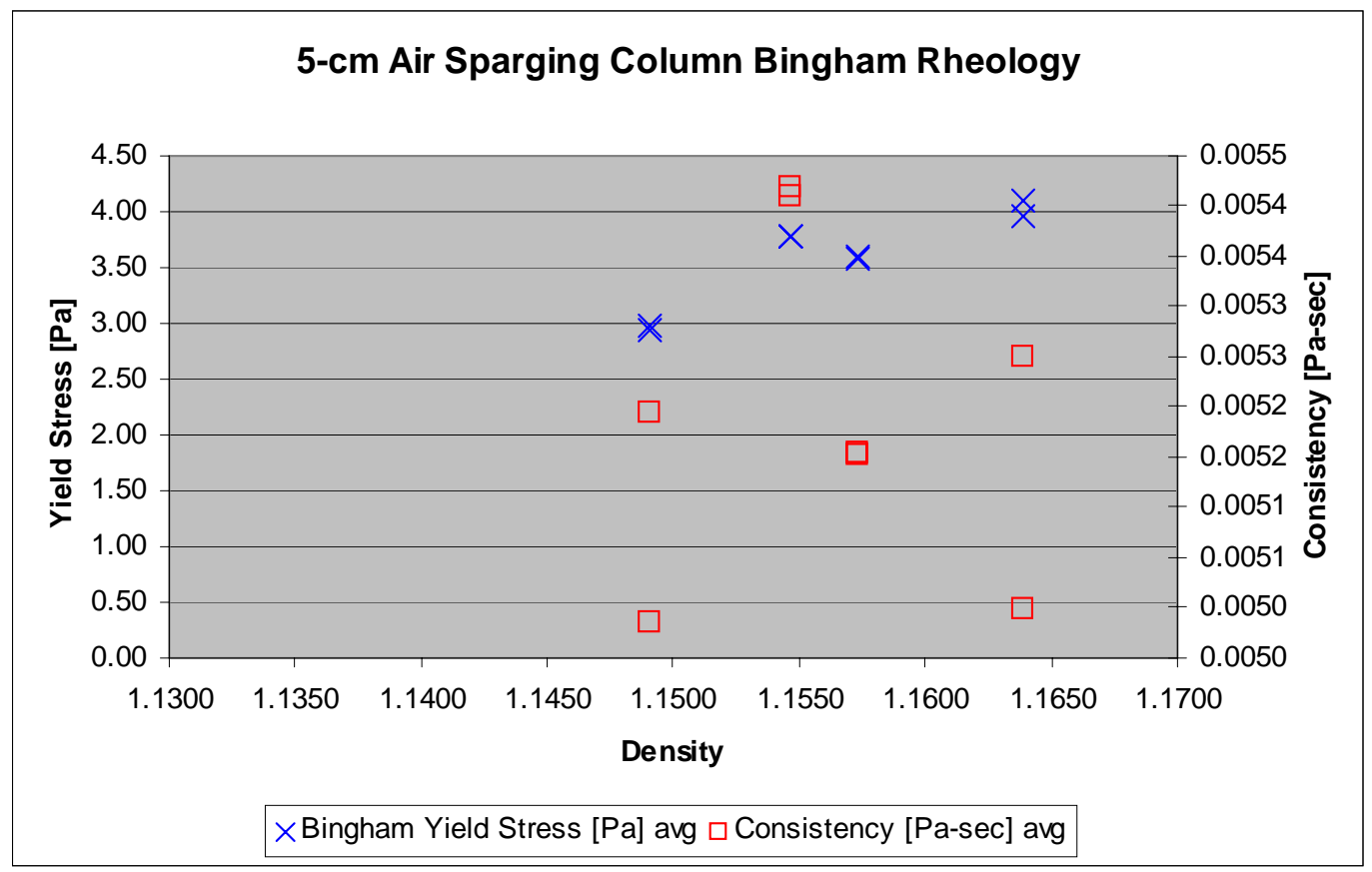

Figure 36. 5-cm Air Sparging Column Bingham Rheology vs. Density 
WSRC-TR-2004-00387, REVISION 0

SRNL-RPP-2004-00053, REVISION 0

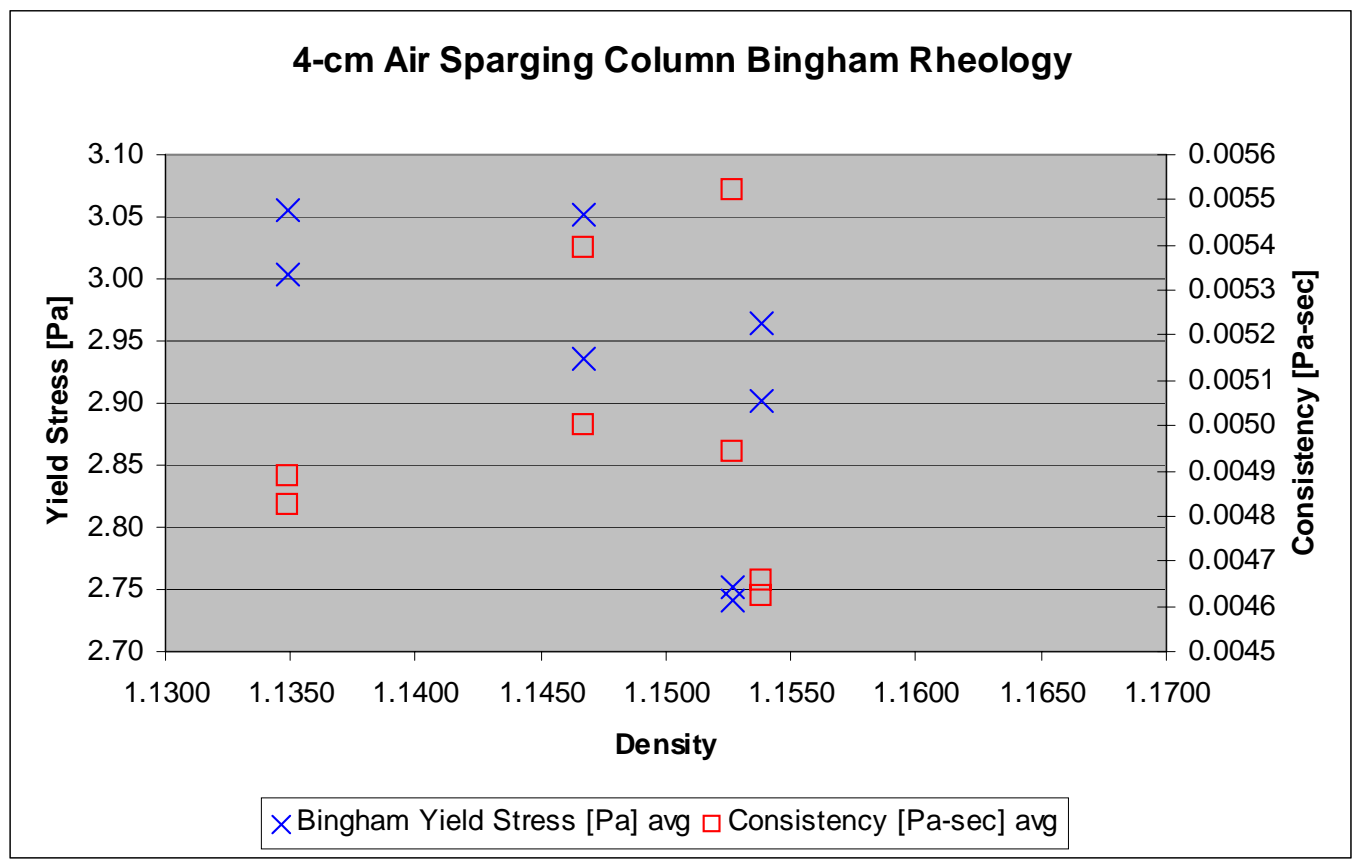

Figure 37. 4-cm Air Sparging Column Bingham Rheology vs. Density

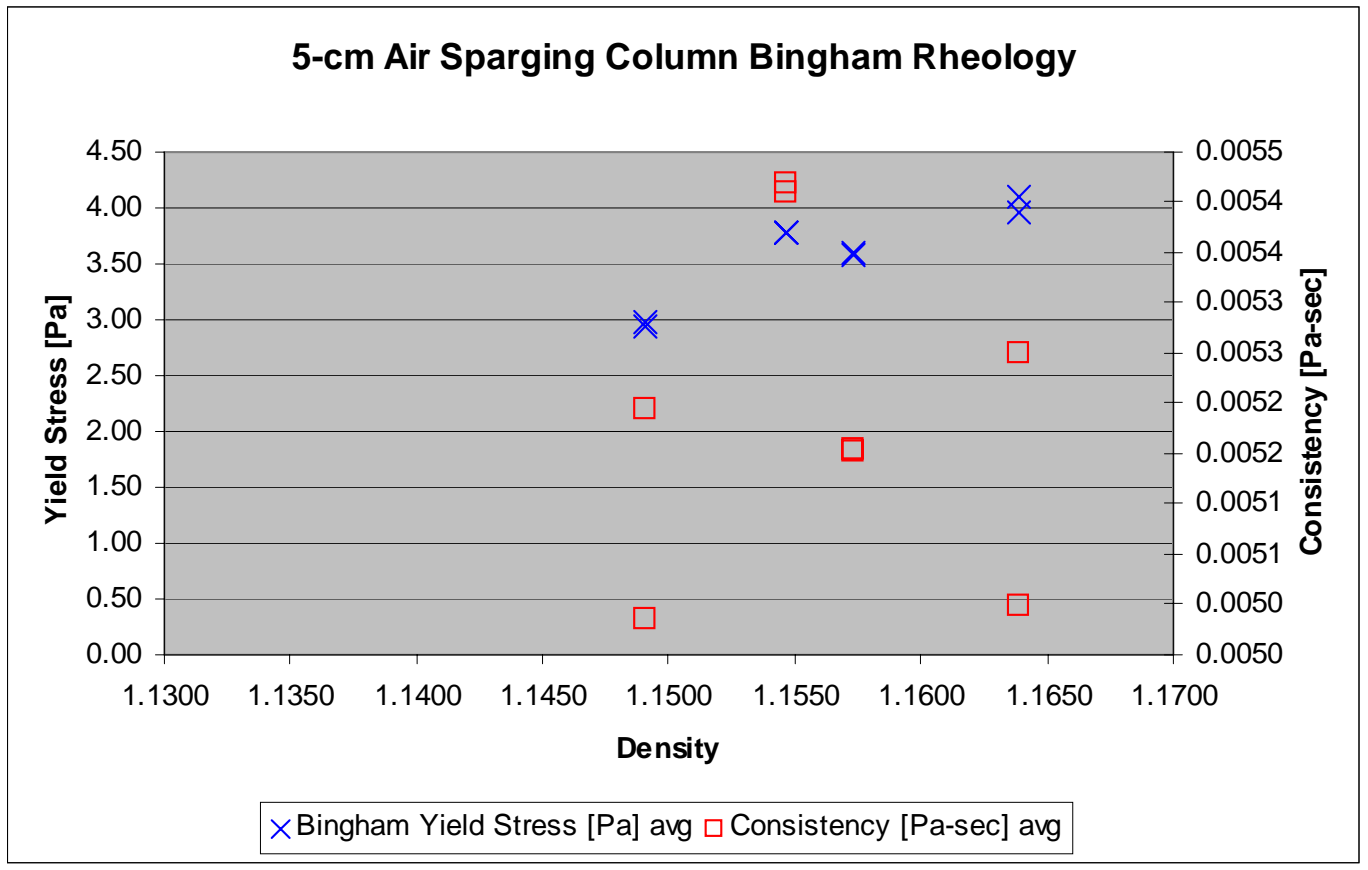

Figure 38. 5-cm Air Sparging Column Bingham Rheology vs. Density 
WSRC-TR-2004-00387, REVISION 0

SRNL-RPP-2004-00053, REVISION 0

This page intentionally left blank. 